\title{
Gendering Temporariness: Stratified Citizenship and Hierarchies of Skill in Canada's Temporary Foreign Worker Program
}

\author{
by \\ Carolyn McKee
}

A thesis submitted to the Faculty of Graduate and Postdoctoral Affairs in partial fulfillment of the requirements for the degree of

Master of Arts

in

Political Science

Carleton University

Ottawa, Ontario

(C) 2015, Carolyn McKee 


\begin{abstract}
The number of workers admitted to Canada through the Temporary Foreign Worker Program (TFWP) has been increasing over time. By 2012, there were almost twice as many temporary residents as permanent residents in Canada (CIC 2013). With the introduction of the Canadian Experience Class, the Conservative government has prioritized the recruitment of high-skilled workers and facilitated their transition to permanence, while limiting the number of low-skill workers and providing them with no such access to permanence. This study considers evidence from parliamentary committees to prove that the government has consistently chosen to maintain the divide between temporary and permanent citizenship despite agreement among witnesses that all temporary migrant workers should have access to citizenship. The study also shows that the TFWP is based on gendered and racist categorizations of skill which places women and racialized workers in predominantly low-skilled categories, making them less able to access formal citizenship and rights.
\end{abstract}




\section{Acknowledgements}

I would like to express the utmost gratitude to my supervisor, Laura Macdonald, for her consistent support and patience in guiding me through this project. I would also like to thank Christina Gabriel for providing me with valuable comments, as well as Amrita Hari. Additional thanks goes to friends and family for their encouragement and understanding through the writing process. In particular, my mother, my sister, CL, JS, and $\mathrm{KH}$. 


\section{Table of Contents}

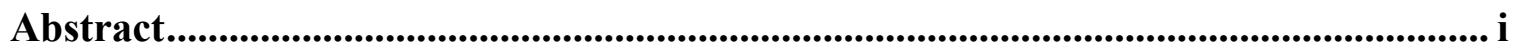

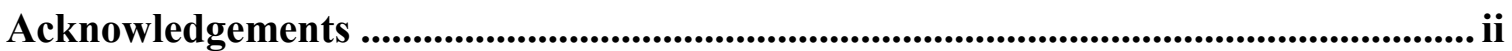

Table of Contents ...................................................................................................ii

List of Tables ............................................................................................................................. v

List of Figures............................................................................................................................... v

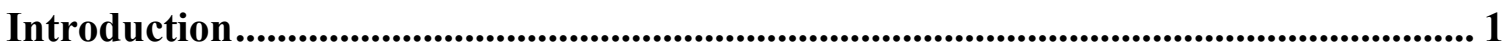

1 Chapter: Theoretical and analytical framing …………............................................... 10

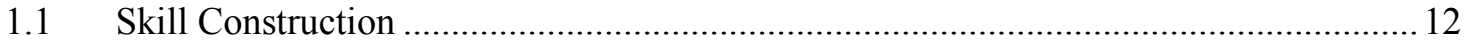

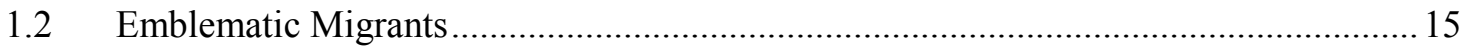

1.3 Discourses on temporary labour migration: international organizations ......................21

1.4 Discourses on temporary labour migration: civil society organizations ......................25

1.5 Disrupting the dichotomy between temporariness and permanence.............................30

\section{Chapter: History of Temporary Foreign Worker Program and Changes Over}

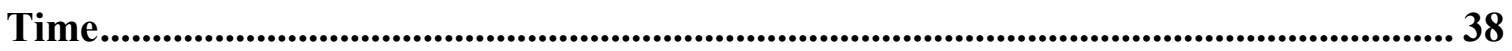

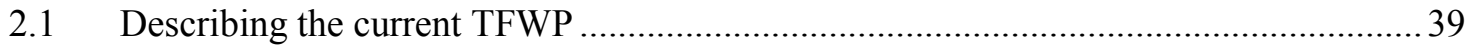

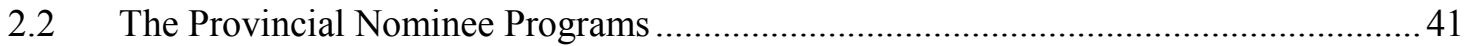

2.3 Origins of the TFWP and the growth of temporary categories ................................... 42

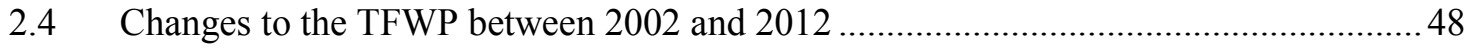

2.5 Changes to the TFWP in the 2013 federal budget ...................................................53

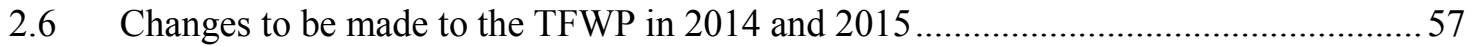

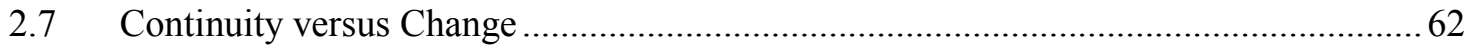

3 Chapter: Uncovering the links between skill, gender and citizenship .................. 64

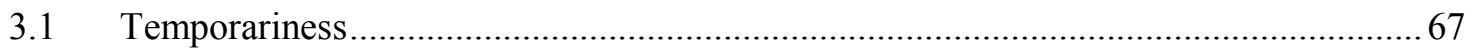




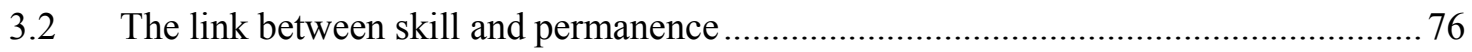

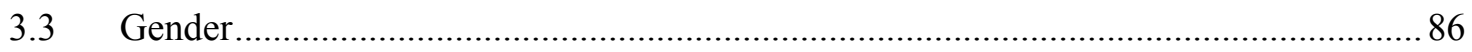

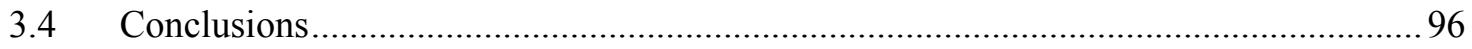

4 Chapter: "People are skilled:" An Analysis of the intersections of gender, skill,

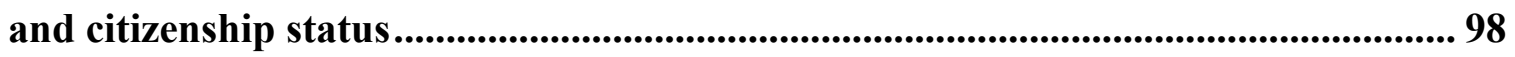

4.1 Important findings on skill, temporariness, and gender ..........................................99

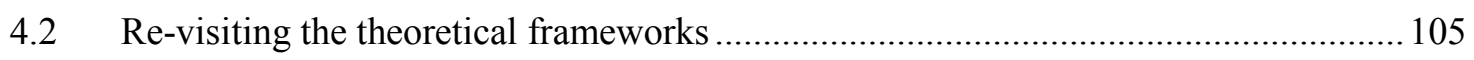

Conclusion: Final thoughts and uncovering spaces to disrupt power flows............ 109 Appendix A: National Occupation Classification (NOC) Skill Level Criteria........ 119

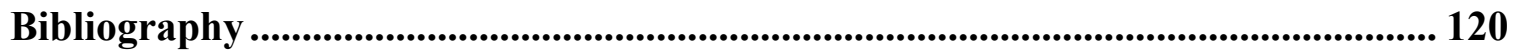




\section{List of Tables}

Table 2.1 Pre-2014 Temporary Foreign Worker Program Streams ............................. 43

Table 2.2 Post-2014 Temporary Foreign Worker Program Streams ........................... 44

\section{List of Figures}

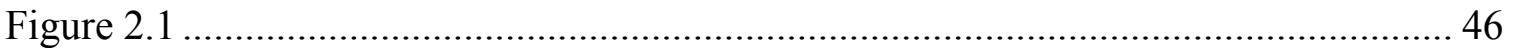

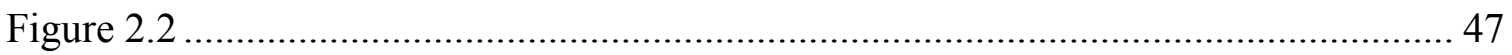

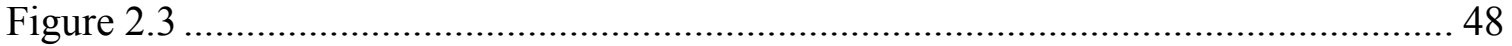

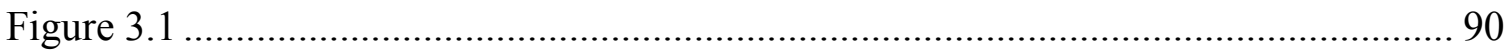

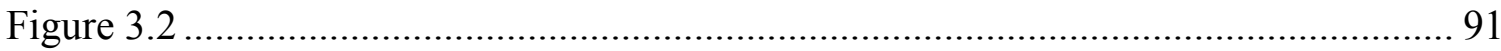

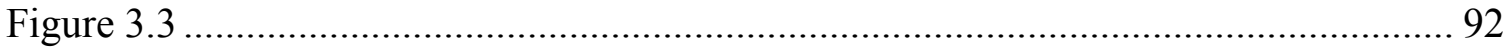




\section{Introduction}

Temporary labour mobility programs exist in different forms around the world, but typically involve three main types of actors: states, private organizations, and migrant workers themselves. States create the programs and organize the movement of workers, particularly in the form of immigration policy. Private organizations also contribute to the administration of these programs and can financially benefit from assisting migrants in their job search and travel. Migrant workers perform labour in a country that is not their own for a limited time, to their own financial benefit and to the economic benefit of the state. Each of these actors serves to benefit from temporary labour mobility arrangements to different degrees or in different ways, depending on the structure of the program. As a result of their temporary citizenship status, combined with other factors related to race, gender, or even language skills, migrant workers can be rendered vulnerable. They can suffer workplace abuse, be unable to access social services, or have difficulty being socially included in the community in which they work. Importantly for this project, they can also have variable access to citizenship in the country in which they work.

Canada's Temporary Foreign Worker Program (TFWP) originated in 1973 and has undergone many changes in its structure over time. The TFWP includes streams which employ workers of all skill levels and categories, as defined in the National Occupation Classification (NOC) 2011. The Conservative government has made changes to the TFWP that make clear their intention to prioritize the hiring of skilled workers, and provide them access to citizenship. The question used to guide this research was, to what extent do gendered constructions of skill affect workers' citizenship? I argue that 
occupations traditionally gendered female (and often racialized) are placed at the bottom of the skills hierarchy, formalized through the NOC, limiting women's ability to access citizenship through the TFWP. In general, the government prioritizes non-racialized, male workers for permanence, while (often racialized) women are more likely to be trapped in a cycle of "permanent temporariness" which makes them less able to exercise their rights as workers.

The research question was pursued through analysis of primary government documents. The resources consulted for this project include statistics retrieved from the Department of Citizenship and Immigration Canada (CIC), as well as other government resources such as parliamentary reports and CIC's annual reports to parliament. In addition, sources such as the Parliamentary Budget Officer's 2015 report on temporary workers were consulted, as well as publications from research organizations such as the Maytree Foundation. A significant portion of the research draws on analysis of committee evidence from the Standing Committee on Citizenship and Immigration Committee and the Standing Committee on Human Resources, Skills and Social Development and the Status of Persons with Disabilities between 2008 and 2014. This time period was chosen for two main reasons. First, 2008 was the year during which the Standing Committee on Citizenship and Immigration journeyed to cities across the country to gather evidence from relevant witnesses to include in the subsequent parliamentary Report of the Standing Committee on Citizenship and Immigration on Temporary Foreign Workers and Non-status Workers, published in 2009. Therefore, 2008 was a year in which there was concentrated, critical discussion on the TFWP, 
during which witnesses from across the country provided comment on the TFWP's merits and challenges for both employers and migrants themselves.

The second reason why the 2008-2014 timeframe was selected is because Bill C-50 was passed in 2008 without amendments. This budget bill included changes to the 2002 Immigration and Refugee Protection Act which included increased power for the Minister of Citizenship and Immigration. The Minister could now made decisions that fundamentally alter immigration policies and programs without having to go through the parliamentary process. According to Naomi Alboim and Karen Cohl in a report they published for the Maytree Foundation, Ministerial Instructions were used for the first time in November 2008 to "limit new federal skilled worker applications to those with an arranged employment offer, in specified occupations, or already in Canada as students or temporary foreign workers" (Alboim and Cohl 2012, 3). Another significant change that occurred in 2008 was the creation of the Canadian Experience Class (CEC), which allows some international students and high-skill temporary foreign workers to transition to permanent residence. Alboim and Cohn argue that, based on public speeches and announcements, the main drivers for the government's immigration change agenda are to improve the relatively poor outcomes of recent cohorts of immigrants, increase the shortterm contribution that immigration programs could make to the Canadian economy, address application backlogs, and prevent fraud and minimize abuse of the immigration and refugee system (Alboim and Cohl 2012, 3). This project explores the implications of prioritizing the recruitment of high-skill workers over low-skilled workers and is critical of basing access to permanence on skill categories. 
This study takes a mixed-method approach to questions of the gendered nature of skill construction and temporariness itself. Due to the fact that in many of the data sources there is little discussion of gender beyond statistics, secondary sources like those outlined in chapter one will be used in order to gain insight into how migration can be a gendered process and how gender intersects with skill and temporariness from a theoretical perspective. Other secondary sources like those from organizations such as the Maytree Foundation have also been drawn upon as they address the Canadian context specifically and provide a good synthesis and analysis of major changes to immigration policy in Canada.

Primary data has also been collected from statistical databases, specifically from CIC. These resources proved useful, but there are some limitations. For example, the elimination of the mandatory long form census in 2010 resulted in a significant dearth of data in many areas. This makes in-depth analysis of the program difficult. There is also a noted lack of data concerning labour market and skills shortages, another common refrain of committee members and witnesses. This is a problem because it becomes unclear where temporary foreign workers are truly needed. A final limitation in terms of the collection of the statistical data has been that it is often not divided by gender. CIC has in fact made a significant effort to disaggregate their data by the sex of workers, but finding data from other sources which does so remains a challenge. Regardless, CIC data in particular has proved very useful as there is a great deal of information on the amount of temporary migrant workers in the country under specific programs and streams, which has helped to support some theoretical arguments related to skill division. 
Government documents and parliamentary reports also proved useful for this study. For example, CIC provides a report to parliament each year which includes information on whether immigration targets were met and whether the department has any recommendations for the future. These reports also include some gender-based analysis which usually looks at data spanning several years in order to illustrate how gender patterns of immigration have changed over time. This is done in an effort to show whether gender gaps in immigration are closing. Other government or parliamentary documents that were analyzed for this project include the Parliamentary Budget Officer's 2015 report, titled "Temporary Foreign Workers in Canada: A look at regions and occupational skill." While it was released outside the stated time period of 2008-2014, this report holds some significant information about temporary work and skills specifically. It is also significant that gender is not mentioned in this report.

The final source of primary data used for this project is analysis of committee evidence transcripts. The committee evidence comes from meetings of the Standing Committee on Citizenship and Immigration Committee (CIMM) and the Standing Committee on Human Resources, Skills and Social Development and the Status of Persons with Disabilities (HUMA) that took place between January $1^{\text {st }}, 2008$ and December $31^{\text {st }}, 2014$. The website for the Parliament of Canada makes the transcripts for these meetings readily available and a search was conducted to return results related to temporary foreign workers for each committee. These transcripts proved useful to this study for two main reasons. First, they helped create understanding of various political representatives' positions on the TFWP and examine the kinds of discussions being held in this political forum. This makes it clear the priorities of both the government and the 
opposition parties. These transcripts are analyzed not to critique one party or the other for their views, but to see how political representatives bring issues related to temporary work to the forefront of political discussion. These transcripts were also analyzed to determine if there were any popular narratives constructed or reflected among the group, such as those related to the value of temporary workers and whether they are taking jobs away from Canadians, or if they are performing work which Canadians are unwilling to.

These transcripts were also used for this study to gain insight into the kinds of witnesses that were invited to committee and what they had to say about the TFWP. Reading committee evidence was a way to hear a variety of voices and hear perspectives from many different sides of the issue. For example, during the time of study, witnesses included representatives of specific industries, small business-owners, franchise owners, high-level bureaucrats, labour advocates and researchers, as well as ministers themselves. Also, when the committee did a tour across the country in 2008, they were able to access a larger variety of witnesses that may not have been called to a meeting in Ottawa or have been unable to attend. This was also a way to hear perspectives from witnesses from many different geographical regions, which is significant given that temporary workers are not evenly distributed across the country. Witnesses provided valuable insight into the realities of the TFWP in a way that political representatives or formal documents could not, due to their differing relationships to the program. For example, labour researchers approached the program from a human and labour rights perspective, while employers discussed their experiences hiring workers and how useful they found this program.

These transcripts were found using the Parliament of Canada's database. A search was done with filters applied that specified the desired committees and time period, and a 
keyword search was also done that included the phrase "temporary foreign workers." Many search results were returned, the bulk of which were from 2008, in the lead-up to the publication of the 2009 report on temporary workers. The transcripts from each committee meeting were read in their entirety, and quotes were selected and placed in a document based on their relevance to issues of temporariness, skill, gender, or citizenship. Attempts were made to include quotes from as many actors as possible, but there is a risk of bias in those chosen. Once the quotes were selected, they were coded by committee and theme and included in chapter four, which is also organized by theme.

The results of this study are organized as follows. Chapter one outlines the theoretical background that grounds the findings in terms of gender, skill construction, and temporariness. Broader analytical framing in this chapter includes discussion of the divide between temporary and permanent citizenship, and ideas on citizenship more generally. Chapter one also includes a more descriptive discussion of how various actors (i.e. international organizations, and civil society) view temporariness. Chapter two includes a statistical profile of workers in the TFWP and provides a detailed background on the TFWP and outlines how it has changed over time, which is significant as it will show the shifts from expanding to limiting low-skilled movement in the program. Attempts will be made in this chapter to explain how the government has justified these changes. Chapter three presents the main findings of the project which are grouped by three themes: temporariness, skills and citizenship status, and gender, and includes information from the sources mentioned above. This chapter provides evidence that the Conservative government's changes to the TFWP result in more privileged forms of 
citizenship for male workers. Chapter four attempts to provide a more in-depth analysis of the findings and explain their significance. This chapter will discuss, among other things, how occupations classified as low-skill are not only traditionally gendered, but are also often racialized. The study will conclude with some discussion of resistance to the current structure of the TFWP, as well as some consideration of how civil society has influenced major changes to the TFWP in the past, such as extending citizenship options to live-in caregivers.

This project uses statistical data, analysis of primary documents, and theory to show that gendered skill construction is significant in the TFWP as it results in more women being classified as low-skill than high-skill, affecting their ability to access permanence. The study uses a theoretical background that frames how skill and knowledge can be gendered, and then proceeds to map these conclusions onto the realities of the TFWP. While I believe that this study does tie together scholarship on temporariness, gender, and skill more explicitly than has been done in the past, I also recognize that temporary labour migration programs are a complex area of study. Study of such programs requires consideration of many areas, including immigration policy, labour standards and enforcement, federal and provincial jurisdictional issues, as well as considerations of how migrant workers' social locations can affect their experience in the program. In addition, migrants journey to Canada as a result of many different factors and have varying experiences in temporary labour migration programs. While this project is meant to consider the TFWP from a critical perspective, it is also important to note that many temporary migrant workers have positive experiences and economically benefit from the program. Therefore, the project is not designed to provide specific or concrete 
policy solutions, but is instead an attempt to contribute to analysis of intersections of migration, gender, and labour. 


\section{Chapter: Theoretical and analytical framing}

Understanding how gender maps on to skill dichotomies in Canada's Temporary Foreign Worker Program (TFWP) and affects workers' citizenship requires a consideration of literature in several key areas. While gender and skill will be assumed to be social constructions in this project, literature will be explored which argues that the process of skill construction itself is gendered. This is an important starting point for exploring how occupations are differently valued, evident by different skill and wage categories, and how occupations that are highly valued are rewarded with citizenship in Canada's TFWP. This chapter will first discuss gendered skill construction more generally, and will then focus on Eleonore Kofman's work on emblematic migrants, which will form a significant portion of the theoretical framework for the project.

Another key area of theoretical focus will be on temporary labour migration itself, as well as temporary as opposed to permanent citizenship. Scholarship on temporary labour migration programs provides a critical view of these programs in terms of how they can render migrants vulnerable and socially excluded. Much of this scholarship also argues that stratified citizenship, or the way in which citizenship is classified, indicates what types of migrants are worthy of citizenship, and which are not. While citizenship categories are often referred to as being hierarchical, this project also refers to them as stratified based on the belief that this provides a more complex view of these categories, recognizing that those at the top of the hierarchy are not without limitations (See Heater 1999). The idea that citizenship categories can be blurred and are not distinct will be 
further elaborated in this chapter. Literature on the divide between temporariness and permanence will also be outlined, as well as broader arguments about citizenship and its capacity to be a tool of exclusion.

The chapter will begin with a review of the literature on skill construction more generally, to explain how it is gendered. Kofman's work on emblematic migrants will then provide more specific arguments about how gendered skill construction finds reality in temporary labour migration programs. The chapter will then take a descriptive turn in order to introduce the idea of temporary labour migration. This section will provide a description of how temporariness is perceived at the global level as well as among Canadian civil society organizations. Finally, the chapter will build upon those descriptions of temporary labour migration in order to provide a more comprehensive analytical framing of how and why states construct different categories of citizenship, and how these can be based on migrant qualities such as gender or race.

The theoretical and analytical framing in this chapter will allow for exploration of skill, gender, and temporariness in connection with one another and in the TFWP, as opposed to examining their relationship with the program separately. Analyses of the TFWP often focus on one of these elements, as opposed to creating a more complex picture of how all three are intimately connected and have the potential to affect migrants' mobility or citizenship. Understandings of temporariness and permanence, as well as both the importance and limitations of citizenship, allow for more complex consideration of what citizenship categories mean and how they can be used as tools to include certain groups and exclude others. 
In the context of immigration policy and legal status, temporariness "refers to state authorization to enter and remain in a country for a limited duration" (Goldring 2014, 220). However, it can also encompass notions of non-citizenship and refer to "an assigned inferior status or condition" (Latham et. al 2014, 4). The literature reviewed below suggests that high-skilled migrants tend to be more readily accepted as worthy of permanence than do low-skilled migrants. Therefore, permanent temporariness, a sustained non-citizenship that includes an inability to transition from temporary to permanent status, results in the exclusion of low-skilled migrants from the state and therefore renders them less capable of accessing their rights. This literature that will be explored below provides a strong basis for analysis of these issues in the context of the TFWP specifically.

\subsection{Skill Construction}

The first area of literature that will be explored is related to the gendered nature of skill construction. It is widely accepted among social scientists that skill itself is a social construct and not a neutral concept. From this basis, one can explore how skill construction is gendered. Jane Jenson (1989) was one of the early authors to draw the connection between gender and skill. In her article, "The talents of women, the skills of men: flexible specialization and women," Jenson argues that skills are historically constructed and that social construction is part of the process by which unequal social relations are reproduced (Jenson 1989, 142). She further argues that these social relations may not only reflect unequal structures of power, but also race, ethnicity, language, and sex, among others (Jenson 1989, 142). In explaining why the work women perform is 
classified as non-skilled, Jenson argues that it is because it is considered too "natural" and/or "merely dexterous" (Jenson 1989, 151). This point is furthered by Eleonore Kofman who argues that embodied work (such as domestic work) is "undervalued and remunerated" (Kofman 2013, 585). Kofman's work will be explored in greater detail below.

Carmen Diana Deere (2009) provides an example of how skill construction can be gendered in her discussion of rural Mexico during the neoliberal economic restructuring of the 1980s and 1990s. She explains that men who were farm workers often had to migrate to either urban centres or north in order to find work after these economic changes. When male heads of households did leave the home, the women of the household took on these roles of farm work and management. When men filled these roles they were considered skilled workers; however, when women moved into these same positions in the absence of the men, their work on the farms was seen as an extension of their household duties, and not an exhibition or acquisition of skills (Deere 2009, 108).

Gendered skill constructions can also result in unequal patterns of mobility in the global labour mobility regime. It is often generalized that many women in the Global South are not able to achieve a high level of education due to certain gender norms, restrictions, and practices, and thus are often unable to achieve high levels of skill in the first place. Kofman and Raghuram (2006) complicate this notion. They argue that education is unlikely to be the main cause of gender imbalance in skilled worker categories because immigration statistics show that migrant women do not necessarily have low educational levels, but rather encounter a series of barriers to gaining economic 
autonomy and suitable employment (Kofman and Raghuram 2006, 294). This is consistent with the work of Steinburg (1990) who argues, based on Creighton (1982), that "employers take advantage of the social and domestic skills acquired by women through gender role specialization," thus potentially not hiring them for the high-skilled work for which they are qualified, but for work in which it is assumed they possess skills (Steinburg 1990, 453).

Steinburg also draws from Lee's (1981) idea of comparable worth theory, meaning "the selection of particular types of skills and responsibilities as justifications for higher levels of compensation is socially constructed as an outgrowth of particular historical circumstances" (Steinburg 1990, 454). This idea that wages are socially constructed is important and is relevant to the TFWP as the classification of workers was recently changed from skill to wage, evidence of the government's lack of understanding that wages are not objective measures of value. Thus it can be seen that the sexual division of labour based on gender stereotypes and assumptions has a historical background and can result in women facing added barriers to gaining skills in the first place, but also to finding appropriate employment and wages that are in line with their experiences. Schneider (1985) argues that this "claim-making" around categories of work are “institutionalized in ongoing labour processes" (Schneider in Steinburg 1990, 455). This becomes apparent when analyzing temporary labour migration programs as they are starkly divided based on categories of skill. Immigration and citizenship in Canada depend on these categorizations and definitions of what constitutes skill and therefore, what types of skill are seen as economically and socially valuable. This makes consideration of how skill construction can be gendered significant, because it could lead 
to outcomes where one gender is able to immigrate more easily than another, or one gender is disproportionately recruited into labour in a category that is underpaid, undervalued, and subject to exploitation, like domestic care work.

\subsection{Emblematic Migrants}

A key theoretical framework for this project is Kofman's theory of emblematic migrants. Kofman argues that "in the recent literature on global migrations, two emblematic figures have emerged," one being the Information Technology and Communication (ITC) worker who is usually male, and the other being the domestic/care worker who is usually female (Kofman 2013, 579). Though this study is focused on the separation between occupations classified as high- or low-skilled more generally as opposed to focusing specifically on the ITC or care worker, the theory still provides valuable insight. Kofman argues that "immigration policies increasingly reflect the calibration of desirable knowledge, human capital and skills against a hierarchy of stratified statuses" (Kofman 2013, 580). This conclusion, while based on Kofman's research on European migration, can also be applied to Canada. Many of Canada's streams for economic migrants rely on a particular set of skill classifications. This makes the discussion of skills and gender extremely relevant to the Canadian Temporary Foreign Worker Program.

Kofman's work delves deeper into the different valorizations of skill based on gender. For example, she explains how the receiving state (favourably) perceives the male ITC worker as mobile with transferable, standardized, and generic skills (Kofman $2013,580)$. She also connects the value of this worker to the increasing emergence and 
importance of the knowledge economy. This shift towards a knowledge economy has resulted in a simultaneous shift away from more physical work. She also states that the "IT worker's worth is measured in his capacity to earn a higher-than-average salary, a characteristic which is seen to make him unproblematic in terms of integration into a national society, a thus a valuable citizen" (Kofman 2013, 580). Here, Kofman is making an important connection between a migrant's perceived worth (related to their skills) and their ability to contribute to the neoliberal project.

In contrast to the IT worker assumed to be male and highly-skilled, is the female, low-skill care worker. Kofman says that domestic work, though increasingly indispensable due to the erosion of the welfare state, is "lowly valued, poorly remunerated and minimally recognized" and that the skills for these services are embodied, "transferred from practices in the domestic sphere and depicted as innately female" (Kofman 2013, 580). She adds that "these skills have been picked up rather than acquired through formal education" and thus "are not considered to have added to the stock of human capital" (Kofman 2013, 580). Kofman's argument that positions requiring embodied work are often categorized as low-skilled finds expression in the NOC. Many low-skill occupations in the NOC require some degree of embodied knowledge, such as food service, retail, and agricultural work. While Kofman's emblematic figure of a low-skill worker is female, embodied work can also be gendered male, as is the case with agriculture. This will be explored in greater detail in later chapters.

Kofman argues that different types of knowledge are "not equally mobile, transferable and translatable" and that they "are also valued unequally in terms of the 
status attached to the occupation, the person and the individual's earning power" (Kofman 2013, 583). She goes on to classify four different types of knowledge, which are worth briefly describing here. The first is embrained knowledge, perhaps the highest valued, which is dependent on "conceptual skills and cognitive abilities" (Kofman 2013, 584). The second is encoded knowledge, which is "embedded in signs or symbols to be found in traditional forms such as books, manuals, codes of practice and websites" and is associated with professions related to medicine, law, and education (Kofman 2013, 584). Kofman does note that this type of knowledge can be difficult to transfer between countries due to differing systems of accreditation. The third type of knowledge is embodied knowledge, which "results from experience gained from physical presence, practical thinking, material objects, sensory information and learning-in-doing" (Kofman $2013,584)$. The author notes that this type of knowledge can be acquired through formal training, in contrast to common belief. Finally, Kofman describes encultured knowledge "where meanings are derived from shared understandings arising from socialization and acculturation and where language, shared experiences and sociality are the key elements of knowledge creation (Kofman 2013, 584). She adds that these skills are frequently equated with gendered and racialized attributes where, for example, aggressive men and empathetic women are sought after as employees for different types of work (Kofman 2013, 584-5).

The types of knowledge that are most useful to focus on in this analysis are embrained and embodied forms of knowledge, largely because this division often coincides with the high-low skill dichotomies prevalent in Canada's immigration policies. However, encultured knowledge can also become significant when one 
considers how employers could make up the social composition of their workforce based on perceived traits of certain races or genders, a trend largely seen in agricultural work and with live-in caregivers. This is an idea put forward in Janet McLaughlin's (2010) work on "ideal" migrant workers. Hiring workers based on perceived traits is also evident in the feminization of labour in export-processing zones, justified by the idea that women have "nimble fingers" and thus are better able to perform certain tasks (Dunn 1994, 21). Encalada and Preibisch, in their study of gender and race in the Seasonal Agricultural Worker Program (SAWP), argue that, "Canadian employers and civil servants hold rigid gender ideologies that perceive women as less suitable for farmwork [sic]" (Encalada and Preibisch 2010, 301). The authors also comment on the idea of the ideal worker in terms of race, arguing that racialized discourses about workers' attributes "serve to characterize men and women from the global South as naturally suited to agricultural work and less deserving of the employment options, working conditions, and legal entitlements Canadian citizens enjoy" (Encalada and Preibisch 2010, 302). This relates to Zolberg's work, discussed below, about how certain workers are deemed suitable for labour but unsuitable for membership, and thus ties in to this project's discussion of stratified citizenship.

Of course, while Kofman delineates clearly between these types of knowledge, they can also exist in combination with one another. Kofman explains that embrained knowledge is (unsurprisingly) usually the most highly valued and this value is heightened when it is combined with encultured knowledge "which enables the migrant to approximate as closely as possible the non-migrant, in terms of similar kinds of disposition and modes of communicating and comportment" (Kofman 2013, 585). While 
not mentioned by Kofman, the fact that migrants with embrained knowledge are often using the "universal languages" of maths and sciences for their work may ease communication with non-migrants who do similar work. This potential ease of communication between migrants and non-migrants could be another reason that a highly-skilled migrant is seen as less "problematic" to social integration.

Kofman also addresses women's ability to acquire skills in their home countries. She suggests that in OECD countries, "the proportion of female migrants with a tertiary degree is only three points less than the proportion of men, but they are more likely to have gained their qualifications in humanities and social-science subjects" (Kofman 2013, 591). This reinforces the idea that occupations requiring training in the sciences may not necessarily demand any higher level of formal training or qualifications, but they are more highly valued partly because of "the perceived connection with global processes and the higher salaries they are able to command," not to mention the fact that they also tend to be gendered as male occupations (Kofman 2013, 591). She also argues that women may also face more problems in having their qualifications recognized, especially those who enter as a spouse and end up in jobs well below their education levels (Migration Advisory Committee cited in Kofman 2013, 592).

Kofman's work on emblematic migrants is a useful frame for this project because it can help directly connect theories about the gendered nature of skill divisions and dichotomies with the study of immigration policies. While Jenson's work allows one to understand different valorizations of skill, Kofman's work allows for consideration of how these different valorizations translate into immigration policies. Kofman confirms this, saying that "questioning the categorisation of knowledge and the construction of 
skills is vital if we are to contribute to a critical engagement with immigration policies, increasingly based on the selectivity of highly rewarded skills" (Kofman 2013, 595). Again, while her work is focused in Europe, her conclusion about "destination" countries preferring highly skilled migrants over those with a (perceived) lower level of skill is a global trend that is reflected in changes to Canadian immigration policy as well, as this study will show. Kofman argues that the intersections of migration, gender, and knowledge require further analysis at a time when the knowledge economy selects women and men who can migrate and "determines how they should be incorporated as migrants into a country" (Kofman 2013, 595). Using her framework of emblematic migrants and her focus on knowledge classification allows this project to contribute to this broader conversation.

The theoretical approach outlined above gives rise to several key research questions that will guide the analysis of Canada's TFWP in this thesis. For example, Kofman's work on emblematic migrants in Europe is a good starting point, but the question for this project is whether her conclusions are accurate in the context of the Canadian TFWP. In addition, while her examples of the emblematic figures of the ITC worker and the domestic care worker are methodologically useful, are there other occupations that would fit into gendered categories of skill in the TFWP? This question is important as it would expand the significance of the study and allow for broader conclusions about gender and skill to be drawn. 


\subsection{Discourses on temporary labour migration: international organizations}

Understandings of the connections between gender, skill, and knowledge are key to the theoretical background for this study. However, another major theme for the project is to analyze and critique the concept of temporary labour migration itself. The position of some international organizations will be explored, as well as those of Canadian labour unions and migrant rights organizations to show how different types of organizations perceive and construct temporary labour migration. This section will take a more descriptive than analytical tone, but the positions of international organizations are still worth outlining as it provides context for Canada's TFWP as well as for the scholarly critiques of temporary labour migration programs that will follow this section.

International bodies such as the International Organization for Migration (IOM), the Global Forum on Migration and Development (GFMD), the UN, and the Global Commission for International Migration (GCIM) have been including discussions of temporary labour migration programs in their reports. At this global level, temporary labour mobility has been characterized as a positive strategy and "triple win" scenario in which migrants gain employment, destination countries are able to fill labour gaps and the sending countries experience poverty reduction, especially as a result of remittances. Additionally, the global discourse constructs temporary labour mobility as low-skilled, despite the existence of many temporary labour programs geared toward high-skilled workers. A brief consideration of major organizations' statements concerning temporary mobility is useful to illustrate how it is perceived at the global level.

The International Organization for Migration (IOM) is an inter-governmental organization that prioritizes "the humane and orderly management" of migration by 
working with governmental, inter-governmental, and non-governmental actors (IOM 2015). The IOM's 2008 World Migration Report, entitled Managing Labour Mobility in the Evolving Global Economy provided a new focus on labour migration and temporary labour. The report outlines how many of the major global organizations committed to organizing the movement of people are supportive of temporary mobility. Most organizations or initiatives are sure to emphasize that temporary mobility will only be effective if it is "legal, protective, and linked to real labour needs" (IOM 2008, 93). There are several themes that run through each organization's statement on the issue. One such theme is that labour migration will be the most beneficial if it involves migrants moving from the global south to the global north, though for different reasons. The World Bank states that "greater emigration of low-skilled emigrants from developing to industrial countries could make a significant contribution to poverty reduction," as a result of sending remittances (IOM 2008, 93). The Global Commission for International Migration (GCIM) expresses that theme in a different way and introduces another in its statement that "states and the private sector should consider the option of introducing carefully designed temporary labour migration programmes as a means of addressing the economic needs of both countries of origin and destination" (IOM 2008, 94). Not only does this statement consider the economies of both the sending and receiving states (with less emphasis on poverty reduction), but it also explicitly links the state and the private sector in designing migration programs, a second theme.

The third theme is the focus on temporary work being truly temporary by promoting the return to the state of origin. For example, the World Bank promotes managed migration programs that "combine temporary migration of low-skilled workers 
with incentives for return" (IOM 2008, 93). The International Agency for Migration Management (IAMM) suggests implementing measures to facilitate "multiple short stays" as opposed to permanent settlement (IAMM 2005, 35). According to the IOM's 2010 World Migration Report, temporary migration programs have "considerable benefits for destination countries" such as helping them adjust to labour shortages and "increasing the flexibility of labour markets to respond to seasonal and cyclical fluctuations in the economy" (IOM 2010, 12). The IOM also makes clear their support for bilateral mobility agreements to ensure that both origin and destination countries benefit, as well as migrants themselves, supporting the idea that such programs create a “triple win" (IOM 2010, 24). The global discourse around temporary mobility programs and their benefits legitimizes their role in migration governance.

While the above international organizations focus predominantly on the benefits of temporary labour migration programs, when considering them from a gender perspective they do acknowledge these programs' weaknesses. The World Bank (2006) notes that the gender implications of all types of migration remain poorly understood (World Bank 2006, 57). Regardless, many organizations provide comment on the gendered impacts of temporary migration in their reports. While this is a positive step towards understanding the gendered impacts of these programs, gender is still often discussed in a limited way. Gender is often discussed in the sections of the reports about precarious work, low-skilled work, or human trafficking. While women are often employed in these areas, only discussing them in relation to vulnerable work risks reinforcing the paradigmatic separation of the highly-skilled male and the low-skilled female, as discussed in Kofman’s (2013) work. 
International organizations consistently acknowledge that being a migrant can make one vulnerable to exploitation, and belonging to a marginalized group (related to race and gender for example) can further contribute to this vulnerability. Many organizations advocate for "gender-sensitive migration policies that address the special problems faced by women migrant workers," like the ILO in its Multilateral Framework on Labour Migration (IOM 2008, 281). The ILO also argues that female labour migration is often characterized by a concentration in lower-skilled occupations associated with traditional gender roles which often leave women vulnerable to exploitation (IOM 2008, 82). While this in some ways contributes to the idea that women are often low-skilled, the IOM highlights that this is a stereotype and that "studies on the specific situation and profile of skilled female migrants are scarce" (IOM n.d., 1). The GCIM adds that "because [migrant women] are confronted with gender-based discrimination, including restricted access to regular migration opportunities, female migrants with irregular status are often obliged to accept the most menial informal sector jobs" (GCIM 2005, 34). This explains that women are involved in these sectors due to gender-based discrimination, not because of their abilities.

Like the ILO, the IOM argues that gender-sensitive labour migration policies should be adopted to "fully enable women to safely enter the temporary labour market and benefit from it" (IOM n.d., 2). Specifically, the IOM advocates measures to ensure decent working conditions and "protection in vulnerable employment markets and protection while abroad, such as maintaining the family rights, social protection standards and freedom of association to trade unions or organizations for the defense of their rights" (IOM n.d., 2). In a 2013 report focused on ASEAN countries, UN Women went 
so far as to say that "migrant workers, especially women, who migrate via TFWPs for long-term employment, should be considered long-term migrants. They should receive the same human rights and labour and social protections as citizens and long-term residents in countries of destination - and be included in national laws and policies" (UN Women 2013, 7). While stopping short of advocating for pathways to permanent citizenship for temporary migrant workers, this statement is an example of "undoing the link between permanence and rights" discussed by Rajkumar, which will be elaborated below (Rajkumar et. al 2012, 505).

\subsection{Discourses on temporary labour migration: civil society organizations}

In addition to international and academic actors, civil society ${ }^{1}$ groups provide valuable perspectives on temporary labour migration. Many Canadian civil society organizations (CSOs) either advocate for justice for migrant workers as their sole purpose, or as one of their main issue areas. Civil society has been critical of changes made to the TFWP within the timeframe of this study (2008-2014). For the most part, these groups focus on those migrant workers constructed as "low-skill" as they are often the most vulnerable to exploitation. CSOs do not advocate for the elimination of jobs for migrant workers, but rather for migrants to be able to access citizenship. It is worth noting that this research uncovered no mention of the gendered effects of temporary citizenship in statements from CSOs unless they focused on the LCP.

\footnotetext{
${ }^{1}$ In this project, civil society refers to any organization that exists outside of government that seeks to express the interests of citizens and influence government policy (World Bank 2010).
} 
For the purposes of this project, civil society includes labour unions. It should be noted that while labour unions are presently standing in solidarity with migrant workers, migrant worker justice can also been viewed as a threat to organized labour (No One is Illegal, n.d.). Labour unions and migrant advocacy groups could be seen to have competing interests as the former is advocating to protect "Canadian" jobs and the latter is often constructed as "taking" those jobs. Regardless, many Canadian labour unions are showing dedication to researching migrant workers' vulnerability as workers and advocating for their labour rights.

The Ontario Federation of Labour (OFL) released a statement in December 2014 that continued their call for a migrant workers bill of rights to end exploitation. OFL President Sid Ryan stated that, "the real issue is that migrant labour is being used as a permanent replacement for meaningful immigration reform," and repeated the common narrative of if "workers are good enough to work in Canada, they are good enough to stay" (OFL 2014). The OFL envisions a bill of rights for migrant workers "that would entrench labour protections and human rights for all migrant workers, including access to permanent residence and citizenship rights, union protection, health care benefits and a ban on recruitment fees and exploitation" (OFL 2014).

The United Food and Commercial Workers Canada (UFCW) has been at the forefront of advocating for the rights of migrant workers, with a focus on those in the agricultural sector. In their 2010-2011 report on the status of migrant workers, they make a variety of recommendations to change the TFWP including giving migrants (in Ontario) the right to collective bargaining, rights regarding their health and safety, and the option of applying for permanent citizenship. In this way they are not exceptional among other 
unions in how they are critical of the TFWP. UFCW has also supported the creation of the Agricultural Workers Alliance, is a member of the Migrant Workers Alliance for Change, and has filed human rights complaints on behalf of migrant workers regarding gender discrimination in hiring in the Seasonal Agricultural Workers Program. ${ }^{2}$

The Canadian Labour Congress (CLC), an organization which brings together Canadian and international unions and councils, has done extensive research on the injustices faced by migrant workers. Researchers from the CLC have often appeared as witnesses in parliamentary committee hearings. The CLC's 2011 report, titled Canada's Temporary Foreign Worker Program (TFWP): Model Program or Mistake? includes both evidence of exploitation and comments on temporary work. They argue that policymakers need to consider how the TFWP "encourages employers to import predominantly racialized workers from low income countries," which echoes Vosko's (2000) sentiments, mentioned below, about seeing workers as commodities. The CLC also comments on the skills dichotomy used in the TFWP. They argue that there are many occupations, such as elder and childcare jobs, that are being erroneously categorized as low-skill jobs "and/or the migrant workers in these jobs are under-utilizing their training and skills due to economic necessity" (Flecker 2011, 20). While stopping short of discussing whether and how these occupations are gendered, the CLC is recognizing the problem of categorizing skill in a limited way. Overall, the CLC argues that the TFWP “operates to serve employers' interests with little meaningful regard for compliance, monitoring, or enforcement of national or subnational labour standards"

\footnotetext{
${ }^{2}$ This is one instance where gender does play a role in migrant worker advocacy. However, it is concerning equitable hiring practices as opposed to discussing how temporariness can be gendered. For more about discriminatory hiring practices in the SAWP, see Hennebry and Preibisch (2010).
} 
(Flecker 2011, 53). This again contrasts the views of some international organizations mentioned above, which are encouraging of working with the private sector to craft migration policies.

The unions mentioned above are better resourced than smaller grass-roots organizations and thus are often better equipped to produce research and statements on issues of temporary labour migration. However, some non-union CSOs have also made their perspectives clear. The Toronto-based group No One is Illegal describes itself as "a migrant justice movement rooted in anti-colonial, anti-capitalist, ecological justice, Indigenous self-determination, anti-occupation, and anti-oppressive politics" (No One is Illegal, n.d.). It will come as no surprise given the name of the organization that No One is Illegal advocates for access to permanent citizenship for all migrant workers. Syed Hussan is the co-ordinator for Migrant Workers Alliance for Change, another grassroots organization. He wrote an op-ed in April 2014 in which he equated a fear of migrant workers with xenophobia. Speaking on behalf of his organization, he countered some common narratives about Canadians losing jobs to foreign workers and, like the other CSOs discussed, advocated for full immigration status for all (Hussan 2014).

Finally, Justicia for Migrant Workers (J4MW), a volunteer-based community group, advocates for the protection of and access to human rights for migrants who work on farms. J4MW provides emergency support to migrant farm workers in crisis, conducts workshops for workers on issues pertaining to life and work in Canada, and organizes migrant workers to fight for their rights (J4MW 2006, 1). J4MW prioritizes the promotion of migrant workers' rights to employment insurance, to regularization, to be treated with respect and dignity (i.e. protection under employment standards legislation), 
and the right to appeal unfair treatment (J4MW 2006, 2). From these priorities it can be understood that J4MW and other civil society organizations are in agreement in their main position that migrants should be able to access justice and work in a safe environment like their non-migrant counterparts, and that they should have access to citizenship.

From these statements from various CSOs, it is clear that civil society is in agreement on three main points. First, while they are critical of temporary labour migration programs as a whole, they recognize that it is unlikely that these programs will end and thus they focus on advocating for making them just for migrant workers and not just states and employers. Second, they argue that migrant workers' rights are often threatened or inaccessible. Finally, civil society groups advocate for migrant workers to be able to access citizenship. This is in agreement with many scholarly critiques of temporary labour migration programs as well, as the rights they are fighting for are often tied to rights associated with citizenship.

The description of international organizations' and civil society organizations' positions on temporary labour migration programs provided above is important as it provides an understanding of the broader context in which changes to Canada's TFWP are taking place. At the international level, temporary labour migration programs are celebrated as a way to organize the movement of individuals in a way that benefits multiple actors. However, civil society organizations are critical of these schemes as they can render migrant workers vulnerable to exploitation. The work of scholars in the areas of citizenship, migration, labour, and gender studies outlined below will illuminate 
critical perspectives of temporary labour migration programs on a more theoretical level, allowing for a deeper understanding of how and why such programs are structured.

\subsection{Disrupting the dichotomy between temporariness and permanence}

While many actors in the international community are in favour of temporary labour migration programs, the academic community has provided valuable critiques of this kind of labour which are drawn on considerably in this project. A main critique of temporary labour migration is that because workers lack permanent status and are often tied to one employer, they are unable to mobilize for their rights. The ILO and the UN have set out guidelines to protect the rights of temporary migrants; however, many states, including major destination countries like Canada, have not ratified these conventions. Deepa Rajkumar and her co-authors suggest that the ability of migrants to access these rights lies in "undoing the link between permanence and rights so that all temporary migrants, not just the privileged, enjoy full social and civil rights" (Rajkumar et. al 2012, 505). Chapter three of this project includes testimony from witnesses that point to the link between permanence and rights as a major cause for concern and justification for the argument that all migrant workers should have the opportunity to access citizenship.

Access to rights is important for any individual, but because temporary work often involves vulnerability to poor wages and working conditions, it becomes even more important for migrants to access their rights. However, even if working conditions were improved, Emily Gilbert argues that this is only a short-term solution and will not "alter the structural precariousness of temporariness" (Gilbert 2014, 153). Patricia Landolt and Luin Goldring agree, stating that even workers who are able to move from temporary to 
permanent status often face barriers and that "the current age of global migration is distinguished by compounding insecurities generated at the intersections of precarious legal status and precarious work [emphasis in original]" (Landolt and Goldring 2013, 155). This means that the problems do not lie either in the fact that temporary migrants do not have permanent status or that the work itself is precarious, but that both of these challenges must be taken into account when considering how to improve the situation of temporary workers.

While this project focuses on barriers to citizenship for low-skilled workers, it is worth expanding on the above point that the shift from temporary to permanent legal status does not necessarily address issues concerning the nature of the work. This also opens up a space to discuss understandings of citizenship. Goldring and Landolt (2013) define precarious work as "a job that is unstable and insecure, offers limited rights, protections, and benefits to workers, allows workers little control over their schedules, and gives workers little say in decisions of how work will be done" (Goldring and Landolt 2013, 157). Many occupations in streams under the TFWP would fall into this category, partly because of the fact of the temporary nature of the employment.

The authors expand on the connections between precarious work and precarious legal status and suggest that citizenship and non-citizenship should be understood less as a rigid binary and more so as fluid for two main reasons, based on the idea of citizenship as a negotiated and relational practice. First, they argue that "social dimensions such as gender, race, racialization, class, sexuality, and disability intersect with formal legal status to produce varying experiences and practices of citizenship for particular individuals and social groups of citizens" (Goldring and Landolt 2013, 159). This relates 
directly to this project as women workers and racialized workers often experience different forms of citizenship than their white male counterparts. Second, they suggest that "citizenship is never fully fixed, permanent, or stable and can be eroded in practice, meaning in specific encounters" (Goldring and Landolt 2013, 159). In addition, they argue that "crossing the boundary into secure citizenship does not guarantee less precarious work" (Goldring and Landolt 2013, 172). Walsh also comments on these themes. He argues that though highly-skilled migrant workers are privileged compared to low-skilled workers, they "possess diminished rights vis-a-vis the domestic population" (Walsh 2014, 598). Walsh adds that "given their reliance on the sponsorship and support of their employers in obtaining permanent status, highly-skilled workers are rendered dependent and acquiescent" (Walsh 2014, 598). This has some truth in the Canadian context. For example, as will be explored in chapter two, even the Canadian Experience Class and the Live-in Caregiver Program enable migrants to access permanence, but they are dependent on their relationship with their employer in order to do so, and even if it is achieved their mobility is still restricted in Canada.

While Goldring and Landolt suggest that the distinction between citizenship and non-citizenship is blurred, Stasiulis argues that the analytical distinction between permanence and temporariness be maintained "so as to retain the visibility of temporary migrants and more effectively confront the potential and actual exploitation inherent in non-permanent statuses" (Stasiulis 2008, 96). Ultimately Goldring and Landolt agree that workers with temporary status are inherently more vulnerable than those with permanent status because "non-citizenship, by definition, is associated with limits in terms of voice, membership, and rights in a political community, and with social exclusion and 
vulnerability" (Goldring and Landolt 2013, 3). Therefore, the focus in this project on constructing the limited access to permanence for low-skilled workers as problematic is still valid and relevant.

The divide between temporariness and permanence relates to Sharma's argument that "citizenship has acted as a difference-making device" that has "constructed complex and layered levels of inequalities" (Sharma 2006, 142). She goes on to say that "these inequities are created in large part through national state categories of differential membership that accomplish, both materially and ideologically, the gendered racialization of class in Canada" (Sharma 2006, 142). Sharma argues that this differential membership or inclusion is more complicated than exclusion, meaning that it is not only that some migrants are accepted and some are not, but that migrants are divided into "separate spaces of belonging" for various types of people "classified according to deeply entrenched ideologies of separate races and gender roles" (Sharma 2006, 17). These ideologies about race and gender are reflected in how different types of work (and skill) are valorized. Classification systems like the NOC may not create these ideologies, but they institutionalize and therefore sustain them. In fact, Sharma makes a similar argument, stating that the TFWP "reflects and further entrenches the gendered division of labour already in operation in Canada" (Sharma 2006, 126).

Closely related to the idea of citizenship as an exclusionary or differently inclusionary tool is the degree to which migrants experience social inclusion. For example, Leah F. Vosko argues that migrant workers are treated as commodities (Vosko $2000,14)$. This commodification of migrant workers can contribute to their construction as "others," which is also based on hierarchies of race, class, and gender. Walsh states 
that "mobility regimes" such as temporary labour migration programs are crafted by the state to "ease the flow and settlement of prioritized travelers, while limiting the movement and incorporation of those viewed as undeserving of citizenship and belonging" (Walsh 2014, 585). This argument is taken up in chapter three of this study which shows how the Conservative government facilitates the settlement of high-skilled workers, while limiting recruitment of low-skilled workers. Highly-skilled migrant workers are seen as more capable of integrating into Canadian society and contributing to the neoliberal project, whereas than low-skilled workers are often seen as problematic and are thus often denied membership to the nation-state.

Gilbert, quoting Aristide Zolberg, argues that "the very characteristics that make these human beings suitable as labour renders them undesirable from the perspective of membership" and that "the hostility toward including these racialized, low-skilled workers in the community propels the temporariness of these programs [emphasis in original]" (Zolberg cited in Gilbert 2014, 158). These authors are making the argument that states keep some labour migrants' status permanently temporary based on expected xenophobic reactions of citizens to racialized migrants' social inclusion. However, the state still has an economic need for these workers, often in sectors that are considered “dirty, dangerous, and demanding;" these positions are often classified as low-skill (Lenard and Straehle 2010, 283). Gilbert even cites the World Bank regarding the "desirability" of unskilled migrants, which says that "large or permanent movements of unskilled workers would not be acceptable to the citizens of most destination countries" (World Bank cited in Gilbert 2014, 159). The nation-state and employers make decisions about which migrants can acquire membership based on levels of skill in an effort to 
depoliticize the criteria on which this membership is based. However, through the above account of the literature, it is clear that skill is socially constructed and intimately linked with one's place in social hierarchies both at home and abroad, contributing to what kinds of migrants are hired under particular temporary migration programs.

While there is much scholarship that provides a gendered perspective to studies of migration and labour, there has been less of a focus on temporary migration and gendering temporariness. Christine Hughes notes that "there is a considerable body of scholarship examining the impacts of temporary or circular migration on household gender practices, roles, and relations" (Hughes 2012, 151). However, gender dynamics related to temporary labour migration programs that take place outside of the home are under-studied in comparison. In Canada, discussions of gender and temporary citizenship usually revolve around the Live-in Caregiver Program (LCP) and, to some extent, agricultural streams like the Seasonal Agricultural Worker Program (SAWP). Abigail Bakan and Daiva Stasiulis in particular have contributed to scholarship around the LCP. They often discuss the complexities of women performing household work as migrant caregivers in a space that has historically been theorized by feminist political economy as "principally a place of unpaid, rather than paid, domestic labour" (Bakan and Stasiulis 2012, 203).

Encalada and Preibisch (2010) take a different approach to exploring gender and temporary work. Their study filled a gap in the literature by studying women's experiences migrating from Mexico to work in commercial agriculture in the Canada, as opposed to their experiences on family farms. The authors outline how gendered and racist assumptions about workers' characteristics affect how they are hired and their lived 
experiences in farming. The authors are critical of temporary labour migration programs, arguing that "the systems of labor control and forms of work organization made possible through these programs rely on multiple systems of oppression, particularly power relations based on gender, race, and citizenship, among others" (Encalada and Preibisch 2010, 309). Encalada and Preibisch also argue that these programs "grant employers access to a highly vulnerable group of workers who, once in Canada, are positioned disadvantageously within the labor market through a range of social and political disentitlements" (Encalada and Preibisch 2010, 309). This speaks to the research presented in this project which shows that low-skilled workers are less able to access formal rights and citizenship than are high-skilled workers.

The analytical framing outlined above is useful in theorizing the way temporariness and permanence are structured and how they can produce inequalities. It is also useful as it is a reminder that citizenship itself should be considered with a critical lens. This will be important to keep in mind in the following chapters because while this study does argue that low-skilled temporary workers should have access to citizenship, this is not without understanding that citizenship categories are themselves problematic and can be used to exclude migrants or alienate them from their rights, thus reinforcing difference between different categories of migrants. The literature reviewed above problematized the temporary/permanent divide by suggesting that these categories are blurry and even if one transitions to permanent status they will not necessarily have full access to their rights; however, temporary status or non-citizenship leaves workers even 
more vulnerable. The chapters that follow will explore how the TFWP stratifies citizenship based on gendered skill categories. 


\section{Chapter: History of Temporary Foreign Worker Program and Changes Over Time}

Before there can be close examination of the findings, it is important to understand the history of the Temporary Foreign Worker Program (TFWP) in Canada, as well as how it is structured today. The TFWP's first iteration, the Non-Immigrant Employment Authorization Program (NIEAP) began in 1973. However, Canada has been admitting migrants on a temporary basis to provide labour at least since the construction of the national railway in the $19^{\text {th }}$ century. Chinese migrants were recruited to perform this labour, the conditions of which have been likened to slavery and are still used as comparative examples with conditions many migrant workers face today. Currently, the TFWP is one broad "umbrella" program that includes many streams, some of which now include pathways to citizenship (like the Live-In Caregiver Program) and many of which do not.

The conditions of employment for temporary foreign workers (TFWs) as well as the structure and regulation of the program have undergone many changes since 1973, many of which will be outlined in this chapter. The chapter will begin with a basic explanation of the structure of the TFWP and provide some statistics that describe the composition of workers in the program based on factors like gender and skill. There will then be a brief discussion about the Provincial Nominee Program as this is one program through which low-skill migrants are able to access citizenship, and thus it is important to explain why this program was not included as a main focus in this project. The rest of the 
chapter will explain the history of the TFWP, beginning with its original form and intentions and the shift in immigration policy from permanence to temporariness. The latter part of the chapter will explore the changes made to the program between $2002^{3}$ and 2015 and the motivations for these changes, as well as showing how they illustrate the shift to temporariness. This chapter aims to provide a detailed background on the TFWP, as well as create a basis from which the gendered effects of temporariness and the privileging of high-skilled movement can be considered.

\subsection{Describing the current TFWP}

The current TFWP facilitates the movement of many kinds of temporary workers, such as international students, agricultural workers" and "high-skilled" professionals. The program is a joint effort between the provinces and territories, Employment and Social Development Canada (ESDC), and Citizenship and Immigration Canada (CIC). For many occupations, employers must apply to ESDC for a Labour Market Impact Assessment (LMIA), formerly known as a Labour Market Opinion (LMO), after which the worker must then apply to CIC for a work permit. The LMIA requires employers to provide information on the position and to make a demonstrated effort to hire Canadian workers first, as the TFWP is designed to (temporarily) fill labour market and skills shortages.

\footnotetext{
${ }^{3}$ Although the time period of study for this project is $2008-2014$, significant changes were made to the program prior to 2008 that provide important context for later analysis.

4 This stream includes the Seasonal Agricultural Worker Program as well as "lower-skilled" occupations (e.g., general farm, greenhouse and nursery workers) and "higher-skilled" occupations (e.g., farm managers and supervisors. However, most workers under this stream are lower-skilled (Elgersma, Library of Parliament, 2014).

5 The use of the terms "high-skilled" and "low-skilled" refer to the definitions of skill as outlined in the National Occupation Classification 2011 (See Appendix A).
} 
The composition of the TFWP in terms of the gender and skill level of workers will be examined in detail in the next chapter. However, a more basic statistical profile will be outlined here to provide context for the following discussion of the evolution of the TFWP. As of December $31^{\text {st }}, 2013$, there were 104,160 workers in Canada with a valid permit under the TFWP (CIC 2014). Of the total mentioned above, $62.4 \%$ of migrant workers in the TFWP were men, and $37.6 \%$ were women. The skill distribution among the total number of migrants is fairly even, with $48.7 \%$ of migrant workers classified as high-skilled, and 50.8\% classified as low-skilled ${ }^{6}$ (CIC 2014). However, as will be shown in chapter three, $70.0 \%$ of all female TFWP permit holders were classified as low-skill, while only $39.2 \%$ of all male TFWP permit holders were classified as lowskill (CIC 2014).

The top source countries for the TFWP are not disaggregated by skill level, and I would not speculate that the low-skilled temporary migrant workers category is the only one with a high number of racialized workers. However, three of the top five source countries for temporary workers are in Asia and Latin America, with the Philippines consistently ranking at the top of the list, likely because most LCP workers are from the Philippines (CIC 2014). When the International Mobility Work Program (IMP) work permit holders are considered, the top source country is the United States and aside from India, the top source countries are predominantly white: Australia, France, and the UK, respectively. As will be briefly mentioned below, the IMP is only open to high-skilled workers. This supports the argument that high-skilled workers are less likely to be

\footnotetext{
6 "Higher-skilled" occupations are those included in NOC codes 0 , A, and B, while "lower-skilled" occupations are those included in NOC codes $\mathrm{C}$ and D. For a more detailed description of skill levels as outlined in the NOC, see Appendix A.
} 
racialized. Finally, as this project concerns the likelihood of temporary migrants transitioning to permanence, it is worth noting that 6,457 unique TFWP work permit holders became permanent residents in 2013, the majority of whom did so through the economic class (as opposed to the family class or as refugees) (CIC 2014).

\subsection{The Provincial Nominee Programs}

It is important to note that while low-skilled workers are excluded from programs like the CEC or the Federal Skilled Worker Program, they are able to access permanence through a Provincial and Territorial Nominee Program (PNP). PNPs are agreements between the federal government and a province or territory under which the province or territory can determine its own criteria for the selection of potential immigrants, based on its demographic and labour market needs and priorities (Nakache 2013, 89). All provinces and territories have such agreements with the federal government with the exception of Quebec and Nunavut. Admissions under these programs have increased from approximately five hundred in 1999 to 36, 419 in 2010 (Nakache 2013, 89).

Nakache argues that PNPs can be an alternative through which low-skilled workers can access permanence, but identifies two main limitations. First, most PNPs are employer-driven which means that migrant workers are only eligible for nomination if they have a full-time permanent job offer with a local employer, which Nakache argues could create a power imbalance between the worker and employer (Nakache 2013, 89). Second, although several PNPs have specific categories for low-skilled migrant workers, these categories "often limit eligibility to a narrow range of occupations or industries" (Nakache 2013, 89). Nakache suggests that PNPs are designed to attract low-skilled 
workers to a specific province or territory permanently but are a "limited time offer" until a labour shortage is filled, and therefore the PNP is not always open to low-skilled workers (Nakache 2013, 89). Therefore, while the PNP may be a viable option for lowskilled workers in specific instances, it is not nearly as available as is the CEC for highskilled workers, for example.

\subsection{Origins of the TFWP and the growth of temporary categories}

The TFWP as it is known today began as the Non-Immigrant Employment Authorization Program (NIEAP) which came into effect on January $1^{\text {st }}, 1973$. Prior to the NIEAP, Canada had programs in place to recruit migrant workers for specific parts of the labour market, like agricultural work (Sharma 2002, 18). According to Nandita Sharma, the NIEAP "was 'new' in that it provided an overarching frame in which to bring in people temporarily to fill certain, employer-identified shortages in the labour force" (Sharma 2002, 18). Like workers recruited through the TFWP today, workers who arrived in Canada through the NIEAP had temporary residency, no options for permanent immigration, and their status was linked to their employer (CUPE 2013). Sharma is critical of the NIEAP, saying that while on the one hand, the government removed explicitly racist restrictions on immigration from the south in 1967, the NIEAP "served to deny many migrants access to the entitlements of or permanent residency and, therefore, Canadian citizenship while recruiting them to work in Canada under conditions deemed unconstitutional for Canadians" (Sharma 2006, 92). Of course, many migrants are still unable to access citizenship through the current iteration of the program, so this remains a relevant critique. Sharma also comments on the relationship of Canadian identity to 
temporary labour migration programs when she states that "key to the organization of legitimacy for coercive state actions against migrants at the time the NIEAP was introduced was the reshaping of an identity that was tolerant but still very much entitled to exclude Others" (Sharma 2006, 92). This speaks to the discussion in chapter one concerning how citizenship categories can sustain 'otherness.'

The current TFWP is an umbrella program which includes several streams. The streams are divided into those that require an LMO, and those that do not. Foreign workers in positions exempt from LMOs include those moving under international agreements like NAFTA or other free trade agreements, as well as international students. Prior to 2014, the TFWP included the following streams that require an LMO:

Table 2.1 Pre-2014 Temporary Foreign Worker Program Streams

\begin{tabular}{ll}
\hline High-skilled & $\begin{array}{l}\text { Occupations coded at } \\
\text { NOC skill level A or B (i.e. management } \\
\text { positions, those in the technical or skilled } \\
\text { trades) }\end{array}$ \\
\hline Low-skilled & $\begin{array}{l}\text { Occupations coded at NOC skill level C or D } \\
\text { (i.e. food service workers, service personnel, } \\
\text { or general labourers) }\end{array}$ \\
\hline Seasonal Agricultural Worker Program & $\begin{array}{l}\text { Based on bilateral agreements, workers } \\
\text { from Mexico and some Caribbean } \\
\text { countries can meet the seasonal needs of } \\
\text { agricultural producers when there is a } \\
\text { shortage of Canadians. }\end{array}$ \\
\hline Agricultural stream & $\begin{array}{l}\text { Employers can hire temporary foreign } \\
\text { workers from any country for on-farm } \\
\text { primary agricultural positions for a maximum } \\
\text { of 24 month when Canadian citizens are not } \\
\text { available. }\end{array}$
\end{tabular}


Live-In Caregiver program

Qualified temporary foreign workers can come to Canada when Canadians are not available to provide unsupervised and fulltime care for children, seniors or people with disabilities in the private residence of those persons for whom they are hired to care.*

Source: Overhauling the TFWP, ESDC, 2014, pg. 8.

*As of 2014, caregivers in the LCP are no longer required to live in the residence of their employer.

As of 2014, the primary streams of the TFWP have changed (though the data for this study focuses on the former structure of the program). The LMO-exempt streams have been grouped together under the newly titled International Mobility Program, though they still technically exist under the TFWP. The table below shows the post-2014 primary streams of the TFWP.

Table 2.2 Post-2014 Temporary Foreign Worker Program Streams

\begin{tabular}{ll}
\hline High-wage & $\begin{array}{l}\text { Includes positions at or above the } \\
\text { provincial/territorial median wage. Examples } \\
\text { of high-wage occupations include managerial, } \\
\text { scientific, professional and technical positions } \\
\text { as well as the skilled trades }\end{array}$ \\
\hline Low-wage & $\begin{array}{l}\text { Includes positions below the } \\
\text { provincial/territorial median wage; examples } \\
\text { of low-wage occupations include general } \\
\text { labourers, food counter attendants, and sales } \\
\text { and service personnel. }\end{array}$ \\
\hline Primary Agricultural Stream & $\begin{array}{l}\text { Includes positions related to on-farm primary } \\
\text { agriculture such as general farm workers, } \\
\text { nursery and greenhouse workers, feed lot } \\
\text { workers and harvesting labourers. This stream } \\
\text { includes the Seasonal Agricultural Workers } \\
\text { Program. }\end{array}$ \\
\hline
\end{tabular}




\begin{tabular}{ll}
\hline $\begin{array}{l}\text { Highest-demand, highest-paid, or shortest } \\
\text { duration }\end{array}$ & $\begin{array}{l}\text { LMIAs for in-demand occupations (skilled } \\
\text { trades), highly paid occupations (top 10\%) or } \\
\text { short-duration (120 days or less) entries will } \\
\text { be provided within a } 10 \text { business day service } \\
\text { standard. }\end{array}$ \\
\hline Live-In Caregiver program & No change
\end{tabular}

Source: Overhauling the TFWP, ESDC 2014, 8.

The TFWP (or NIEAP) was originally intended to be a limited, controlled and selective program to meet specific labour market needs usually in highly-skilled industries, as well as the live-in caregiver and agricultural sectors. The TFWP also, unsurprisingly, emphasized that workers were to remain in Canada on a purely temporary basis as the program was not designed to provide pathways to citizenship for applicants. Sharma marks the creation of the NIEAP as a shift in Canadian immigration policy "away from a policy of permanent immigrant settlement towards an increasing reliance on temporary migrant workers" (Sharma 2006, 20).

The policy shift from permanent to temporary migration is evidenced by the increase in temporary work permit holders over time, as shown in Figure 2.1 below. The graph indicates that the number of TFWs (regardless of the stream through which they enter Canada) has been increasing for over two decades, with sharp increases occurring since about $2003 .^{7}$ In comparison, the number of permanent residents in the country has remained fairly consistent over the same period of time. This could be explained by the fact that permanent immigration programs are based on set targets for immigration, and

\footnotetext{
${ }^{7}$ This is likely due to the introduction of the NOC C\&D Pilot Project in 2002 which expanded low-skill categories in the TFWP. This will be discussed in more detail later in the chapter.
} 
thus are not driven by employer demand. However, it is also indicative of the shift away from encouraging permanent settlement to increased reliance on temporary foreign workers.

Figure 2.1

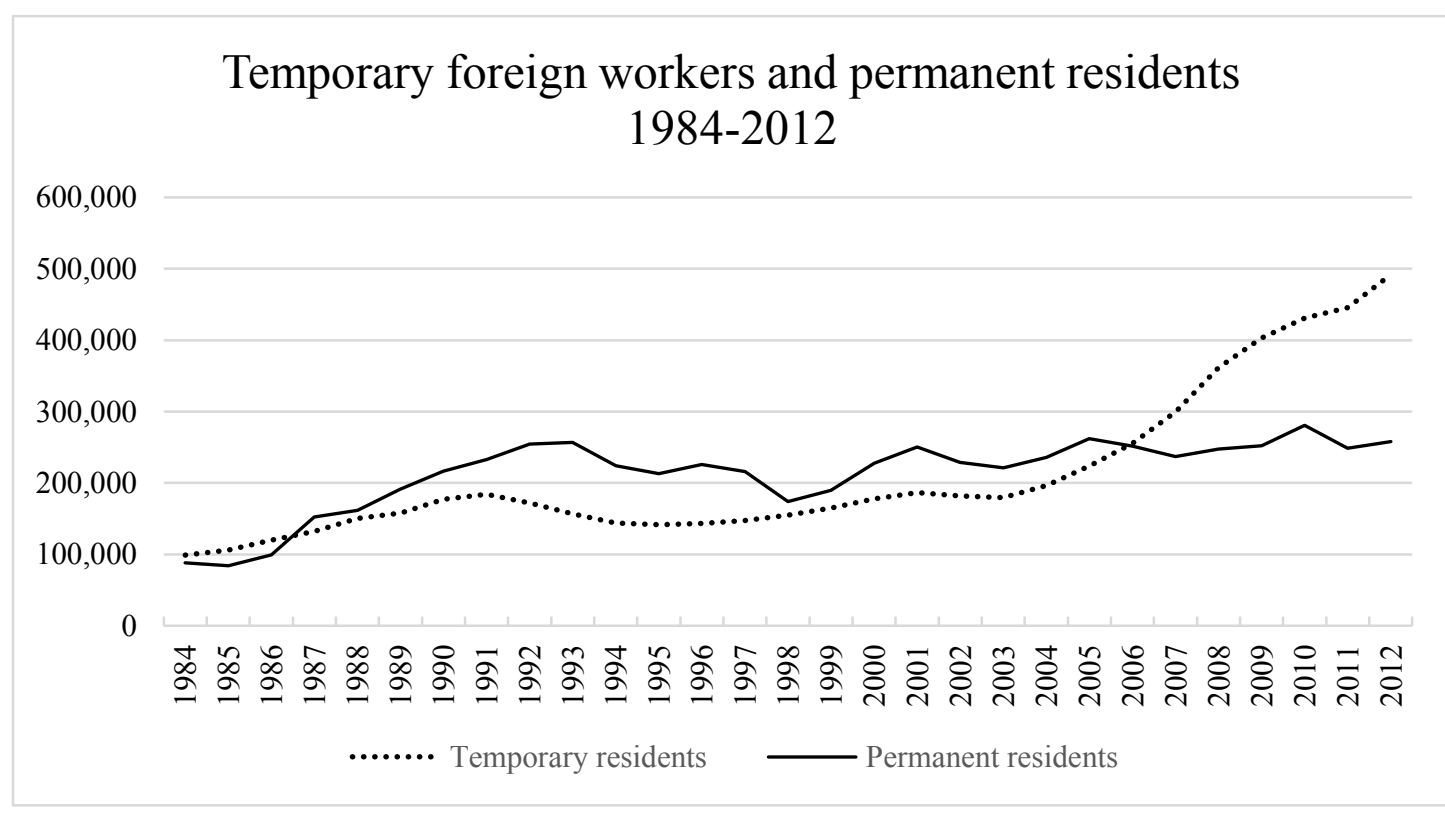

Source: CIC Facts and Figures 2008 (1984-1987); CIC Facts and Figures 2012 (19882012). ${ }^{8}$

Figures 2.2 and 2.3 below show the number of temporary migrant workers divided by gender and the number of temporary migrant workers divided by skill category (though this data only includes 2003-2012). The graph depicting TFWs' gender shows that while the number of male TFWs has been consistently higher than the number of females, both gender categories follow the same upward trend over time. The graph that divides workers by skill category ${ }^{9}$ shows that while there have been more high-

\footnotetext{
${ }^{8}$ Data from Facts and Figures 2013 was excluded from the graph because it was incompatible with those provided in earlier years.

9 "Higher-skilled" occupations are those included in NOC codes 0, A, and B, while "lower-skilled" occupations are those included in NOC codes C and D. In addition, there was a category in the raw data which described when the skill category was not stated. This was excluded from the graph.
} 
skilled than low-skilled workers overall, the two categories have also followed a similar trend over time. However, if there were data on skill prior to 2002, it might have been possible to see the effect of the Liberal government's expansion of the low-skill categories (which will be discussed below). In addition, the changes to the TFWP made by the Conservative government in 2014 represent an effort to limit the number of lowskill workers, which is not represented on the graph below.

Figure 2.2

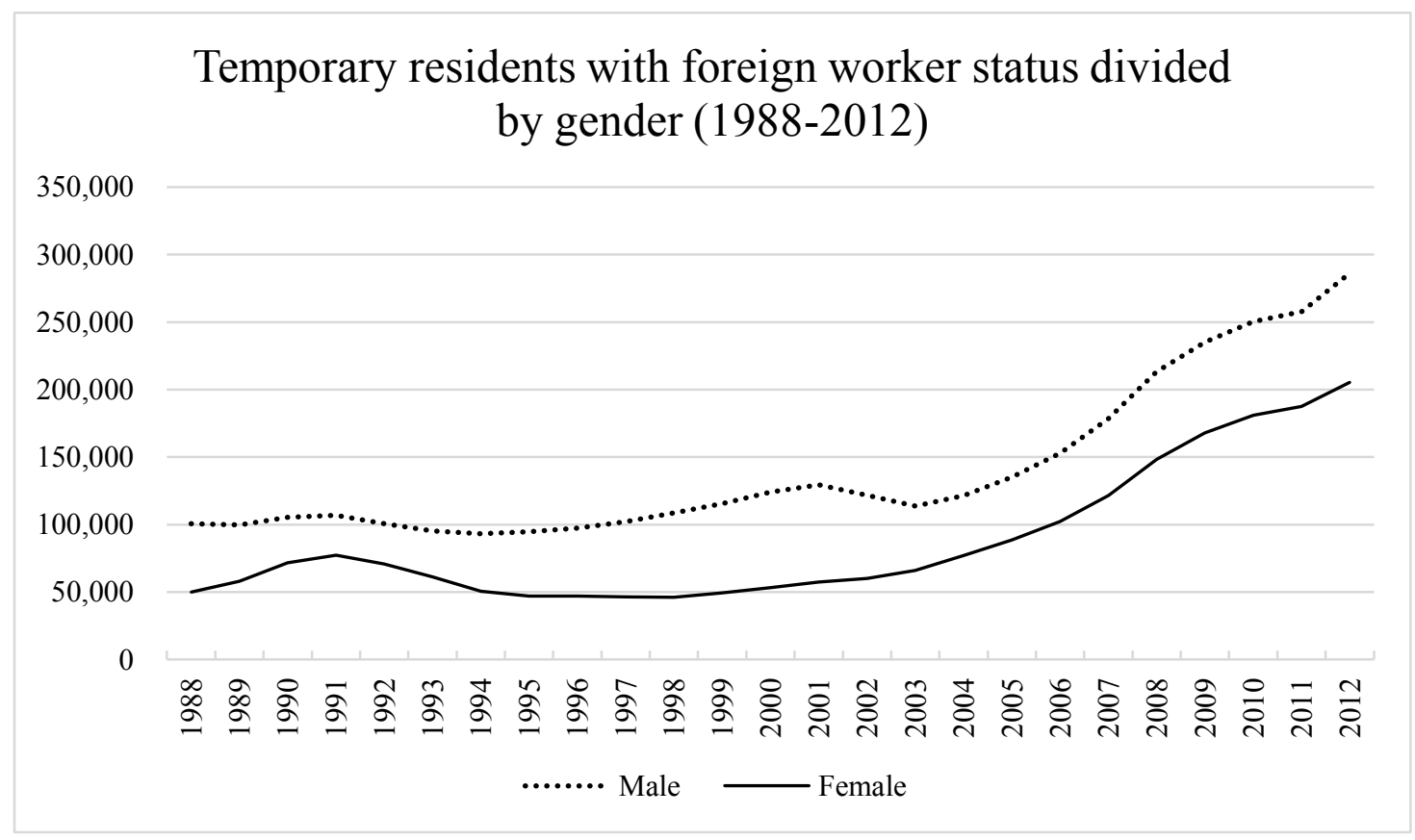

Source: CIC Facts and Figures 2012 
Figure 2.3

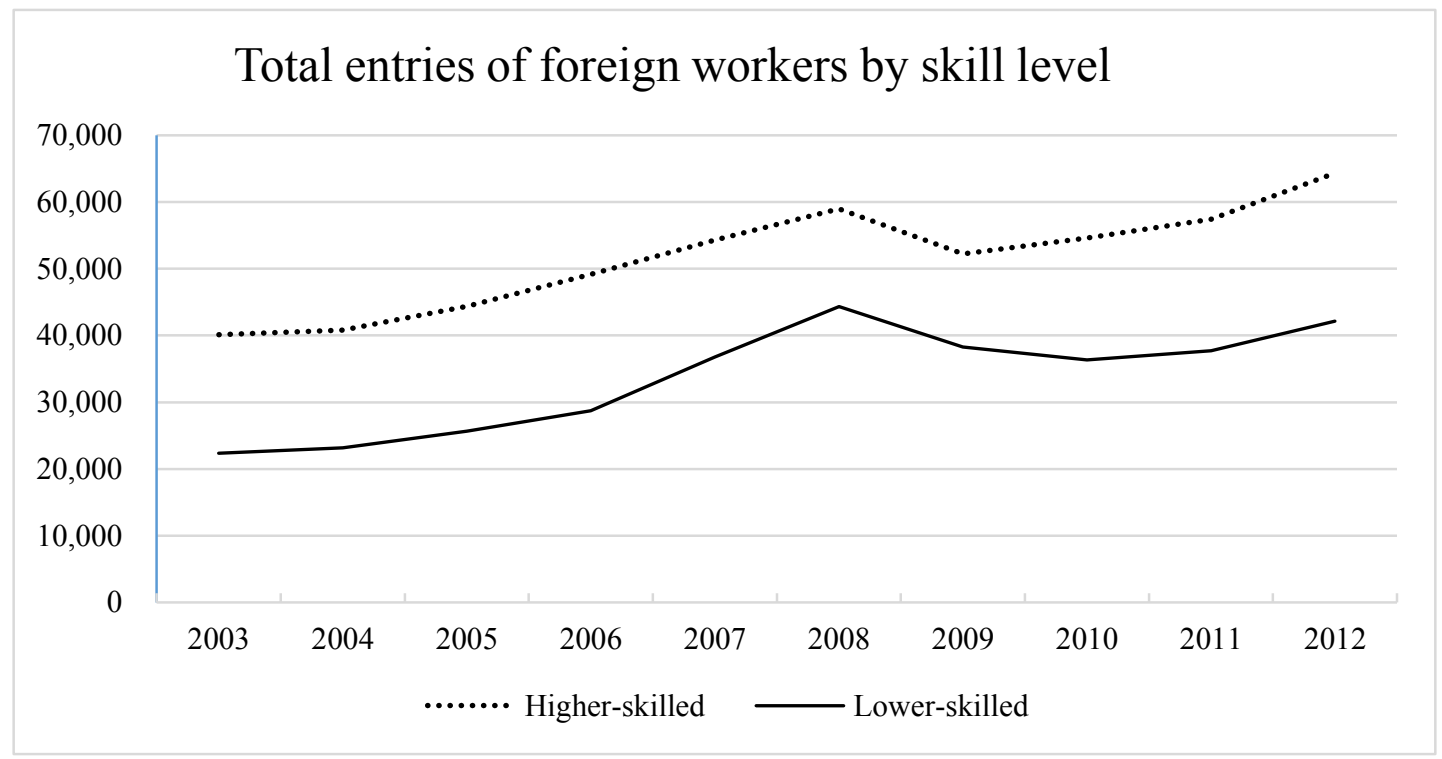

Source: CIC Facts and Figures 2012

\subsection{Changes to the TFWP between 2002 and 2012}

The NIEAP remained largely unchanged in its structure throughout the remainder of the twentieth century, but began to undergo significant changes beginning in 2002 with the Liberal government's introduction of the "Low-Skill Pilot Project," now known as the Pilot Project for Occupations Requiring Lower Levels of Formal Training (National Occupation Classification C and D), herein referred to as the NOC C\&D Pilot Project. ${ }^{10}$ According to Valiani, this policy change was primarily in response to "claims of shortages by employers having neglected to invest in apprenticeship training in the skilled trades sectors from the 1990s" (Valiani 2013, 61). The data indicate that there has indeed been an increase in the number of TFWs classified as "low-skilled." In 2004, about 55\% of TFWs were classified as high-skilled (CIC 2014). By 2013, the number of

\footnotetext{
10 The Immigration and Refugee Protection Act (IRPA) was also passed in 2002, replacing 1976's Immigration Act.
} 
low-skilled TFWs had surpassed their high-skill counterparts, with approximately $51 \%$ of TFWs being employed in low-skill positions. The introduction of the NOC C\&D Pilot Project also increased the overall number of TFWs hired to work in the country. In 2002, there were 37,222 TFWP work permit holders; by 2013, this number had nearly tripled to 104,160 (CIC 2014). Researchers at the Maytree Foundation argue that the NOC C\&D Pilot Project sparked a trend of employers_using TFWs to fill low and unskilled jobs quickly with those who do not have the minimum points required by the Federal Skilled Worker point system, thus replacing permanent status immigrants with temporary migrant workers (Maytree n.d., 2).

In 2006, the Conservative government facilitated even more hiring of low-skill TFWs by expanding the list of occupations that qualified for the Low-Skill Pilot Program and increasing the speed of processing applications (CUPE 2013). These expansions of low-skill categories and increases in the numbers of TFWs supports Sharma's argument that there has been a shift over time from permanent to temporary migration. However, as will be noted below, the Conservative government changed its position and instead made policy changes to restrict the recruitment of low-skilled workers.

In order to hire a TFW, employers were required to apply for a Labour Market Opinion (LMO). A positive LMO indicated that Employment and Social Development Canada (ESDC) had determined that the employer has "tried but failed to find a Canadian or permanent resident for the job, the job offer is genuine, and the employer has met job offer commitments to TFWs they have hired in the past" (CIC 2015). This process was designed with two (contradictory) objectives in mind. The first was to help ensure that employers were making an effort to hire Canadians first. Once it was determined that 
there was a genuine lack of Canadian applicants for the position, the LMO system was intended to speed up application processing times.

Part of this process required employers to actively advertise the available position domestically for a specified period of time. In 2011, the Conservative government shortened this period from six weeks to two, but increased it once more to four weeks in 2013. The shortening of the advertising period contradicts the message that the government wishes to prioritize hiring domestic workers, and contributes to the trend of privileging temporariness over permanence. In April 2012, the government introduced the Accelerated Labour Market Opinion (ALMO), which was designed for employers that had been issued an LMO in the previous two years. The ALMO only applied to highskilled TFWs and operated as a fast-tracked LMO, again speeding up the process of hiring (highly skilled) TFWs (CUPE 2013). The ALMO also allowed employers to pay TFWs up to fifteen percent less than the prevailing wage for a high-skilled occupation and five percent below the prevailing wage for a low-skilled occupation (Alboim and Cohl 2012, 6). According to ESDC, which implements the TFWP, this wage flexibility was introduced "to ensure that temporary foreign workers were compensated at the same wage as Canadians working in the same occupation in the same location" (ESDC 2014). As a result of criticism from labour groups and opposition parties who argued that the fifteen percent rule would depress wages in the labour market, the government eliminated the rule in 2013 (Curry 2014).

Naomi Alboim and Karen Cohl produced a report for the Maytree Foundation that outlines the major changes made to the TFWP between 2008 and 2012. Based on their research, the authors argue that the main drivers for the government's immigration 
change agenda are to improve outcomes for immigrants, increase the short-term contribution immigration programs could make to the Canadian economy, address application backlogs, and prevent abuse of the immigration and refugee system (Alboim and Cohl 2012, 3). One of the major changes made to the TFWP occurred with the passing of Bill C-50, a budget bill that included amendments to the IRPA. One of these amendments increased the power of the Minister of Citizenship, Immigration, and Multiculturalism by enabling the minister to make discretionary decisions about applicants without going through parliamentary processes. These decisions were called "Ministerial Instructions" and could be issued to immigration officers. Because this change was embedded in a budget bill, there was little debate on the matter as a vote against the bill would signify a vote of no confidence and trigger an election.

Another significant change to immigration policy in Canada in 2008 was the creation of the Canadian Experience Class (CEC), which allows some international students and highly skilled TFWs to make the transition to permanent residence from within Canada (Alboim and Cohl 2012, 3). As will be examined in more detail in chapter three, actors from both business organizations and civil society advocate for migrants to have access to permanence. The CEC is a step in that direction, and so perhaps was meant as a response to those advocating for permanence. However, it privileges highly skilled workers over lower skilled workers (who have no access to permanence through this stream), which neglects to address another critique of the program. As of January 1, 2015, applicants to the CEC must use the Express Entry system where they complete a profile outlining their skills, education, work experience, and language ability, and are then entered into a pool of candidates from which the ones with the most points will be 
“invited” to apply for permanent residence (CIC 2015). Therefore, even highly skilled migrant workers are not guaranteed access to citizenship and must demonstrate that they possess qualities that are in line with Canadian immigration priorities.

The creation of the CEC represents a shift toward an employer-driven model of immigration where migrant workers can only access permanence with their employers' support. Salimah Valiani argues that migrant workers' dependence on their employers renders them vulnerable. She says that "within the context of weakened and poorly enforced employment standards legislation in most Canadian provinces, migrant workers hoping to remain permanently in Canada and eventually sponsor their families are thus rendered yet more dependant and exploitable by employers well aware of their employees' precarious legal and economic status" (Valiani 2013, 62). The TFWP has always been an employer-driven program where employers choose the number of workers they hire (after applying for an LMO when necessary). However, expanding employers' power by allowing them to be able to play a significant role in deciding which workers should be granted permanent citizenship is a newer process, and makes workers' even more dependent on their employers.

Highly-skilled workers in the CEC are not the only ones that can apply for citizenship, however, as Live-in Caregiver (LCP) workers are eligible to apply for permanent status after working in Canada for twenty-four months. In 2012, LCP workers became able to have an open work permit once they completed their two-year work obligations (Alboim and Cohl 2012, 5). Civil society groups had also long fought for the live-in requirement for LCP workers to be removed from the program, arguing that it was restrictive and often resulted in abuse of the workers. In October 2014, the government 
announced that the live-in requirement for LCP workers would officially be dropped and the LCP's structure as a whole would be altered. Two new pathways for caregivers to find work in Canada were introduced in November 2014: one for child-care providers and the other for those who care for the sick or elderly (CTV News 2014). This restructuring has received criticism from civil society actors and within migration scholarship. Walsh states that even though the LCP includes access to citizenship, "the program's structure creates conditions in which workers are rendered vulnerable; integration is stalled, and it is difficult to satisfy requirements for permanent residency" (Walsh 2014, 595). Walsh also highlights the low rates of retention of LCP workers, citing that despite institutionalized access to permanent status, only 53 percent of live-in caregivers entering between 2003 and 2005 had successfully transitioned by 2007 (Walsh 2014, 595). The difficulty of achieving permanent residency is part of the reason why many civil society groups advocate for permanent status upon landing for live-in caregivers.

\subsection{Changes to the TFWP in the 2013 federal budget}

Major reforms came to the TFWP in the 2013 federal budget, partly in response to intense criticism of the program from various actors over time. Many of the criticisms of the program are from civil society actors ${ }^{11}$ and researchers ${ }^{12}$ who highlight workers' vulnerability to poor (and even abusive) working conditions. These criticisms of the

\footnotetext{
${ }^{11}$ For example, labour unions, organizations like Justicia for Migrant workers, and immigrant serving agencies.

${ }^{12}$ Jenna Hennebry and Kerry Preibisch $(2010,2011,2012,2015)$ have done extensive field research about the conditions of agricultural labour and migrant's access to social services in particular. Hennebry also appeared before the Citizenship and Immigration Committee in 2008.
} 
program have been raised for some time and stories about individual migrants’ experiences are becoming increasingly prevalent in the media. Significantly, many of the migrant workers who share stories about poor working conditions are describing positions that are classified as low-skill. ${ }^{13}$ The Conservative government's changes to the TFWP in the 2013 budget are likely a result of increased media exposure of working conditions and continuing pressure from civil society groups to alter the program's structure to increase protection for workers, in addition to complaints from Canadians that migrant workers were taking their jobs.

Many aspects of the TFWP were addressed in the 2013 changes. For example, the efforts in 2012 to expedite the application processes were largely overturned as the ALMO was temporarily suspended. The government also eliminated employers' ability to pay ALMO workers fifteen percent less than the prevailing wage, requiring employers to always pay TFWs "at or above the prevailing wage for that occupation in the region" (ESDC 2014). User fees for corporations were announced, though according to CUPE there is no indication of how these fees will be kept from being passed on to workers (CUPE 2013). These changes represent some listening to advocates' demands for worker protection in terms of paying workers the prevailing wage, but neglect to consider how user fees might be passed on to workers.

As mentioned previously, while the required length of domestic advertising efforts was cut from six weeks to two in 2011, the requirement was increased to four weeks in 2013. Since 2013, employers have also been required to use two additional methods of recruitment beyond Canada's national Job Bank website, "one of which needs

\footnotetext{
${ }^{13}$ Such as food service and some agricultural positions.
} 
to be national in scope if hiring for a high-wage occupation" (ESDC 2014). Employers hiring for low-wage positions are also required to make a demonstrated effort to hire Canadians from under-represented groups in the work force (ESDC 2014). In terms of language requirements, since 2013, English and French are the only languages that can be identified as a job requirement "to prevent employers from advertising a position where the applicant's skills in a foreign language are not linked to a genuine job requirement" (ESDC 2014). These regulations represent an effort to privilege the hiring of Canadians over TFWs, made clear by the indicated "putting Canadians first" priority of the government (ESDC 2015). This priority stems from the idea that businesses are too quick to hire foreign workers and have built their business model on the TFWP instead of hiring domestic workers (ESDC 2014). According to ESDC, "employers must do more to recruit, hire and train Canadians" to decrease the number of TFWs in Canada and "end the distortion in the labour market caused by their prevalence in some sectors and regions" (ESDC 2014).

The 2013 changes to the TFWP are intended to ensure that employers are only using the program when they are truly unable to find Canadian workers to fill the positions. Bonnie Mah, writing for The Maytree Foundation, highlights some examples of these efforts, including that employers have to answer additional questions on the LMO form to confirm that they are not using the program to facilitate the outsourcing of Canadian jobs, that they have a plan to transition to a Canadian workforce over time, and that the government will have increased authority to suspend and revoke LMOs if the program is being misused (Mah 2013). Mah points out that the changes in 2013 only focus on TFW positions that require an LMO, and argue that because only forty percent 
of TFWs come to Canada with an LMO, the changes do not address the majority of TFWs (Mah 2013). Examples of streams that do not require an LMO include youth exchange programs, post-doctoral fellows, spouses of international students, and workers who enter the country under international agreements such as the North American Free Trade Agreement (Mah 2013). Mah also argues that no changes were made to help temporary migrant workers access the services and benefits they contribute to, and that none of the changes address the trend towards replacing permanent immigration with temporary labour migration.

Permanent immigration is still possible for some temporary migrant workers, but is largely reserved for migrant workers who are classified as high-skill (for example, through the CEC) or through the PNP, as was outlined at the beginning of this chapter. Jason Kenney, the former Minister of Citizenship and Immigration, mentioned that the Canadian public's opinion on immigration should be taken into consideration when designing immigration programs. He stated in a 2011 committee meeting that "eight out of ten Canadians are consistently telling us that immigration levels are already high enough or too high," though he does not cite his source for this data (41-1, CIMM 11, Nov $\left.24^{\text {th }}, 2011\right)$. He went on to say that while Canada "has never had a serious organized political expression of xenophobia or anti-immigrant sentiment," in order to maintain that "broad consensus" it is important to "constantly demonstrate to Canadians that immigration is working for Canada and that we are welcoming a number of people we can realistically accept, employ, and integrate" $\left(41-1\right.$, CIMM 11 , Nov $\left.24^{\text {th }}, 2011\right)$. This indicates a political motivation to limit the number of temporary workers transitioning to permanent status in an effort to placate (likely Conservative) Canadians. Kenney seems 
convinced that it is not xenophobia that causes Canadians to disapprove of high levels of immigration. However, the focus on the exclusion of low-skilled workers for membership is telling, as this study shows that workers in these categories are more likely to be women and are often racialized. To recall a quote from Zolberg in chapter one, low-skill workers are suitable for labour for the same reasons they are excluded from membership and that it is hostility towards including low-skilled workers in the community "propels the temporariness of these programs" (Zolberg cited in Gilbert 2014, 158).

\subsection{Changes to be made to the TFWP in 2014 and 2015}

Even more changes to the TFWP were announced in 2014, some of which will significantly alter the program's overall structure. ESDC produced a document in 2014 that outlines the government's intention of "over-hauling" the TFWP to "put Canadians first," or to privilege the hiring of Canadians over TFWs. It is worthwhile to mention some of the most significant changes that have either very recently been applied to the program or will be in the near future to determine if they follow previous trends. The first significant change that was immediately put into effect was to base the TFWP on wages instead of on the National Occupation Classification (NOC) because, according to the ESDC publication, "wage is a more objective and accurate reflection of skill level and labour need in a given area" (ESDC 2014, 7). This change means that instead of being classified as high- or low-skilled, TFWs will be categorized as either high- or low-wage depending on if they are paid above or below the provincial or territorial median wage. This could be seen as a positive change as it marks a shift away from subjective and problematic categorizations of skill. However, this classification is problematic as it still 
operates on a dichotomy, and it is unclear if one's wages are separate from one's skill classification in reality. It is unlikely that a "high wage" worker would be classified as "low-skill" based on the NOC classification. In fact, the ESDC document provides examples of positions that would be considered high- or low-wage that directly correspond to the NOC classification. For example, high-wage positions tend to be managerial or professional, and low-wage positions include general labourers and sales and service representatives (ESDC 2014, 8). In addition, this move to wage categories does not take into account the fact that, like skill, wages are socially constructed. This results in labour market segmentation, which is evident in the gender pay gap. While not specifically considering temporary labour, Statistics Canada reported that in 2011, women earned $87 \%$ of every dollar earned by their male counterparts (Morissette et. al, 2013, 14). Therefore, ESDC's classification of workers based on wage as opposed to skill could still have a gendered effect, as wage categories reflect what kinds of jobs are valued. This connects back to the literature reviewed in the previous chapter which discussed how different types of knowledge are valued and remunerated based on how they are gendered. Skill and wage are socially constructed categories meant to reward those with occupations that are highly valued by society.

Another change that has taken place is that the LMO has been changed to a Labour Market Impact Assessment (LMIA) that is intended to be more "comprehensive and rigorous" in an effort to provide more checks on employer power (ESDC 2014, 9). Employers must provide more information about their efforts to hire Canadians and explain why Canadians that applied were not hired, consistent with the "putting Canadians first" narrative. LMIAs for occupations that are in high demand and are highly 
paid, or have short-duration work periods (120 days or less) will be rewarded with an expedited application process estimated at ten days (ESDC 2014, 14).

While the TFWP has previously been expanded to facilitate the movement of lowskill workers, the government is now introducing a cap to limit the proportion of lowwage temporary migrant workers that a business can employ (ESDC 2014, 10). This change is designed to shift the TFWP back to its original purpose, which was to hire more high-skilled workers for a specified period of time, and to encourage businesses to hire and train more Canadians. The government expects that this change will cut the number of low-wage temporary migrant workers in half (ESDC 2014, 10). In addition, ESDC has declared that they will no longer process applications for positions that "require little or no education or training" in "economic regions with an unemployment rate at or above six percent" (ESDC 2014, 11). The government also intends to reduce the time a low-wage TFW can work in Canada to ensure the TFWP remains "truly temporary" (ESDC 2014, 12).

The "putting Canadians first" promise of the 2014 changes combined with the measures to limit abuses of TFWs (discussed below) brings to mind Harald Bauder's (2008) work on competing narratives about immigration in Canada. Through his analysis of Canadian newspaper articles, Bauder shows that there is a construction of a victim and perpetrator narrative prevalent. According to one viewpoint, "immigrants are the victim of exploitation and deskilling perpetrated by Canadian regulators," whereas according to the other viewpoint, "immigrants threaten the economic well-being of Canadian society" (Bauder 2008, 142). The former viewpoint is often re-iterated by civil society groups and scholars, whereas the latter viewpoint is used by the government to make changes to the 
TFWP under the framing of "protecting" "Canadian" jobs, as evidenced in the changes outlined throughout this chapter.

These changes make it clear that the government wants to focus on attracting high-skilled (or high-wage) workers as opposed to low-skilled, which has both political and economic motivations. The focus on recruitment of high-skilled workers is contextualized in the global "race for talent" described in chapter three. As Canada (and other countries) shifts to a knowledge economy, the market for workers in such industries (classified as high-skilled) becomes more competitive. Therefore, in order to recruit such workers, the government believes that it is in the country's interest to make streams for high-skilled occupations more attractive, such as by offering workers the "carrot" of citizenship. This is evident through programs like the CEC. Also, high-skilled workers are seen as desirable partly because it is argued that they will integrate into society more easily than low-skilled workers, thus potentially being less of a burden on the government and communities..$^{14}$

While the changes to the TFWP outlined by ESDC are focused on shifting priority back to high-skilled workers and short work placements, as well as checking employer power, the government has also taken some measures to mitigate abuses suffered by TFWs. One way in which they intend to do so is by increasing the number and scope of inspections of temporary migrant worker workplaces. Inspections will be performed as a result of tips, employers being deemed high-risk, and random audits (ESDC 2014, 17). In addition to increasing the number of inspections, the authority of inspectors has been expanded to "better catch employers who are breaking the rules,"

\footnotetext{
${ }^{14}$ This argument was made in committee hearings that are outlined in chapter three.
} 
including by conducting on-site visits without warrants and interviewing temporary migrant workers about their experiences (ESDC 2014, 17). The government also launched a Confidential Tip Line in April 2014 to report abuse of the TFWP (ESDC $2014,19)$. If an employer is suspected of or proven to have broken rules, ESDC has the authority to suspend or revoke an LMIA, and will be banned (blacklisted) from the TFWP and fined (ESDC 2014, 22). While these reforms are designed to provide more checks on employers, organizations like CUPE and Maytree, as well as Fay Faraday of Osgoode Law School, are unconvinced that this will work. Faraday says the "complaintsbased" model of reporting abuse will not result in enforcement of workers' rights because workers will not report abuse for fear of being deported (Leo 2014).

The Conservative government has made many changes to the TFWP since their election in 2006. Most of these changes were made to prioritize the hiring of Canadian workers first, closely followed by high-skilled temporary migrant workers. Efforts have also been made to limit abuse and exploitation of temporary foreign workers. However, the government neglects to change migrant workers' visas so that they are not tied to one employer. Many argue that the tied visa is at the root of the problem of workplace abuse. Workers are reluctant to report abuse because they risk being deported. As mentioned, one of the most recent changes to the TFWP is that if the government receives a report of abuse and confirms it, they will suspend or revoke the employers' LMIA. This approach is problematic for two reasons. The first is that the complaints-based method of reporting is unlikely to yield results because workers fear being fired and deported if they report abuse. The second is that if the government punishes the employer by suspending or revoking their LMIA, the worker still suffers as with no employer support, they lose their 
status and must return to their home country. The government has made changes to increase workplace monitoring and has provided workers the opportunity to report abuse. However, it is unclear why they have refrained from altering the visa. Justicia for Migrant Workers recommends giving migrant workers the opportunity to move to another employer if a job becomes available, meaning their visa would tie them to an industry as opposed to a specific employer (Noakes 2015). This could serve as a compromise between allowing migrant workers access to citizenship and keeping their visa tied to one employer.

\subsection{Continuity versus Change}

The TFWP has undergone many changes since its first iteration as NIEAP in 1973. While the program was initially intended to promote recruitment of workers for highly-skilled industries, the program was expanded to include more low-skill categories in the early 2000s. The Conservative government has made many changes to the TFWP between 2006 and 2015, some of which represent continuity and others that represent change. Despite the creation of pathways to citizenship for high-skilled temporary workers like those in the CEC (which are in themselves not a guarantee), the Conservative government has continued with practices of maintaining many workers' temporary status. As will be seen in chapter three, the government resists extending the option of permanence to all temporary migrant workers, despite the consistent testimony in committee hearings from witnesses and members of parliament that advocate for permanence. This defense of temporary categories of citizenship status has remained largely consistent over time. 
The Conservative government has also shifted its focus to the recruitment of highskilled workers. In some ways, the policy changes regarding skill represent both continuity and change. The Conservatives' cap on the number of low-skill workers is a complete reversal from the 2002 Liberal government's expansion of low-skill categories. In 2014, Prime Minister Stephen Harper commented that Canada needs fewer temporary foreign workers and more permanent foreign workers (Nuttall 2014). However, the prime minister and his government have made it clear (partly with the introduction of the CEC), that they only want high-skilled workers to become permanent residents. The focus on high-skilled workers is a change from the Liberal governments' policy changes, but represents continuity with the TFWP's original purpose, which was to fill temporary labour shortages in industries requiring highly-skilled workers. The Conservative government believes that more jobs will be maintained in Canada and wages will remain more consistent if businesses stop relying on temporary workers.

As discussed in the next chapter, the findings in this project show that because low-skill workers are predominantly women and often racialized, these immigration policies have disproportionate effects on different kinds of migrants. In addition, the project questions the idea of basing citizenship on subjective categories of skill. While efforts can be made to limit abuses suffered by temporary migrant workers, ultimately their inability to access citizenship largely determines the rights they are able to access. As will be explored in the following analysis, not only does one's status affect one's workplace rights, but one's gender and skill level can indeed impact that status. 


\section{Chapter: Uncovering the links between skill, gender and citizenship}

The aim of this research project was to explore how gendered constructions of skill affect workers' citizenship status through the TFWP. Kofman's theory of emblematic migrants included the argument that different types of knowledge are valued differently and women are more likely to possess the kinds of knowledge that are valued less. The

findings focus on categories of skill as opposed to knowledge on the assumption that skill categories correspond with differently valued knowledge, but ultimately show that women are more likely to be employed in low-skilled occupations, which are also typically gendered female.

The findings below show that men and women are hired for different positions in the TFWP and I argue that this is because of their gender (which influences their skill classification). The Canadian government has the power to make changes to the TFWP that affect which migrants are able to cross borders for work, and obtain permanent status in Canada. The findings below show that despite over-whelming support for low-skilled migrant workers access to permanence through the TFWP among witnesses of various backgrounds, the government refuses to permit this change to the program. In addition, while the government has made changes made to the TFWP that were presumably designed to protect migrant workers, they have ignored the advice of committee witnesses who recommend changing the visa from being employer-specific to industryspecific. The government's selective changes to the TFWP and refusal to enact witness recommendations shows that they wish to keep certain workers in a space of permanent 
temporariness, and privilege the movement of workers who work in occupations that are traditionally gendered male and are not racialized.

The gender dynamics at play in the TFWP can be uncovered by examining a variety of sources. The findings that will be presented in this chapter are mainly based on data from Citizenship and Immigration Canada (CIC) and evidence from parliamentary committee hearings. Transcripts from two House committees were reviewed for the period 2008-2014: the Standing Committee on Citizenship and Immigration Committee (CIMM) and the Standing Committee on Human Resources, Skills and Social Development and the Status of Persons with Disabilities (HUMA). The topics of these hearings ranged from discussing employment or immigration more generally, to temporary foreign workers specifically. For example, the 2008 CIMM meetings centred on the topic of temporary foreign workers as the committee traveled across Canada holding hearings in order to present a parliamentary report on the subject in 2009. Hearings from 2008 also included some discussion of the controversial aspects of Bill C50, namely the amendments to the Immigration and Refugee Protection Act (IRPA) that provided the minister of Citizenship and Immigration more power in discretionary immigration decisions. Many of the other meetings of both committees were discussing the topic of the main or supplementary estimates of the federal budget. In the second session of the forty-first parliament, discussions in many of HUMA's hearings were related to the committee's study on the renewal of labour market development. In this context, temporary foreign workers were discussed in relation to employment rates and labour shortages. 
As mentioned in the introduction, transcripts from the meetings were accessed through the online database provided by the Parliament of Canada. The two committees were selected based on their relevance to the themes of this project (i.e. employment and citizenship). A search was done using the keywords "temporary foreign workers" in order to return the most relevant results. Transcripts from all meetings that contained this phrase were reviewed in full in order to draw out key themes, or even phrases. In this way the review of the transcripts is more akin to a discourse analysis than a content analysis. Quotes were selected if they even remotely related to gender or skill, or included an opinion on whether migrant workers should have access to citizenship. The quotes were then organized according to their themes, which are described below. Quotes that provided the most interesting perspective on a theme or were generally regarded as representative of similar opinions were ultimately selected to be included in this thesis.

While gender is the primary focus of this study, the importance of skill and temporariness are also key and in many ways these are the entry points from which gender has been studied. As such, the findings are organized according to several themes. The first is the idea of temporary citizenship. This theme will serve as the basis for considering whether temporariness is a useful citizenship category and whether temporariness can be gendered. The second theme is that a worker's status is tied to his or her skill category. Skill is the main entry point from which gender is studied in relation to the TFWP, and showing how skill influences status will prove that skill is a crucial factor. Once these themes are established, the findings related to gender will be presented. This section will include instances in the studied publications and meetings when gender was mentioned in relation to skills, temporariness, or the TFWP 
specifically. It will also include mentions of where gender discussions were lacking or absent. This structuring of the findings according to key themes will allow for deeper analysis to follow in the next chapter and enable for connections to be made between skills, gender, and citizenship.

\subsection{Temporariness}

The idea of temporariness was well-established in the first chapter. As discussed in that chapter, many international organizations are in favour of this type of citizenship stratification and many scholars note the inequality it can produce or sustain. The purpose of this section will be to uncover how these concepts play out in the discussions around temporariness in the Canadian context. When discussing the TFWP in general, many witnesses (mostly in the Citizenship and Immigration Committee) made arguments about whether or not temporariness was useful for the state, businesses, or the migrant themselves.

While some temporary migrant workers can apply for permanence after spending a specified amount of time working in Canada, ${ }^{15}$ the majority of migrant workers in positions requiring an $\mathrm{LMIA}^{16}$ have in common the fact that they enter the country with temporary status. As mentioned in chapter two, the original purpose of the TFWP was to keep workers temporary, meaning that at the end of their work term they would return to their home country and perhaps be re-hired to work in Canada at a later time. Many are in

\footnotetext{
${ }^{15}$ For example, highly-skilled migrant workers can apply for residence under the Canadian Experience Class, care workers can apply under the LCP, and some workers can achieve status through Provincial Nominee Programs.

${ }^{16}$ About forty percent of temporary migrant workers in Canada require an LMIA (Alboim and Cohl 2012, 46). The remaining sixty percent move to Canada under International Mobility Programs, for example, the North American Free Trade Agreement.
} 
favour of this arrangement and argue that temporary workers should not necessarily be able to access status, though for different reasons. For example, Sheila Fraser, Canada's Auditor General from 2001 to 2011 (now serving on the board of directors at Manulife), suggested that if migrants wished to stay in Canada, then they should not use the TFWP. Fraser stated that,

...because the processing time under the federal skilled worker program was so long, people were coming in under the temporary program and staying. If these people really have the skills we need in this country, they should be encouraged to apply under the permanent program, the federal skilled worker program (40-2, CIMM 36, Nov 26 $\left.{ }^{\text {th }}, 2009\right)$.

Robert Carrier, a Bloc Québecois Member of Parliament (MP), also expressed an opinion on permanence for migrant workers in relation to administrative decisions. In response to witnesses who called for migrant workers to be granted permanence, Carrier said that that move would be "a major decision for a government" because of the significant criteria that would need to be developed in order to manage the application backlog that might ensue (39-2, CIMM 30, Apr 10 $\left.{ }^{\text {th }}, 2008\right)$. He also indicated that "it would be preferable at least to have people who have been the subject of an analysis and whom we consider could be good residents," though it is unclear what Carrier's criteria for a "good resident" might be (39-2, CIMM 30, Apr 10 $\left.{ }^{\text {th }}, 2008\right)$.

While Carrier's and Fraser's comments focused on the practical and administrative side of migrant workers achieving status, Chris Alexander, Minister of Citizenship and Immigration, seemed more concerned about migrants' ability to integrate into Canadian society. He stated in a 2014 meeting that, "We [the government] think that those who have a deeper experience of Canada, who've actually been physically present here for four years, will have a greater ability to participate fully in the civic life, political 
life, and economic life of Canada, which is what we expect from citizens" (41-2, CIMM 2, June $\left.11^{\text {th }}, 2014\right)$. MP Devinder Shory (CPC), echoed this sentiment, saying that "citizenship should be earned" and proceeded to ask, "In order for someone to become a Canadian citizen, is it too much to ask them to spend a significant amount of time in Canada?" (41-2, CIMM 2, June $\left.11^{\text {th }}, 2014\right)$. The comments from Fraser and the two CPC MPs demonstrate concern about the length of time a temporary worker might spend in Canada and are used to justify the imposed time requirements for workers to spend in the country before being able to apply for citizenship.

As will be elaborated later in this chapter, some committee witnesses disagree with this idea on the basis that temporary migrant workers often do establish ties in Canada regardless of how long they have been in the country. In addition, migrants working in temporary labour migration programs often spend a great deal of time in the destination country. This is especially true for workers in the SAWP who work in Canada for eight months before returning to their home country. Many of these workers are hired back for multiple seasons, sometimes resulting in them spending more of their lives in Canada than their home country. Despite the amount of time they spend in Canada, these workers are not eligible for permanent status through the TFWP. If the Conservative MPs quoted above are suggesting basing the decision of which migrants should be granted citizenship on the amount of time they spend in Canada, presumably some agricultural workers would be eligible. Therefore, the argument that temporary workers should not have access to permanence because they have not spent a great deal of time in Canada is flawed and suggests that there might be other reasons why the government wishes to restrict some workers' citizenship. 
The Conservative government does not want to grant access to citizenship to all temporary migrant workers under the TFWP. However, the 2009 report of the Standing Committee on Citizenship and Immigration (CIMM) on temporary foreign workers and non-status workers included a recommendation that "the Government of Canada create a path to permanent residency for all temporary foreign workers modeled on the opportunity currently available to live-in caregivers" (CIMM 2009, 13). Despite this report from the committee, the Supplementary Opinion of the Conservative Members of the Committee included the following statement:

It is our view that there is a place for a temporary program in our immigration system to address our temporary labour needs, and therefore we oppose any move to alter the design of the Temporary Foreign Worker to make it a permanent program in all but name. That would undermine the integrity of the Federal Skilled Worker Program and, thus, our immigration system. As such we respectfully dissent from recommendations $3^{17}$ and $6^{18}$ (CIMM 2009, 75).

It is interesting to note that at the time of the report's publication, the Conservatives held a majority on the committee. However, they disagreed with the main recommendation of the committee's report (that all temporary workers have the ability to access status). The Government of Canada formally responded to the committee's report, making the argument that it is "important to maintain a clear distinction between the objectives of the permanent and temporary immigration programs" (GoC 2009). The government has

\footnotetext{
${ }^{17}$ Recommendation 3: The Committee recommends that the Government of Canada initiate dialogue and facilitate cooperation with the provinces and territories, so that the temporary foreign worker and provincial nominee programs function together smoothly to provide a pathway to permanent residency (CIMM 2009, 11).

${ }^{18}$ Recommendation 6: The Committee recommends that the Government of Canada create a path to permanent residency for all temporary foreign workers modeled on the opportunity currently available to live-in caregivers (CIMM 2009, 13).
} 
consistently held this position. For example, in 2015, Employment and Social

Development Minister Pierre Poilievre stated that the purpose of the TFWP is "for it to be temporary," and "that's why they're called temporary foreign workers" (Graveland 2015). The introduction of the CEC, as well as evidence in the next section, shows that the government does not wish to restrict access to permanence to all workers, but primarily to low-skilled workers.

Not all those present in committee meetings agreed that temporary migrant workers should be denied the ability to access citizenship. In fact, after hearing testimony throughout 2008, the 2009 CIMM report recommended that "all temporary foreign workers in the current programs should have the opportunity to apply for permanent residency after meeting certain criteria" (CIMM 2009, 9). The committee described its immigration "vision" as follows:

The Committee's vision is the vision of immigration that Canada has long cherished: mutual commitment on the part of immigrants and this country to work hard and invest in improving the future. We want immigrants to feel that Canada is welcoming and that there are no barriers to social and economic participation. We also want them to feel that it is worthwhile to commit their time, talents and their children's futures here. These commitments follow naturally from permanent immigration, serving all parties - employers, workers, and communities — well. The Committee recognizes that many workers and employers desire their employment arrangement to be permanent and we feel that permanent migration is in Canada's best interests. Of course, those who do not wish to apply to remain in Canada would be under no obligation to do so (CIMM 2009, 9).

The committee also argued that "temporary work programs diverge from the Committee's vision of immigration" as described above and added that in the long term, a path to permanent residency may not be necessary because the TFWP would be reserved for more "genuinely temporary situations" (CIMM 2009, 9). 
While the above comments are the result of a synthesis of witness testimony from 2008 , it is worth examining individual comments from that year and the years that followed in order to uncover trends. For example, many of those arguing in favour of providing temporary workers with citizenship options were either part of civil society or from the business community. Speaking on behalf of the Immigration Network, Sima Sahar Zerehi argued that employers wanted their workers to be in Canada on a permanent and stable basis and that it was "common business sense" because otherwise workers are forced to leave after spending time being trained and settling into their new jobs (41-1, CIMM 9, Nov 15 $\left.{ }^{\text {th }}, 2011\right)$. Michael Atkinson, President of the Canadian Construction Association, also asserted that employers want permanent workers, saying that "We [employers in the association] want permanent workers. We want workers for our future labour needs" (41-2, HUMA 28, June $\left.5^{\text {th }}, 2014\right)$.

Zeheri disagreed with the previously mentioned idea put forward by Chris Alexander that those who have spent more time in Canada will be better equipped to participate in public life. She argued that, contrary to their temporary status, migrant workers do have ties to business and communities in Canada and they have already been subjected to criminal and health checks $\left(41-1\right.$, CIMM 9, Nov $\left.15^{\text {th }}, 2011\right)$. From this basis she said that her organization recommends "expanding the Canadian economic class to allow long-term residents and temporary workers to land" and that "the government reform its requirements under the Immigration and Refugee Protection Act and bring workers to Canada permanently, rather than rushing in these potential immigrants as temporary cheap labourers" (41-1, CIMM 9, Nov 15 $\left.{ }^{\text {th }}, 2011\right)$. 
A frequent witness appearing before the CIMM was Victor Wong, the Executive Director of the Chinese Canadian National Council. In a 2008 meeting, Wong argued that Canada was "moving down the wrong path" when it comes to immigration because it is "not about filling labour market shortages with just-in-time labour," adding that CIC is "not a temp agency" (39-2, CIMM 26, Apr $\left.8^{\text {th }}, 2008\right)$. Wong said that Canada should "be building a nation of active citizens" and that "temporary foreign workers and non-status residents deserve real choices that include a clear path to permanent status and citizenship" (39-2, CIMM 26, April 8, 2008).

Several witnesses also criticized temporariness because it can affect workers' access to their rights. The 2009 CIMM report states that workers are vulnerable to mistreatment by employers and "workers are made vulnerable by the very fact of their temporary status [emphasis added]" (CIMM 2009, 27). Although this statement did not result in many changes to the program in regards to temporary status specifically, it is significant because Members of Parliament are acknowledging the link between temporariness and vulnerability which their witnesses highlighted. For example, Jill Hanley, appearing as an individual, said that "In my research everything I've seen about the social rights implications for temporary foreign workers seems to indicate that the very temporary nature of their status creates barriers for their human and social rights" (39-2, CIMM 29, Apr 10 $\left.{ }^{\text {th }}, 2008\right)$. Under advisement of their witnesses, the committee suggested that by "removing the threat (real or perceived) of being sent home, providing all workers with a path to permanent residency should significantly reduce the potential for temporary status to hold workers hostage to bad employment situations" (CIMM 2009, 27). Again, despite this overwhelming agreement from witnesses and in spite of 
other changes made to the program, the government has thus far refused to adhere to the recommendations that all workers should be able to access pathways to citizenship.

One final argument that is sometimes made in favour of temporary status is that not all migrant workers actually have a desire to immigrate to Canada. ${ }^{19}$ Janet McLaughlin, a researcher who appeared before the CIMM as an individual in 2008, did not see this as a reason to eliminate the option to apply for permanence. She stated that "even if not all workers wish to emigrate to Canada, those who do should be given the choice" and that they should "still have the freedom to change employers and to come and go as necessary, as family needs and emergencies arise, without the fear that they will never be allowed back" (39-2, CIMM 24, Apr $\left.7^{\text {th }}, 2008\right)$. In this statement McLaughlin also criticized the fact that the TFWP visa ties workers to one employer, another aspect of the TFWP that the government has been unwilling to change, for reasons they have not made clear.

As evidenced by the quotes above, there are many views on temporary status coming from a variety of actors. Non-government actors tend to advocate for permanent status for all workers, as do employers and other members of the business community. In fact, none of the witnesses that appeared before the committee supported sustaining the dichotomy between temporariness and permanence. However, political actors, especially MPs from the governing party, are more likely to defend the TFWP's emphasis on temporary status and to argue that if workers wish to immigrate to Canada, then there are

\footnotetext{
${ }^{19}$ For example, Trevor Mahl, President of TC Hunter (an employment agency), said that "The reality is that a lot of these workers don't want to come here on a permanent basis. They've made it very clear to us that they're here to work, they're here to make money. I can only speak for construction. I can't speak for manufacturing or some of the other areas, but they're here to make money" (39-2, CIMM 19, Apr 1 2008).
} 
other programs available. The government seems to have two main justifications for keeping TFWP workers temporary. The first argument they make is that Canadians should have first access to jobs, the "putting Canadians first" narrative prevalent in the recent changes to the TFWP (as outlined in chapter two). Jason Kenney, former Minister of Employment and current Minister for National Defence and Minister for Multiculturalism, defended the changes to the TFWP in 2014, saying that the reforms are positive in every region "because they ensure that Canadians come first to access available jobs" (CBC 2014). This narrative is persistently used by the government despite the other common narrative that workers are doing the jobs that Canadians do not want. ${ }^{20}$

The second justification for the program's structure was alluded to with Carrier's comments in 2008, that allowing temporary workers to apply for permanent status would create a massive backlog of applications, an often-discussed issue in relation to immigration streams. In an October 2011 CIMM meeting, Kenney said that allowing temporary foreign workers access to permanence would mean "adding about 140,000 additional people in the immigration queue" $\left(41-1\right.$, CIMM 4, Oct $\left.20^{\text {th }}, 2011\right)$. He further argued that if the government were to prevent the further growth of backlogs only by increasing admissions, they would have to increase admissions by about half a million permanent resident landings per year $\left(41-1\right.$, CIMM 4, Oct $\left.20^{\text {th }}, 2011\right)$. Kenney continued that if allowing that many permanent residents is "where parliamentarians or this committee want to go, I invite you to be explicit about wanting to invite over half a million immigrants, essentially more than doubling immigration levels to Canada" to "let Canadians participate in that debate" $\left(41-1\right.$, CIMM 4, Oct $\left.20^{\text {th }}, 2011\right)$. While the general

\footnotetext{
${ }^{20}$ See references to Bauder on page 63 of this thesis.
} 
Canadian public has not been polled on this issue, this section has shown that the committee has made it very clear that they wish to extend the option of permanence to all migrant workers. Also, Kenney himself has said that not every migrant worker wishes to immigrate to Canada, ${ }^{21}$ in which case the numbers he proposes could be exaggerated. Committee witnesses who were not associated with the government did not agree with the government's justifications for keeping workers in the TFWP temporary, and showed overwhelming support for allowing migrant workers access to permanent status.

\subsection{The link between skill and permanence}

Another important theme relates to the way in which workers' skills are related to their citizenship status, as either temporary or permanent residents. As discussed in this section, the evidence shows that the status that one can achieve within the framework of the TFWP is closely linked to their skill category. This will be key to understanding the importance of gendered skill construction in the TFWP. This section will touch on the ideas presented in the last theme on temporariness, with one crucial change. The statements included here will not just display arguments for and against temporariness, but will outline arguments that temporariness is justified for certain migrant workers over others, based on their skill level. It is also important to keep in mind the shift in priority in terms of skill level in the TFWP over time. The program was first designed to recruit high-skilled ${ }^{22}$ workers, but between 2002 and 2014, the low-skill streams of the program

\footnotetext{
${ }^{21}$ For example, Kenney stated that many participants in the Seasonal Agricultural Worker Program "are not people who are applying for permanent residency or come here with the expectation of it" (41-1, CIMM 78, Apr 25 $5^{\text {th }}, 2013$ ).

${ }^{22}$ The term "high-skilled" refers to occupations classified as high-skill by the Canadian government under the National Occupation Classification (NOC) categories.
} 
were expanded. Since 2014, the government has instead prioritized the recruitment of high-skilled workers to the TFWP which is reflected in the expansion of programs that provide pathways to citizenship for high-skilled workers through the Canadian Experience Class (CEC).

In the global landscape of the "race for talent," 23 the Canadian government has made clear its recent intentions to prioritize the recruitment of high-skilled workers over low-skilled. ${ }^{24}$ This priority is outlined in many government documents and initiatives, such as the Overhauling the TFWP document released in 2014. Economic Action Plan 2013 includes a section on intended changes to the TFWP partly on the basis that "Canada continues to experience major labour and skill shortages in many regions" 25 (GoC 2013, 84). In addition, the CIC's 2013 report to parliament states that "reforms to our economic immigration program will accelerate the arrival of highly skilled immigrants who can fill acute labour market shortages, integrate more quickly into our work force and immediately begin making contributions to our economy" (CIC 2013, 1).

Transcripts from parliamentary committee hearings also include statements (largely from MPs) claiming that Canada should be recruiting high-skilled workers. Dr. Julie Drolet, an associate professor at the University of Calgary appearing as an individual,

\footnotetext{
${ }^{23}$ See Shachar (2006).

${ }^{24}$ The term "low-skilled" refers to occupations classified as low-skill by the Canadian government under the National Occupation Classification (NOC) categories.

${ }^{25}$ It is important to note that the nature of these labour and skill shortages and whether or not they are being filled by TFWs, is disputed. In 2013, Kevin McQuillan from the University of Calgary published a paper entitled "All the Workers We Need: De-bunking Canada's Labour Shortage Fallacy." He argues that there is no evidence showing that these labour shortages cannot be filled by domestic workers. Dominique M. Gross released a report on behalf of the C.D. Howe Institute in April 2014 entitled Temporary Foreign Workers in Canada: Are They Really Filling Labour Shortages? In the report Gross discusses a lack of data on shortages and argues that changes to the TFWP that eased the hiring of TFWs accelerated the rise in unemployment rates in Alberta and British Columbia.
} 
provided a background on the international race for skilled labour in which these debates are taking place. She stated that,

There is evidence in the literature reviewed of the international race for skilled labour in the new knowledge economy that makes it necessary for immigration policies and programs to attract the skilled workers that the economy needs, as well as to offer and provide a desirable future for immigrants. The literature describes the pressure to change immigration policies to better reflect labour market realities. The literature also suggests that immigration policies are trying to address common barriers faced by newcomers. The provincial nominee program, Canadian experience class, temporary foreign worker, and express entry, are all prominently featured in the literature with respect to the supply and development of skills (41-2, HUMA 29, June 10 $\left.0^{\text {th }}, 2014\right)$.

Drolet's comments are not providing any normative argument, but the political actors attending committee meetings made statements that suggest that they are indeed aware of the race for talent and wish for Canada to succeed in this context. For example, Costas Menegakis (CPC) said in 2013 that "we want to attract the brightest and the best. It is a competitive world and we want to maintain our economic advantage, if you will, worldwide" (41-2 CIMM 2, Nov 7², 2013$)$. Perrin Beatty, the President and Chief Executive Officer of the Canadian Chamber of Commerce, similarly stated that "the concern among Canadian employers is that we are going to be facing a chronic shortage of skills in Canada and we should be looking at how we address that on a more permanent basis. How do we draw to Canada the best and brightest in the world and have them help us build this country?" (41-1, HUMA 40, May $\left.28^{\text {th }}, 2012\right)$.

In a speech given at an event to announce the 2013 Immigration Levels Plan, which makes room for the rapid growth in the CEC, Kenney emphasized that immigration reforms are designed to "do a better job of selecting people with the capacity to quickly contribute to our economy" (Kenney 2013). He described "immigrants of the 
future" as young, educated in Canada with Canadian work experience, and with strong language skills (Kenney 2013). This coincides with the government's plan to prioritize the recruitment of highly-skilled workers through the TFWP. Alexis Conrad, the Director General for the Temporary Foreign Workers, Skills and Employment branch of ESDC, said that the 2014 TFWP reforms are "intended to ensure that the program continues to operate in the national interest [emphasis added]" (41-2, HUMA 37, Nov 18 $\left.{ }^{\text {th }}, 2014\right)$. Conrad did not expand on what he meant by the "national interest." However, this statement does suggest that the priority is not necessarily for the program to operate in the interests of migrant workers, but more so to extract their labour. These comments show the government's intention to compete on an international scale for highly-skilled workers, justified partly by the idea that these workers can integrate more easily, but also with emphasis on their ability to contribute to the Canadian economy. This is also a comment on how different types of knowledge are valued differently, as it suggests that low-skilled workers are less able to contribute to the economy despite the fact that they produce goods for export or perform care work which contributes to social reproduction, for example.

Sheila Fraser agreed that Canada must compete with other countries, but she stated that this competition is for "permanent and temporary workers with various skills" as opposed to focusing solely on high-skilled workers (40-2, CIMM 37, Dec $\left.1^{\text {st }}, 2012\right)$. Gerry Mills, President of the Atlantic Region Association of Immigrant Serving Agencies (ARAISA), went a step further to argue that Canada needs to attract workers classified both as high- and as low-skilled in order to achieve a balanced model of immigration. She states that, 
ARAISA is certainly not advocating a removal of the skilled worker stream. We appreciate that highly skilled migration is generally politically popular and has been a relatively easy policy for politicians to sell to electorates; immigration of low-skilled workers is often opposed because it's believed that they present an extra source of competition in an already low-paid part of the economy. However, Canada's economy has a need for a balanced immigration program that responds on many levels of need and also includes a flexible, simple entry route for lower-skilled immigrant workers (39-2, CIMM 34, Apr 16 $\left.{ }^{\text {th }}, 2008\right)$.

In the above quote, Mills is acknowledging that states have an interest in attracting highskilled workers and facilitating their move to permanence, but she argues in favour of balanced immigration programs that also include movement options for workers classified as low-skill. She added that "I think with the low-skilled, high-skilled...I hate the word "low-skilled;" people are skilled. We want everybody in Canada. We want lowskilled, middle-skilled, high-skilled" workers (39-2, CIMM 34, April 16, 2008). This is the only found instance of an expressed dissatisfaction with the dichotomy of high- and low-skilled workers, but Mills stops short of criticizing the idea of skill categories altogether.

Many MPs and witnesses in the committee hearings shared more normative views on whether workers' skill categories should be tied to their status in the temporary migrant worker framework. Minister Alexander made it clear in 2014 that "Canada's doors are open to high-skilled workers" and that those workers have a pathway to permanent residence $\left(41-2\right.$, CIMM 2, June $\left.11^{\text {th }}, 2014\right)$. While this statement was meant to prove that some temporary workers are not trapped in a cycle of permanent temporariness, it also serves to reinforce the divide between low- and high-skill workers as the minister did not indicate that low-skilled workers also have access to permanence. Joyce Reynolds, the Executive Vice-president of the Canadian Restaurant and 
Foodservices Association, referring to the introduction of the CEC, said that her organization was "pleased to see a new immigration class established for temporary foreign workers who want to apply for permanent residence status without having to leave Canada" (39-2, CIMM 28, Apr $\left.9^{\text {th }}, 2008\right)$. However, she expressed concern that that immigration stream was only available to high-skill workers, those in NOC codes A, $\mathrm{B}$ and $\mathrm{O}$, which does not include workers in the food service industry, whom she represents. She described the immigration system as "biased" against low-skilled and semi-skilled workers and recommended that the CEC should also provide access to citizenship for workers in NOC codes C and D "so that Canadian job experience acquired by lower-skilled temporary foreign workers is recognized" (39-2, CIMM 28, Apr $9^{\text {th }}$, 2008). Reynolds' comments likely impacted the opinion of the committee as in the 2009 CIMM report it states that while they too were pleased with the introduction of the CEC as a pathway to permanent residency for some workers, it is "too narrow in scope" and all temporary migrant workers (not just high-skilled) should be eligible to apply for permanent resident status after working twenty-four months within a thirty-six month period (CIMM 2009, 13). This clear recommendation from a witness that was also included as a recommendation from the CIMM committee, has not been taken into consideration by the government as the $\mathrm{CEC}$ is still designed to facilitate transitions to permanence only for high-skilled workers.

Andrew Telegdi, an MP from the Liberal Party of Canada (LPC) drew upon history to argue that Canada should welcome migrant workers with varying levels of skills and offer them the option of staying in Canada permanently. In a 2008 CIMM meeting, Telegdi said 
I really am troubled by this whole notion of having more and more temporary foreign workers instead of people who come as citizens to build the country. Historically, this country was built by people with varying levels of skills. Earlier on, the fewer skills you had, the more desirable you were. I remember the men in the sheepskin coats who were brought over to tame the prairies. Now, of course, if you happen to be one of those people, we don't want you--except to bring you in under servitude conditions (39-2, CIMM 41, May 12 $\left.{ }^{\text {th }}, 2008\right)$.

Janet McLaughlin, again as an individual researcher, also suggested that "the Canadian immigration system needs to recognize the value of these so-called low-skilled workers and as Canadians we should never see people merely as economic units" (39-2, CIMM 24, Apr $\left.7^{\text {th }}, 2008\right)$. NDP MP Olivia Chow was also critical of tying skills to permanence.

She asked,

Is it fair to punish those who have lower skill sets? We need their labour, but because their skills are not the degree types of skills, we do not allow them to apply, or even if they apply, they do not have enough points and therefore they cannot become landed immigrants and therefore they would not be able to bring their families to Canada. I don't see that as being fair (39-2, CIMM 18, Mar 31 $\left.{ }^{\text {st }}, 2008\right)$.

This quote does not solely refer to the TFWP, but Canada's immigration policy more generally. However, the sentiment of rejecting linking one's skill category to their citizenship is still relevant. Cosmo Mannella, the Director of the Canadian Tri-Fund, Labourer's International Union of North America, questioned the high- and low- skill dichotomy as well, using a more specific comparison. In a 2008 CIMM meeting, he asked, "why isn't a carpenter ${ }^{26}$ who has been framing houses for four years, and doing it in a credible and honest way, given the same weight as a university student with a threeyear or four-year undergraduate degree?" $\left(39-2\right.$, CIMM 26, Apr $\left.8^{\text {th }}, 2008\right)$. Mannella is

\footnotetext{
${ }^{26}$ Interestingly, trade-related occupations like carpentry, as well as occupations related to agricultural labour, are some of the few occupations that are traditionally gendered male, but not classified as highskilled.
} 
questioning how the Canadian state values different occupations and skill sets, suggesting that while formal education is more valued, different types of labour contribute to the Canadian economy in different ways.

George Maicher, former president of the New Brunswick Multicultural Council, differentiated between the benefit of being a high-skilled worker, who can come to Canada under the Federal Skilled Worker Stream, and being a low-skilled worker, whose options are more limited and usually must apply to the TFWP. He argued that there should not be a stark division between these two skill groups and mentions that skilled workers' benefits include being able to bring their families, and access the healthcare and education systems, which low-skill workers are unable to do (39-2, CIMM 32, Apr 15 ${ }^{\text {th }}$, 2008). He stated that, "When we talk about the difference between skilled and unskilled workers, people who can stay longer than a year and people who cannot stay, I think it's very important to look at the different rights and benefits that we give to those workers" (39-2, CIMM 32, Apr 15th , 2008).

Macdonald Scott, an immigration consultant appearing before the CIMM as an individual, was also critical of the skill dichotomy affecting workers' access to rights and dignity in the workplace. He asked if this is "the kind of Canada we want to create: a Canada where there are two classes of people; a Canada where we have an underclass of people who have no rights on the job" and then "a Canada where we have people in higher-skilled jobs who have no rights, access to services, access to status?" (39-2, CIMM 26, Apr $\left.8^{\text {th }}, 2008\right)$. Nicole Filion also referenced "the negative impact of the temporary foreign worker program on the rights of those who are admitted in what are considered unskilled job categories" (39-2, CIMM 30, Apr 10 $\left.{ }^{\text {th }}, 2008\right)$. On behalf of the 
Ligue des droits et libertés, Filion recommended that "all persons selected in a "worker" category, regardless of their recognized qualifications, should obtain permanent residence upon arrival in Canada" and that "Discrimination based on social condition must absolutely be banished from these programs" (39-2, CIMM 30, Apr 10 $\left.{ }^{\text {th }}, 2008\right)$.

There was at least one witness to the committee who favoured the idea of skills being tied to permanence, at least in terms of integration. Maia Welbourne, the Senior Director of Strategic Policy and Planning at CIC, stated that "Evidence suggests that the selection of skilled immigrants with high levels of human capital, such as higher education, strong official language skills, and relevant work experience, leads to better economic outcomes both initially and over time" (41-2, HUMA 002, Nov $\left.7^{\text {th }}, 2013\right)$. The government's official response to the 2009 CIMM report included a similar statement: "lower-skilled workers generally have limited training, transferable skills and linguistic abilities, which mean adapting to changing conditions and finding their way around in the Canadian labour market could be more of a challenge" (GoC 2009). These comments justify the position that migrants' skills should be tied to their status not just because of Canada's labour market needs, but in the interest of the migrants' own ease of integration.

At least one witness was opposed to the link between status and skill because migrant workers are not always employed commensurate to their skills. This is largely because of issues with maintaining credentials across borders, a relevant subject but one beyond the scope of this project. However, it is important to note that while high-skilled workers usually experience more privileged citizenship even through the TFWP, Yessyl 
Byl from the Alberta Federation of Labour points out that this is not always the case. She claims that

The problems with the program don't extend just to the low-skilled workers; they extend to the skilled workers. I can't begin to tell you how many welders I have helped out who have been dumped by their companies, companies you may hear from. They're laid off; the companies claim they're just not competent to work as welders in Alberta, yet subsequent employers I have found have said these guys ${ }^{27}$ are great, they're wonderful, they work well. We have no protections for those people. These are welders we desperately need, yet there's very little protection for them (39-2, CIMM 19, Apr $1^{\text {st }}$, 2008).

Byl's comments not only reflect an issue with credentials, but also with the fact that workers who come to Canada under the TFWP have their visas tied to one employer. In addition, Byl pointed out that there are no protections in place for the workers in the scenario she described. This again reflects that there are difficulties with workers accessing their rights when their status is tied to their skills.

The link between the high-low skill dichotomy and migrant workers' status in Canada finds expression in the TFWP. While government representatives were in favour of this link, many of the witnesses that appeared before the committees were not, arguing that all types of work should be valued and that it is unfair to allow some workers to access their rights more easily than others. Now that it is clear that government policy has been based upon a link between skills and status (though most of the witnesses challenged that this link should exist), the findings on gender will be presented, as gender was found to be a significant factor in determining a worker's skill category.

\footnotetext{
${ }^{27}$ It is interesting to note that when discussing welders (classified as skill level B), Byl genders the occupation by referring to the welders as "guys." This is one example of how the way some witnesses raise concerns about the TFWP can be problematic because gender is either not discussed or is connected to a specific occupation.
} 


\subsection{Gender}

The third and final theme is gender and how it relates to the previously explored themes of temporariness, status, and skill. This section will explore how gender interacts with each of these elements and show that it is a significant factor affecting migrant workers' rights and citizenship. While women are often the primary focus of the findings related to gender, men are also included in the gender analysis of the program. This section will also note when discussions of gender were lacking in relation to the TFWP. The findings presented here indicate that while gender and status do not directly intersect in the TFWP, because one's skill is classified based on a gendered social construction and one's skill impacts one's status, gender becomes a significant factor in migrant workers' (in)ability to achieve permanent status.

CIC provides detailed information on the TFWP in its annual reports to Parliament, which were analyzed for this project. Gender analysis is included in these reports because the Immigration and Refugee Protection Act (IRPA) included a legislative requirement to "report annually on the impact of this legislation and the corresponding regulations from the perspective of Gender-Based Analysis (GBA), a requirement fairly unique in federal statutes" (CIC report 2008, 44). This indicates some commitment to understanding the gendered impacts of immigration policies, with the TFWP included but not as the main focus of analysis. In accordance with the regulation, CIC developed a Strategic Framework for Gender-Based Analysis for 2005-2010 which planned how they would fulfill the requirement. CIC describes GBA and its importance as follows:

Gender impact analysis focuses on important social and economic differences between men and women, and between different groups of 
men and women, including such variables as age, race, sexual orientation, ethnicity, religion and culture, over their life cycles. It seeks to examine existing and proposed policies, programs and legislation to ensure that they are having their intended effects and producing fair results (CIC 2008, 44).

One way that CIC commits to GBA is by providing sex-disaggregated data in their annual statistics. These proved useful in the research for this project and will be drawn upon later in this chapter. In their 2008 report, CIC also claimed to be working towards applying GBA to policy development in the department. For example, they said that because of concerns raised during consultations with stakeholders about the CEC that the proposed work experience requirement could have a "differential impact on men and women," CIC "removed the obligation for the work experience requirement to be met with full-time and continuous work" (CIC 2008, 45). This indicates a step towards implementing GBA in policy decisions, but neglects to make the connection between skills and gender, as the CEC is only available to high-skilled workers.

The GBA section in CIC's 2009 report to Parliament neglected to include sexdisaggregated statistics for temporary workers, focusing instead on permanent residents. In the 2011 report, CIC reported that "women accounted for a small share of economic principal applicants relative to men" but that "their share has been growing steadily from 26.1 percent in 2002 to 40.2 percent in 2010" (CIC 2011, 31). They acknowledged that there is a growing proportion of economic immigrants who come as live-in caregivers, a category that is predominantly composed of women (and which fell under the TFWP in 2011). Significantly, the 2011 CIC report included reference to one of the major themes of this project: that women are more likely than men to find themselves at the lower end of the occupational skill levels (CIC 2011,31). They also found that in 2010, "25.2 
percent of females with an intended occupation were planning to join the labour force in a lower skilled occupation, compared with only 10.7 percent for males" (CIC 2011, 31). These statistics describe trends for all economic class migrants (including but not limited to those in the TFWP).

In the 2012 CIC report, the GBA section was significantly expanded in terms of length and detail, though it repeated some content from previous years' reports. The GBA section also included more information on temporary residents (of whom temporary workers are one category). CIC found that men continued to represent "the clear majority" of temporary residents but that the gap in proportion between men and women had decreased (CIC 2012, 32). CIC used foreign workers as an example, showing that the proportion of female temporary migrant workers' initial entries has "steadily risen" since 2002, hitting a peak of 41.4 percent in 2009, and remaining stable since then (CIC 2011, 32). CIC also noted a counterpoint to this trend with the LCP. They found that since 2007, there has been a downward trend in the number of live-in caregivers entering Canada as temporary residents, meaning that the growth in the number of female temporary workers is attributable to streams other than the LCP (CIC 2011, 32).

It is noted in the 2014 report that CIC successfully completed the implementation of all elements of the Departmental Action Plan on GBA which was based on recommendations from the auditor general in 2008. According to the 2014 report, CIC has become a model for other federal departments and agencies for its use of GBA (CIC 2014, 24). In terms of the actual findings in the 2014 report, CIC reports that in 2013, the 
percentage of women in economic classes ${ }^{28}$ has increased from 21 percent in 2004 to 34 percent in 2013, but the CEC had seen a decline in female admissions from 41 percent in 2009 to 35 percent in 2013 (CIC 2014, 25). CIC again noted that the LCP is an outlier in terms of gender participation as women comprised 96 percent of all entries in that category in 2013, and that this number has not fallen below 94 percent in the last ten years (CIC 2014, 25). CIC found that the number of female principal applicants is "consistent or slowly increasing" across the economic class, which in their view suggests that "these programs are successfully recognizing the human capital of female immigrants" (CIC 2014, 25). CIC also noted that they wish to "continue to welcome qualified men and women [emphasis added]" which again distinguishes the priority of recruiting high-skilled workers (CIC 2014, 25).

The CIC reports include summaries of key findings from their data collection, but they do not go into much detail about the gendered patterns of movement in each program. However, their Facts and Figures, produced quarterly and per annum, provide more information on gender and the TFWP specifically. Figure 3.1 shows the number of female and male TFWP work permit holders between 2004 and 2013. ${ }^{29}$ The data show that while at the beginning of the decade the number of male and female permit holders was almost at parity, the number of male permit holders has since been consistently higher than that of female permit holders. Since 2011, there is a distinct increase in the gap between male and female permit holders, with the number of males increasing

\footnotetext{
${ }^{28}$ Economic classes are those designed for permanent immigration and includes the Federal Skilled Worker Program, the Provincial Nominee Program, Live-In Caregivers, entrepreneurs, and those in the Canadian Experience Class.

${ }^{29}$ The raw data included a "gender not stated" category which was not included in the graph.
} 
rapidly and the number of females slowly declining. These differences cannot be explained by one factor alone, but the fact that there has rarely been parity between men and women in the TFWP, and that the number of men in the program has been out-pacing the number of women in recent years, indicates that gender dynamics are at play in the TFWP.

Figure 3.1

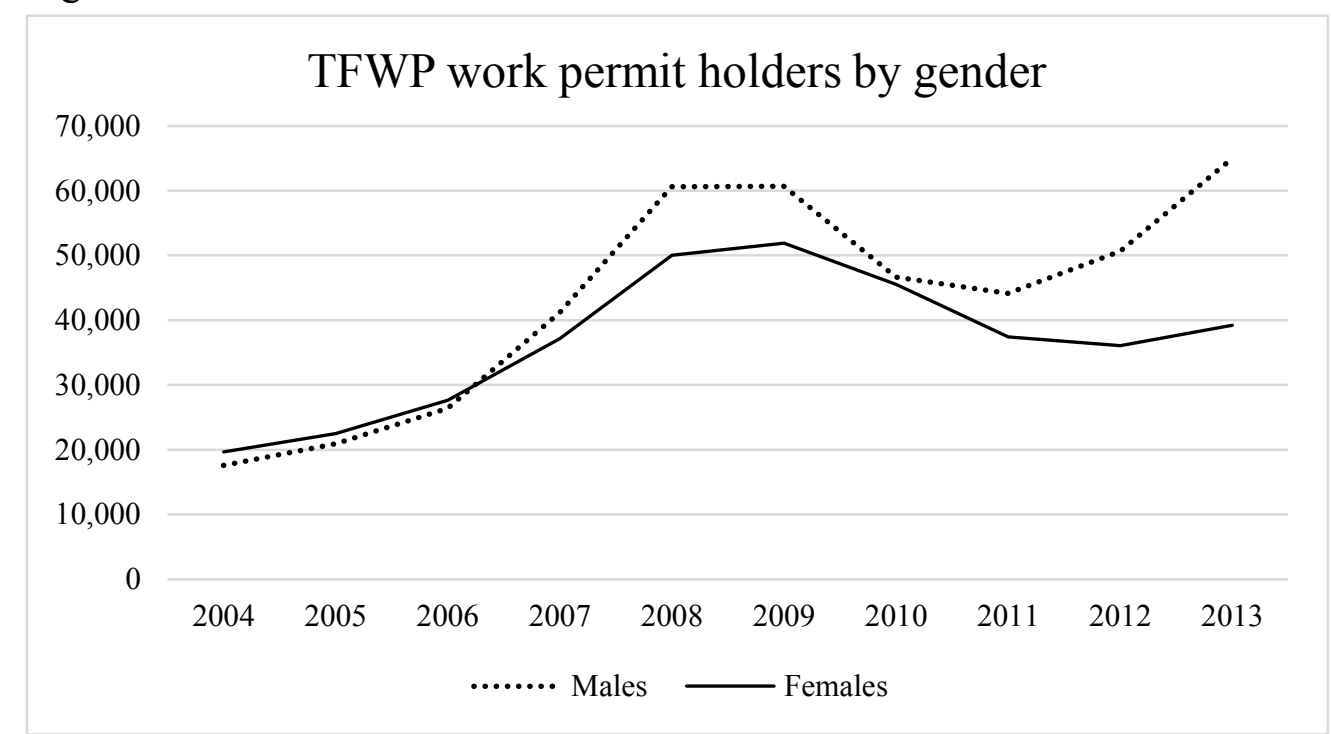

Source: CIC Facts and Figures, 2014

CIC also collected data on the occupational skill level of workers in the TFWP and disaggregated the data by sex, which is useful for this project as it combines the factors of gender and skill. Figures 3.2 and 3.3 below $^{30}$ show the differences (for each gender) between the number of high- and low- skill permit holders. A large majority of females in the TFWP are employed in occupations classified as low-skill according to the NOC classification system. It is evident that the gap between high- and low-skilled females was at its peak between 2008 and 2009. While the number of female high-skilled

\footnotetext{
30 The raw data included an "other occupations" category which was not included in the graph.
} 
workers has remained relatively consistent over time, the number of female low-skilled workers has changed, seeing significant decreases after 2009 but seeming to stabilize by 2011. Contrary to the trend among female workers, the ratio of high-skilled to low-skilled male workers has remained relatively consistent over time, with the gap being the smallest in the 2008-2009 period, the exact inverse of the trend among females. Most significantly for this project, these data show that males have predominantly been employed in high-skill positions, while women have predominantly been employed in low-skilled positions. As of 2013, 70.0 percent of all female TFWP permit holders were classified as low-skill, while only 39.2 percent of all male TFWP permit holders were classified as low-skill. This reiterates the point that low-skilled workers are more likely to be women and gives empirical evidence to support Kofman's emblematic paradigm of the highly-skilled male and the less-skilled female.

Figure 3.2

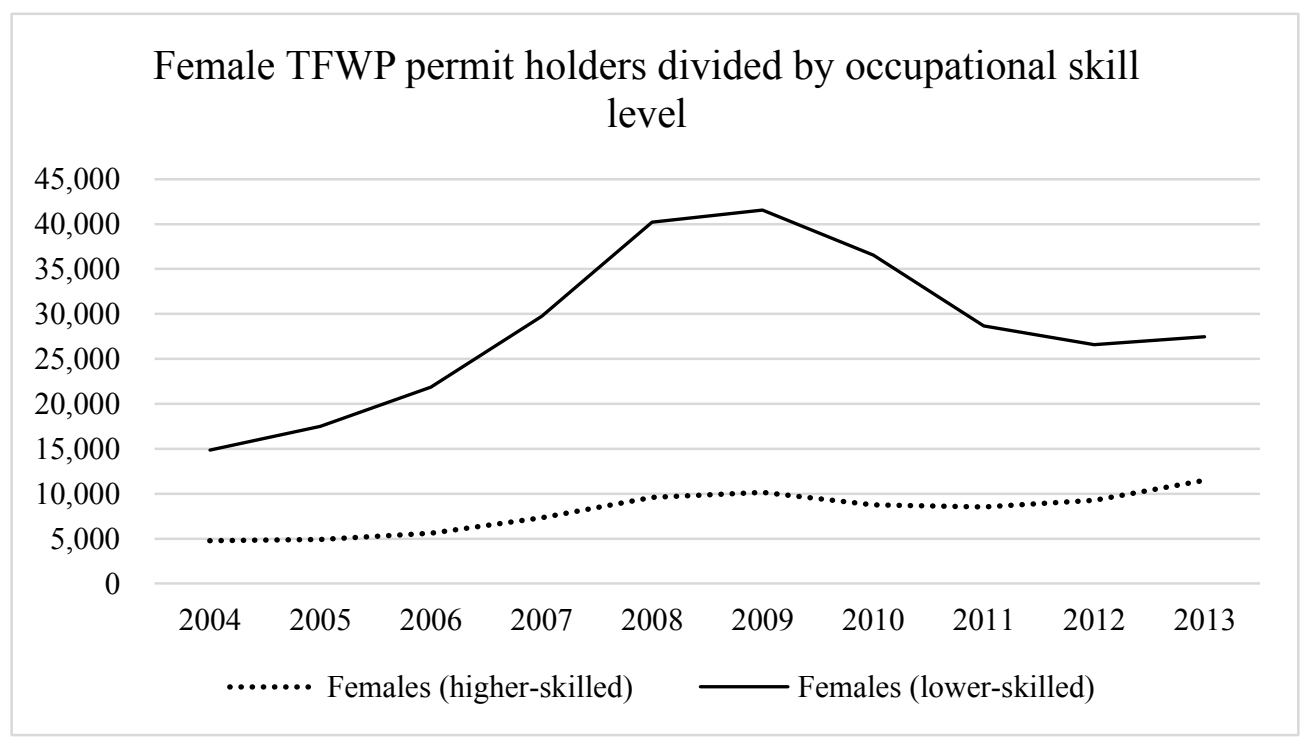

Source: CIC Facts and Figures 2013 
Figure 3.3

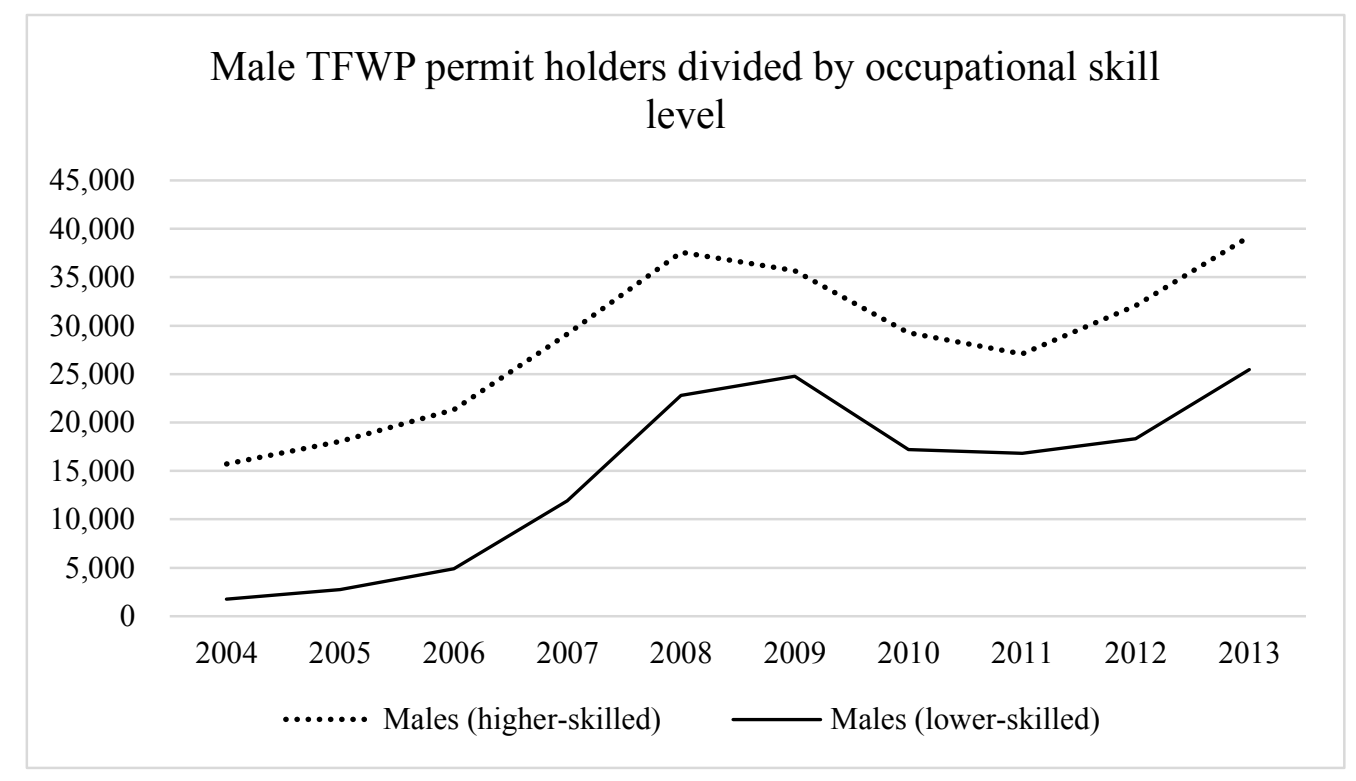

Source: CIC Facts and Figures, 2013

The Parliamentary Budget Office released a report on temporary migrant workers and skill in 2015. The report references Employment and Social Development Canada's (ESDC) annual LMIA statistics by top occupational groups and found that since 2005, Alberta, British Columbia and Ontario had "significant demand for babysitters, nannies and parent's helpers" (PBO 2015, 14). These are classified as low-skill in the NOC and are also traditionally feminized occupations. Many of the most in-demand positions were low-skill and some were traditionally gendered. For example, in Ontario and British Columbia there was a strong demand for farm workers (a traditionally masculinized field). The demand in Alberta was largely for food service workers, an industry that includes mostly low-skilled positions. According to the PBO, these occupations are some of the most highly demanded at the national level since 2007 and are in the low-end of the pay scale, earning a median wage below fourteen dollars per hour (PBO 2015, 15). In 
general, the PBO found that most of the growth between 2002 and 2009 came from workers in low-skill positions but by 2012 , the majority of migrant workers were in skilled positions ${ }^{31}(\mathrm{PBO} 2015,2)$.

Analysis of the documents described above as well as of committee evidence shows that during the period of study, discussions about immigration were more likely to include some consideration of gender than discussions about the TFWP specifically. In fact, in the transcripts of the two committees between 2008 and 2014, gender was mentioned in relation to the TFWP only three times, all of which were during the crosscountry tour in 2008 that occurred prior to the release of the parliamentary report on temporary migrant workers. As discussed in the academic literature on gender and the TFWP and in the committees, gender is almost exclusively discussed in relation to the LCP, a highly feminized stream. Lualhati Alcuitas of Grassroots Women noted in 2008 that often, women who come to work in Canada under the LCP are using that program because they were unable to gain points to come to the country as immigrants. Alcuitas says that "if these women were allowed to come to Canada to work in their professions, and the Canadian government seriously looked at supporting fully the child care and health care problems, we wouldn't have this problem" (39-2, CIMM 18, Mar 31 $\left.1^{\text {st }}, 2008\right)$. This quote from Alcuitas reflects what witnesses and MPs talked about when they talked about gender. The witness is pointing out issues with accreditation and domestic issues with child and health care, suggesting that if these programs were improved there would be less of a need for LCP workers in the country. It is interesting to note that nurses are

\footnotetext{
${ }^{31}$ While data is not available for the specific positions men held, CIC Facts and Figures 2013 shows that $71.1 \%$ of the men classified as higher-skilled were in occupations relating to the skilled and technical trades. Occupations in this skill level are traditionally gendered male.
} 
categorized as higher-skilled in the NOC, but domestic work (such as cleaning), which many women migrant workers end up performing instead, is classified as lower-skilled. This is because occupations requiring formal education are more highly valued than those that, according to Kofman's framework, require embodied knowledge but do not necessarily require formal training. This is also an example of women being hired for low-skilled positions regardless of their level of skill.

One other minor instance of women being mentioned in relation to the TFWP was again in the context of a discussion about abuse of workers in the LCP. Raymonde Falco (LPC) mentioned jurisdictional issues in terms of how the federal government can intervene in worker abuse in the LCP when labour laws are under the purview of the provinces. In reference to LCP workers, Falco asked, "what can the federal government do to help these women? Indeed, they are virtually always women" (39-2, CIMM 30, Apr $\left.10^{\text {th }}, 2008\right)$. This does not provide much insight into the intersections of gender, skill, and the TFWP but is worth noting because the MP is clearly aware of the gender differences in that program and the quote serves as another reminder that gender is usually included in TFWP discussions in relation to the LCP.

The final example of women being mentioned in discussion about the TFWP was again in relation to the care work, but not the LCP specifically. Louise Boivin, of the Committee on the Rights of Immigrants and Refugees of the Ligue des droits et libertés did touch more closely on the intersections of gender and skill. She said in a 2008 meeting that:

In the context of an aging population, home care does require a lot of workers. It's mainly women who work in these sectors. Historically, this is a sector that is under-valued and highly feminized. It is time to value and recognize these professions, as was done with Canadian women who were 
able to "professionalize," join unions and so on. We don't see why this sector couldn't be reformed. That requires notable changes so that women can acquire power equal to that of Canadian citizens in performing these important duties (39-2, CIMM 30, Apr 10 $\left.{ }^{\text {th }}, 2008\right)$.

Boivin makes some important points along the lines of Kofman's work that care work is under-valued and highly feminized. The changes Boivin calls for are in terms of migrant women being able to acquire power equal to Canadian citizens doing similar work. This is an interesting statement for a couple of reasons. First, while Boivin seems critical of how care work is under-valued, her solution does not include changing how it is valued. For example, she does not suggest changing how care work is classified in the NOC, but rather refers to Canadian women's ability to unionize. The second reason why the statement is interesting is that Boivin suggested that while women's work in the care sector is under-valued in general, women who are citizens have more "power" than women who are not citizens. It is not entirely clear what Boivin means by power other than her reference to unions, but her statement is important in making a distinction between citizens and non-citizens. Scholarly positions on citizenship and non-citizenship were reviewed in chapter one and included the argument that even highly-skilled workers experience "diminished rights" in comparison to the domestic population, which supports Boivin's statement (Walsh 2014, 598).

Gender greatly influences one's skill category, which in turn impacts one's ability to access citizenship. While the CIC is making efforts to perform GBA in some aspects of their data and policies, consideration of gender is missing in other areas. For example, even in a year of CIMM meetings committed to discussing many issues related to the TFWP, gender was rarely considered. Some of the federal budgets between 2008 and 
2014 included no mention of temporary workers whatsoever, ${ }^{32}$ let alone include any discussion of temporary work and gender. In the changes the Conservative government has made to the TFWP, gender has been entirely neglected. ${ }^{33}$ In fact, any consideration of how different migrants might experience the TFWP differently is not included. This suggests that the Conservative government sees migrants only as high- or low-skilled, and not as gendered, classed, or racialized. However, the theory and findings presented thus far have shown that skill categories are influenced by these factors and so by privileging the movement of high-skilled workers, the government is making decisions about which kinds of migrants are and are not valuable to the state.

\subsection{Conclusions}

The findings presented in this chapter firmly establish that there is a link between skill and status in the TFWP. This link is sustained by government policy that continues to reward high-skilled workers with citizenship, despite witness testimony that this is an unfair and unjust practice. The findings also showed that women are disproportionately affected by such policies, as women are predominantly employed in positions classified as low-skill. Gender was rarely discussed in relation to temporary work in the committee hearings, as well as in CIC data. The only time gender was discussed in the hearings was in relation to the LCP, which includes feminized occupations. This provides a limited view of how temporariness can be gendered. Many occupations in the NOC are traditionally gendered male or female. While the evidence shows that men are

\footnotetext{
${ }^{32}$ The 2009, 2010, and 2011 budgets did not include any mention of temporary migrant workers.

${ }^{33}$ It should be noted that this is equally true of previous Liberal governments.
} 
predominantly hired for high-skill positions, some low-skill positions in the TFWP are gendered male. For example, agricultural streams like the SAWP are highly masculinized. Encalada and Preibisch argue that farm work is "assigned and ranked according to gender; male bodily qualities are valued for most, if not all, forms of agricultural tasks" (Encalada and Preibisch 2010, 292). It is also interesting to note that the two programs that are classified as low-skill and are traditionally (though differently) gendered, the SAWP and the LCP, are also racialized. Most SAWP workers arrive in Canada from Mexico or Caribbean nations, and most LCP workers are from the Philippines. Encalada and Preibisch argue that racist, negative depictions of the workers legitimizes indenturing Caribbean and Mexican men to agricultural jobs and denying them the opportunity to apply for permanent settlement (Encalada and Preibisch 2010, 301).

The evidence presented in this chapter proves that gender dynamics are at play in the NOC not only between high- and low-skill positions, but also among low-skill positions. Acknowledging the gendered and racialized classifications of skill in the NOC is important because the government facilitates the transition to permanence for highskilled workers, while limiting recruitment of low-skill workers. The analysis that follows will delve further into the significance of the findings in terms of citizenship and further unpack the role of race in skill classification. It will also make connections back to the original research question and theoretical assumptions to prove that gender is significant in the TFWP because it affects workers' citizenship status. 


\section{Chapter: "People are skilled:" An Analysis of the intersections of gender, skill, and citizenship status}

As has been shown in this project, low-skilled work is often traditionally gendered female. Kofman argues that this is because women are more likely to possess the kinds of skills that are valued less. These gendered constructions of skill are institutionalized through the NOC, on which the TFWP is based. While the TFWP was recently changed to classify workers by the wages they earn as opposed to their skill level, wages correspond with skill and still exemplify how different occupations are valued in Canada. Occupations that command a higher wage, such as certain trades and information technology positions, are gendered male and classified as high-skilled. This project was premised on the idea that if temporary workers' access to citizenship depends on their skill category, it is important to examine the profile of high- and low-skill workers to determine if there is one gender that is disproportionately disadvantaged by this system. It was found that temporary migrant workers' ability to access citizenship status is premised on gendered constructions of skill. Because women are more likely to work in occupations classified as low-skill, they are more likely to experience barriers to accessing citizenship.

Chapter three detailed the significant findings uncovered during the study and grouped them into themes of temporariness, the connection between skills and status, and

finally, gender. This chapter will aim to shed light on the significance of the findings and attempt to combine these themes as opposed to looking at them separately. It will also aim to connect the findings back to the original hypotheses and theoretical frameworks 
used to guide the research. Key aspects of the literature and theoretical reviews will be revisited in light of the findings to show that the claims made are relevant in the Canadian context. The concepts guiding the research, including Kofman's emblematic migrants, will also be re-visited to show how the theories find expression in the findings. The chapter will end with a reminder of the importance of the findings.

\subsection{Important findings on skill, temporariness, and gender}

The study confirms many of the academic insights regarding the implications of temporary status. Chapter one described how temporary labour migration is perceived and constructed at the global level as beneficial for sending states, destination states, and for migrants (the "triple win" scenario). Another major theme was that such programs should encourage migrants to return to their home countries, thus keeping them permanently temporary. Some evidence of these themes was present in the findings. For example, Canada's TFWP was first designed to benefit the Canadian state by filling (temporary) labour shortages and the program is still justified by the government on that basis. The statements of the Government of Canada and Conservative MPs were also consistent with the global discourses on temporariness because of their emphasis on the importance of migrants returning to their home countries and not living in Canada permanently. As was shown in chapter three, the Conservative government wishes to maintain temporary streams of employment, especially for low-skilled workers. The Government's "four in four out" rule where after four years, migrant workers must return to their home country or risk being deported, is consistent with the International Agency for Migration Management's suggestion of facilitating "multiple short stays" for migrants 
(IAMM 2005, 35). Government actors justify this "triple win" scenario through claims that migrant workers are advantaged by temporary labour mobility schemes because they gain employment. However, these statements ignore the effect of migrants' gender or race on the type of employment they are able to achieve, as well as the barriers they may face in accessing citizenship.

The Canadian government makes decisions about who is and is not suitable for membership based on the NOC in an effort to depoliticize the criteria on which membership is based. However, the NOC is not a neutral tool as it classifies traditionally gendered occupations as low-skilled. In the 2014 changes to the TFWP, the government exchanged one dichotomy for another by categorizing workers as high- or low-wage, as opposed to high- or low-skill. The change in language was not accompanied by changes to the NOC or the creation of a new classification system. In fact, workers' wage category directly corresponds to their skill category in the NOC. This reinforces that high-skill temporary workers, who are more likely to be men, are also more likely to earn a high wage. Therefore, low-skill workers are not only less likely to be granted access to citizenship, but they are also more likely to earn a low wage.

The NOC is a tool that is promoted as neutral but in fact categorizes skill in a hierarchy based on what kinds of knowledge are valued in Canadian society. The findings showed that the occupations women are predominantly employed in tend to be highly gendered. Many of the low-skill occupations in the NOC are gendered, and can be highly feminized (like the LCP) or highly masculinized (like agricultural work). Both the LCP and the Seasonal Agricultural Worker Program (SAWP) would be considered examples of embodied knowledge, described by Kofman as resulting from "experience gained from 
physical presence, practical thinking, material objects, sensory information and learningin-doing" (Kofman 2013, 584). This type of knowledge is often associated with low levels of formal training, but Kofman argues that this is not always the case. Kofman describes this type of knowledge as undervalued and under-remunerated due to its physical nature and its assumed lack of formal training.

Kofman does not argue that women are less likely to have knowledge, but that they are more likely to possess the kinds of knowledge that are valued less, such as embodied knowledge. This does prove to be true in the TFWP given that $70.0 \%$ of female workers in the program are in low-skill categories (CIC 2014). However, it is important to note that agricultural streams like the SAWP are highly masculinized. Only 4\% of workers in the SAWP are women (UFCW 2014). This shows that embodied work can be traditionally gendered either male or female. Equally important, however, is the fact that the LCP and SAWP are examples of embodied work that are also racialized. As mentioned, LCP workers largely come from the Philippines and SAWP workers arrive in Canada from Mexico or Caribbean nations. Kofman does not address the connection between embodied work and racialization, but the implications of this connection could be that low-skilled and/or traditionally gendered positions are also often racialized. This becomes important because, as mentioned in chapter one, migrant workers from marginalized groups are often rendered more vulnerable than those not belonging to such groups. In addition, the racialization of migrant workers can affect what jobs they are hired for. Researchers like Janet McLaughlin (2010) argue that employers hire SAWP workers based on "racialized assumptions of different groups' abilities and attributes" to find the "ideal migrant worker" (McLaughlin 2010, 83). This is similar to the work of 
Encalada and Preibisch (2010), outlined in chapter one, which argued that employers sometimes hire farm workers based on perceived "attributes" associated with their gender.

The LCP now includes access to citizenship for workers who are employed in Canada for two years; however, as outlined in chapter two, there are limitations to this access. In contrast to the LCP, the agricultural streams do not have this option. Admittedly, because of the seasonal nature of work in the SAWP, even those who recommend allowing temporary workers access to citizenship often exclude the SAWP. ${ }^{34}$ Agricultural work is more cyclical (and therefore justified as temporary) due to its seasonal nature; however, many agricultural workers exist in permanent cycles of temporariness as they are re-hired to work in Canada every year. In addition, the growing season has been extended because of the increasing use of greenhouses, meaning that workers can stay longer each year. Some workers exist in this arrangement for many years, spending the majority of their time in Canada but not being able to work towards achieving citizenship. While it is likely that many agricultural workers are satisfied with their temporary status, it is also likely that others would be interested in immigrating to Canada and face barriers to doing so due to the fact that they are categorized as low-skill. The findings in this project determined that in general men are more likely to be classified as high-skill than low-skill. However, recognizing the gender and race dynamics at play in low-skill streams is an important reminder that temporariness can be gendered male or female, and can also be racialized.

\footnotetext{
${ }^{34}$ For example, Chris Roberts, a researcher for the Canadian Labour Congress, said that "there must be an end to employers' access to low-skilled occupation streams in NOCs C and D, excluding the live-in caregiver program and the seasonal agricultural worker program" (41-1, HUMA 82, May 21 $\left.1^{\text {st }}, 2013\right)$.
} 
While many of the low-skill occupations are traditionally gendered male or female, the findings showed that women are more likely than men to be at the lower end of the occupational skill levels, a fact acknowledged by the CIC. This acknowledgement, while significant, did not result in any changes to the TFWP or the NOC. As mentioned in chapter one, the ILO came to a similar conclusion as CIC, arguing that female labour migration is often characterized by a concentration in lower-skilled occupations associated with traditional gender roles (IOM 2008, 82). The 2015 PBO report noted that some of the most in-demand occupations in the TFWP were babysitters or nannies, types of care work that are classified as low-skill. These occupations are associated with traditional gender roles and it was evident from Figure 3.2 that women's labour migration to Canada under low-skill categories far out-weighed that of high-skill categories. This proved that women dominate low-skill categories of temporary labour migration programs, often resulting in more vulnerability than their high-skilled (and often male) counterparts.

The gendered categorization of skill in the TFWP results in different patterns of mobility and access to status for men and women. This is consistent with hypotheses from chapter one which argued that gendered skill construction could lead to outcomes where one gender is able to immigrate more easily than another, or that one gender category is disproportionately recruited into labour in a category that is underpaid, undervalued, and subject to exploitation. It was found that highly-skilled migrant workers are able to immigrate more easily to Canada than low-skilled migrant workers through the TFWP, largely because of programs like the Canadian Experience Class. Because 
workers classified as highly-skilled are more likely to be men, the hypothesis that one gender experiences fewer barriers to immigration than another was proved to be true.

While many of the committee witnesses, MPs, and civil society actors included in this project advocated for temporary migrant workers to be able to access permanent status, Gilbert (2014) argues that this is not a long-term solution. Landolt and Goldring (2013) agree, arguing that workers who achieve permanent status still face barriers (to social inclusion, for example) and that they may still be working in precarious situations. However, many academics and rights advocates argue that enabling migrants to access permanence is a good first step to mitigating their vulnerability. As noted in the previous chapter, some committee witnesses highlighted that workers in different skill categories have differing rights access, largely due to their ability to access permanence.

Deepa Rajkumar and her co-authors (2012) make the argument that the way to achieve full rights access for all temporary migrants is to "undo the link" between permanence and rights, meaning that no matter their status, all migrants would have the same access to their rights (Rajkumar et. al 2012, 505). Rajkumar is not the only one to suggest undoing the link between permanence and rights. UN Women also alluded to this idea, saying that workers who migrate through temporary programs for long-term employment should receive the same human rights and social protections as citizens and long-term residents in countries of destination (UN Women 2013, 7). While citizenship would provide protection for many migrant workers (compared to non-citizenship), a compromise could be to enhance migrant workers' access to rights and many of the benefits of citizenship, even if the country does not agree to grant them that privilege. This would further blur the lines between citizenship and non-citizenship, thus 
contributing to Goldring and Landolt's assertions that there is not a clear binary between citizenship and non-citizenship. While the idea of undoing the link between permanence and rights is compelling and worthwhile for future research, this project's focus on skill suggests that changing how different skills and knowledge are valued and moving away from skill dichotomies would enable more temporary migrant workers to immigrate to Canada, if they chose to do so. Of course, changing the social valuing of skills is no easy task, and it would require much more than changes to the NOC, as that system is simply a reflection and further entrenchment of this valuing. In Rajkumar's language, these efforts could be described as "undoing the link" between gender and skill. While citizenship may not be the perfect solution for vulnerability, migrant workers' skill category should not determine their ease of immigration, as these categories are constructed based on unfair assumptions about gender and race.

\subsection{Re-visiting the theoretical frameworks}

The theories of emblematic migrants and those related to permanence, temporariness, and citizenship guided this research in different ways. Two of the central arguments in Kofman's work proved to be true in this research. The first argument was that different types of knowledge are valued differently. This was a key element to the project because it helped frame the discussion on the kinds of knowledge that people possess, rather than around who does and does not possess knowledge. This was important as it assumed that all workers have knowledge, an assumption that was carried through the research. This argument also proved to be true in the Canadian context because in the NOC, occupations requiring embrained knowledge, as per Kofman's 
knowledge types, are classified as higher skilled and many occupations requiring embodied knowledge are classified as low-skilled. The "high" and "low" skill distinction can be an indication of how different occupations and different knowledge are valued more highly than others.

Kofman's second key argument was that women are more likely to possess the kinds of knowledge that are valued differently. This framed how the research on gender was both carried out and interpreted. Kofman's conclusions were based on data from Europe, but proved to be true in Canada as well. This argument about the types of knowledge women are more likely to possess was altered somewhat for the purposes of this project, as no work was done on migrants' ability to access work and education in their home countries. Instead, the study hypothesized that in Canada, women are hired for low-skilled work, regardless of their actual level of skill or the kinds of knowledge they possess. This was found to be true from data that described migrant workers' use of TFWP permits disaggregated by gender and skill level. Admittedly, there could be many reasons why women are hired for low-skilled work in Canada. For example, issues with credentials across borders could be a factor, as could the differences in women's ability to migrate based on constraining factors in their households or home countries. Regardless, the initial goal of this project was to determine whether gendered constructions of skill existed in the TFWP, and the very fact of men and women being hired for positions requiring different levels of skill, proves this to be true. While Kofman's male ITC worker and female care worker were not specifically used as emblematic figures in this project, there was an attempt to identify where traditionally gendered occupations were placed in the NOC classification system. Occupations that are 
gendered female are typically categorized as low-skill, contributing to the higher proportion of women in low-skill categories than in high-skill categories in the TFWP.

The TFWP is a program that exists at the centre of provincial labour laws, federal immigration policy, and international human rights laws. In this framework, the federal government of Canada holds power in controlling the movement of migrant workers across transnational spaces. Federal agencies set the rules for immigration and the TFWP specifically, meaning they are able to decide which workers are granted citizenship and on what basis. Citizenship is important partly because it can change how migrants move within and across transnational spaces. Also, as Rajkumar argues, one's citizenship status affects one's access to their rights as workers. This compounds the importance of gender in the TFWP because not only is citizenship important in terms of social belonging to a nation, but also because of the access to rights that citizens have compared to noncitizens.

Employers also play a role in regulating migrants' movement. The TFWP is a demand-driven program, meaning that employers are able to decide how many migrant workers they require, the level of skill the position requires, and the social composition of their workforce. However, with recent changes to the TFWP, the federal government exerted its power by limiting the amount of low-skill workers employers can hire. According to the main argument of this project, the Conservative government's decision to focus on recruiting and opening pathways to permanence for highly skilled workers limits the mobility of and citizenship opportunities for lower skilled workers, who are more likely to be women. Because many MPs and almost all committee witnesses 
disagree with this decision, the Conservative government's approach to immigration policy in the TFWP is also undemocratic. The conclusion of this thesis will address the specific ways in which different actors are attempting to disrupt these power flows in order to or reduce migrant workers' vulnerability. 


\section{Conclusion: Final thoughts and uncovering spaces to disrupt power}

\section{flows}

While many migrants benefit from the Temporary Foreign Worker Program (TFWP) in some way, this study has shown that the program has significant flaws. Under the TFWP, the Conservative government privileges the movement of high-skilled workers and facilitates their transition to permanent residence. Men tend to have greater access to entry under this category. In contrast, women are more likely to work in lowskill categories and disproportionately remain temporary residents which affects their ability to access their rights. The analysis in chapter four considered where power lies in managing transnational flows, concluding that the federal government held a great deal of power because of their ability to shape the TFWP.

Many different actors outside the federal government have worked to make changes to the TFWP to better mitigate migrant workers' vulnerabilities. Some of these efforts will be outlined below. However, there are certain challenges that those wishing to disrupt power flows face when it comes to the TFWP. Perhaps the biggest obstacle to making change is that the TFWP lies at the centre of multiple jurisdictions. The federal government is responsible for creating and administering the program, but shares jurisdiction over immigration with the provinces. Provinces are responsible for crafting labour laws and enforcing employment codes, and employers have some autonomy in the hiring of workers. This complex structure means that there can be confusion as to which body to approach to make change. The examples below describe different strategic 
approaches to make change and disrupt the flows of power in the TFWP. This chapter will then explore the avenues through which the program could be or has been changed, focusing on changes to provincial legislation in Manitoba, grassroots advocacy in the LCP, and legal challenges related to gender discrimination in the SAWP. Each strategy for resistance will be described and reflected upon in terms of its effectiveness. Finally, the strategies will be considered in terms of if they would be effective in making changes relevant to this research, in terms of skill categories and access to citizenship.

One strategy of resistance is making changes to provincial labour laws or crafting new legislation that would include additional protections for temporary workers. Under an NDP majority government in 2009, the Worker Recruitment and Protection Act (WRAPA) was passed in Manitoba. One of WRAPA's most basic components is that businesses must register with the province to get a work permit for a temporary migrant worker. This means that the Manitoba government knows where temporary migrant workers are employed, which is not the case in the other provinces. Having this information allows inspectors in the province to monitor working conditions to ensure that employers follow employment standards and health and safety rules, as well as allowing the province to "block anyone who breaks those rules from bringing in more workers" (Freisen 2014). The special investigations unit in charge of overseeing businesses that employ temporary migrant workers can issue penalties between $\$ 500$ and $\$ 10,000$ per workplace, per visit and in the five years since its creation, it has issued sixteen fines for companies for violations related to TFWs (Freisen 2014). This legislation is seen as the best of its kind in the country by organizations such as the 
Canadian Centre for Policy Alternatives and the Institute for Research on Public Policy. Other provinces see it as a model as well and are adopting similar measures, such as Newfoundland and Labrador and Nova Scotia. Even Jason Kenney has said that he thinks it "is something of a model" (Freisen 2014).

Julie Guard, writing for the CCPA, says that proactive audits can reduce abuses of the TFWP (Guard 2014). While the federal government has put in place some mechanisms of oversight, for the most part they are reactive, in that inspectors are only sent to visit work sites if they receive a complaint. As mentioned in chapter two, many workers are reluctant to come forward with complaints with they hold temporary status because their visa is tied to their employer. Guard also mentioned why it is important to end abuse of migrant workers other than moral reasons, such as the fact that it "drives down wages and working conditions for everyone by eroding basic rights" (Guard 2014). Guard also found that "some employers report that they favour enforcement, including penalties for non-compliance, because they prefer to abide by legal minimums, something they say they can only do if there's a level playing field" (Guard 2014). This shows that proactively monitoring TFWs work environments can also benefit employers. Despite Kenney calling the Manitoba legislation a model, the fact that the legislation predates the 2014 changes to the TFWP, and that even employers are in favour of such measures, the federal government did not put in place proactive monitoring or enforcement measures. Admittedly, this could be due to a lack of resources and the fact that provinces have begun to take on this responsibility. Also, the federal government may not have jurisdiction in this area as labour and employment laws fall under the purview of the provinces. Regardless, the Manitoba legislation is a step forward for the 
protection of migrant workers and represents one strategy of resistance to power structures.

LCP workers and their allies have taken a more grassroots approach to making changes to the program. While now a part of the TFWP, the LCP has a history that predates the TFWP, as Canadians have been hiring workers from abroad to care for their families as early as 1900 , when the workers were automatically granted permanent residency upon arrival in Canada (Tungohan 2012). As the source countries for care workers shifted from being European to instead being former colonies with racialized populations, permanent residency was no longer immediately granted to all workers. In the 1970s, caregivers and Canadian families began the fight for permanent residency. Ethel Tungohan argues that this activism (which took the form of demonstrations, lobbying, and protest letters) in the 1970s was a "key reason" why live-in caregivers were allowed to apply for permanent residency in 1981 through the Foreign Domestics Movement, which was replaced by the LCP in 1992 (Tungohan 2014).

Immigrant advocacy groups had also "demanded the removal of the live-in requirement for decades, citing its tendency to encourage abuses" (Marcelino 2014). In 2014, Minister Alexander announced that the live-in requirement would end. Jane Ordinario, coordinator of Migrante British Columbia, stated that while she welcomes the change, it is still "extremely disappointing to see caregivers are still not given permanent residence upon arrival in Canada" (Marcelino 2014). The Caregiver Action Centre (CAC) in Toronto, Migrante British Columbia, and Philippine Migrants Society of Canada (PMSC) in Ottawa agree. These groups also oppose the 2014 move to the 
Express Entry system for LCP workers, which is supposed to offer a fast path to permanent residency but requires workers to enter into a pool of candidates, only the highest ranking of whom will be selected to become permanent residents. These groups'strategy of resistance is releasing a series of videos to the Canadian public "that probe more deeply into the situations facing live-in caregivers" (Tungohan 2014). Migrante-BC plans to lobby the Canadian government to ratify the International Migrant Workers Convention and the International Domestic Workers Convention, and PMSC will continue with ongoing educational and outreach campaigns to make Canadians aware of the proposed changes (Tungohan 2014).

The strategies of resistance undertaken by LCP workers and their allies follow a distinct pattern of grassroots activism. LCP worker organizations are visible in their attempts to disrupt power flows to secure caregivers' rights and citizenship and often undertake very public campaigns or participate in protests or demonstrations. Some of these campaigns have successfully pressured the government into implementing change, such as the removal of the live-in requirement. However, campaigns to achieve that goal existed for decades before the requirement was lifted. The future plans of the migrant organizations outlined above make it clear that they will continue to draw on grassroots techniques to inform Canadians about changes to the LCP and put public pressure on the government to allow LCP workers status upon landing in Canada.

The Seasonal Agricultural Worker Program (SAWP) pre-dates the TFWP but remains a sub-stream of it, along with other low-skill agricultural streams. Agricultural workers are recruited by their national governments (in Mexico or the Caribbean nations) 
and Canadian employers hire from that pool of workers. Currently, only $4 \%$ of SAWP workers are women, prompting complaints about gender discrimination in hiring practices in the SAWP (UFCW 2014). Thus far, the United Food and Commercial Workers union (UFCW) has attempted to address this issue through legal challenges, a third strategy of resistance.

In July 2014, UFCW filed a complaint requesting that the Ontario Human Rights Commission investigate gender discrimination in hiring practices. The union must file complaints to specific provinces as opposed to the federal government, an example of how it can be challenging to identify where to disrupt power flows. UFCW argued in a statement that "the practice of gender-based discrimination in hiring migrant farm workers violates Mexican and Canadian legislation, as well as international treaties on discrimination and equal access to employment" (UFCW 2014). The Mexican government was not receptive to the call for the inquiry and has publicly declared that under the current Memorandum of Understanding between Mexico and Canada, "SAWP employers have every right to discriminate against migrant agriculture workers based on their gender" (UFCW 2014).

The Ontario Human Rights Commission decided not to conduct an inquiry into the issue of gender discrimination, but did issue a statement. The statement acknowledged that there were far more men hired than women, but also that migrant workers are protected by the Ontario Human Rights Code which means that employers cannot refuse to hire a person based on their sex or include discriminatory preferences in the hiring process. The statement recommended that "employers, agents and other parties who are involved in the recruitment of workers for the SAWP should ensure that their 
hiring practices are in compliance with the Ontario Human Rights Code" but suggests no enforcement or oversight mechanisms (OHRC 2014). UFCW national coordinator Stan Raper then filed a complaint to the Human Rights Tribunal of Ontario, which explained in March 2015 that they could not hear the case because the applicant (Raper), had not directly experienced the discrimination and in order to file on behalf of another person, that person needs to provide their consent. Acquiring the consent of female migrant workers to proceed with the case would be extremely difficult precisely because so few women can apply to the SAWP, as well as the fact that when they do apply, they are not in Canada. These examples of using legal channels to make change may be unsuccessful, but there is one case where filing a legal complaint did achieve some success.

In May 2015, The Human Rights Tribunal of Ontario found that two Mexican women working under the TFWP were discriminated against by their employer, Presteve Foods Limited. The Tribunal also found that the women "were exposed to sexual solicitation, sexual harassment, discrimination in employment, and a sexually poisoned work environment" and were threatened to perform these sexual acts under the threat of being sent home (CBC 2015). This is one example of a successful legal challenge as the Tribunal gave two of the complainants "the highest damages award in the Tribunal's history" (Unifor 2015). This is one example of how legal channels of action that address specific employers can be successful.

The strategies of resistance outlined above represent some success in enabling migrants to advocate for their workplace rights. However, this study shows that there are problematic features of the TFWP which are not being directly addressed, such as the 
gendered constructions of skill in the program. It is difficult to directly address how society values skills, and changing the NOC would not necessarily be sufficient. However, changes can be made which better protect migrants from exploitation, which is important until a solution to the gendering of skill construction can be addressed or all migrant workers have access to citizenship. For example, many migrant workers' rights advocates recommend changing workers' visas to be specific to a region or industry, as opposed to one employer. This could enable migrant workers to voice their concerns in the workplace without fear of deportation. Grassroots activism in the form of protests, combined with a concerted lobbying effort by both business and human rights organizations, would likely be the best method to make this change, which would greatly reduce migrant workers' vulnerability in the workplace. This project is not intended to provide concrete strategies for making changes to the TFWP. However, the examples above, if examined in more detail, could provide valuable lessons for various groups organizing for change. Examples in this project showed that enabling temporary migrant workers to access citizenship in Canada would be in the best interest of many businesses, as well as in the interest of migrants themselves. Perhaps there could be a space in which migrant rights organizations can find new allies in the private sector to lobby the government to make this change.

This project critically examined skill categories, citizenship, and the TFWP and argued that gendered constructions of skill in the TFWP limit women's ability to access citizenship in Canada. Through examination of witness testimony before parliamentary committees, it was shown that the Conservative government has neglected to make the 
changes to the TFWP that would improve migrant workers access to citizenship and rights according to employers, migrant rights groups, as well as other legislators. While providing access to permanence for all temporary migrant workers would improve their ability to voice workplace concerns and access their rights, it was shown in chapter one that permanence is not a panacea. Citizenship can be both a tool of inclusion and exclusion, and migrant workers who transition to permanence still experience limitations in their mobility and rights in comparison to the domestic population. However, citizenship is still preferable to non-citizenship as it would improve workers' access to their rights. Chapter one also included Sharma's (2006) assertion that citizenship can be a form of differential inclusion. This project demonstrated this by showing that certain temporary migrant workers (those constructed as highly-skilled) are considered more worthy of membership to the Canadian state than others. This project also showed that these high-skilled workers often possess other characteristics seen as more "desirable" to the state compared to low-skilled workers, such as the fact that they are more likely to be male.

There is further research that needs to be done to fully explore the issues of gender and skill in the TFWP. While this project did not include an in-depth examination of the Provincial Nominee Programs, it would likely be worthwhile to determine the gender and skill composition of workers in these programs and examine their ability to access citizenship. In addition, it would be interesting to combine this research with issues of accreditation to see if those processes are gendered or racialized in Canada and if this is a significant factor in some migrant workers being categorized as low-skill. This project did not explore entirely new areas of scholarship, as evidenced by reviews of the 
literature in the first chapter. However, it did aim to look more deeply at how gender and skill influence workers' ability to access citizenship in the TFWP in the hopes of contributing to the complex area of scholarship that is temporary labour migration. 


\section{Appendix A: National Occupation Classification (NOC) Skill Level}

\section{Criteria}

\begin{tabular}{|c|c|}
\hline Skill level & Education/training and other criteria \\
\hline A & - University degree (bachelor's, master's, or doctorate) \\
\hline B & $\begin{array}{l}\text { - Two to three years of post-secondary education at community } \\
\text { college, institute of technology or CÉGEP or } \\
\text { - Two to five years of apprenticeship training or } \\
\text { - } \quad \text { Three to four years of secondary school and more than two } \\
\text { years of on-the-job training, occupation-specific training } \\
\text { courses or specific work experience } \\
\text { - Occupations with supervisory responsibilities are also assigned } \\
\text { to skill level B. } \\
\text { - Occupations with significant health and safety responsibilities } \\
\text { (e.g., fire fighters, police officers and licensed practical nurses) } \\
\text { are assigned to skill level B. }\end{array}$ \\
\hline $\mathbf{C}$ & $\begin{array}{l}\text { - Completion of secondary school and some short-duration } \\
\text { courses or training specific to the occupation or } \\
\text { - Some secondary school education, with up to two years of on- } \\
\text { the-job training, training courses or specific work experience }\end{array}$ \\
\hline D & $\begin{array}{l}\text { - } \quad \text { Short work demonstration or on-the-job training or } \\
\text { - } \quad \text { No formal educational requirements }\end{array}$ \\
\hline
\end{tabular}

Source: National Occupation Classification 2011. 


\section{Bibliography}

Alboim, Naomi and Karen Cohl. Shaping the Future: Canada's Rapidly Changing Immigration Policies. Maytree Foundation: 2012.

Bakan, Abigail B., and Daiva Stasiulis. "The Political Economy of Migrant Live-in Caregivers: A Case of Unfree Labour?" In Legislated Inequality: Temporary Labour Migration in Canada, edited by Patti Tamara Lenard and Christine Straehle, 202-226. Montreal \& Kingston: McGill-Queen’s University Press, 2012.

Bauder, Harald. 2008. "The Economic Case for Immigration: Neoliberal and Regulatory Paradigms in Canada's Press.” Studies in Political Economy (82): 131-152.

Canada. Employment and Social Development Canada. 2014. Over-hauling the Temporary Foreign Worker Program, (Publication no. WP-191-06-14E). Ottawa, Canada. Accessed April 17, 2015. http://cmemec.ca/_uploads/_media/4z2n31upr.pdf.

—- Employment and Social Development Canada. "Past Reforms to the Temporary Foreign Worker Program." Last modified June 20, 2014. Accessed May 11, 2015. http://www.esdc.gc.ca/eng/jobs/foreign_workers/reform/past_reform.shtml.

—- Employment and Social Development Canada. "Temporary Foreign Worker Program." Last modified February 23, 2015. Accessed May 15, 2015. http://www.esdc.gc.ca/eng/jobs/foreign_workers//index.shtml.

—- Human Resources and Skills Development Canada. 2011. National Occupation Classification 2011, (Cat. No.: HS18-29/2011E-PDF). Ottawa, Canada. Accessed March 10, 2015. http://www5.hrsdc.gc.ca/cnp/English/NOC/2011/pdf/PrintableVersionNOC2011. pdf

—- Parliament. House of Commons. Standing Committee on Citizenship and Immigration. 2009. Temporary Foreign Workers and Non-Status Workers. Report of the Standing Committee on Citizenship and Immigration. Accessed March 30, 2015.

http://www.parl.gc.ca/HousePublications/Publication.aspx?DocId=3866154.

- - Parliament. House of Commons. Standing Committee on Citizenship and Immigration. (2008). Evidence. Meeting 18, March $31.39^{\text {th }}$ Parliament, $2^{\text {nd }}$ Session. Available: http://www.parl.gc.ca/HousePublications/Publication.aspx?Language=E\&Mode= $1 \& \mathrm{DocId}=3388709$.

_- Parliament. House of Commons. Standing Committee on Citizenship and Immigration. (2008). Evidence. Meeting 19, April 1. 39 ${ }^{\text {th }}$ Parliament, $2^{\text {nd }}$ Session. 
Available:

http://www.parl.gc.ca/HousePublications/Publication.aspx?Language=E\&Mode= $1 \&$ DocId=3381960.

- - Parliament. House of Commons. Standing Committee on Citizenship and Immigration. (2008). Evidence. Meeting 24, April 7. 39 ${ }^{\text {th }}$ Parliament, $2^{\text {nd }}$ Session. Available:

http://www.parl.gc.ca/HousePublications/Publication.aspx?Language=E\&Mode $=$ $1 \&$ DocId=3395043.

- - Parliament. House of Commons. Standing Committee on Citizenship and Immigration. (2008). Evidence. Meeting 26, April 8. $39^{\text {th }}$ Parliament, $2^{\text {nd }}$ Session. Available:

http://www.parl.gc.ca/HousePublications/Publication.aspx?Language=E\&Mode= $1 \&$ DocId=3405274.

- - Parliament. House of Commons. Standing Committee on Citizenship and Immigration. (2008). Evidence. Meeting 28, April 9. 39 ${ }^{\text {th }}$ Parliament, $2^{\text {nd }}$ Session. Available:

http://www.parl.gc.ca/HousePublications/Publication.aspx?Language=E\&Mode= $1 \&$ DocId=3412678.

- - Parliament. House of Commons. Standing Committee on Citizenship and Immigration. (2008). Evidence. Meeting 30, April 10. 39 ${ }^{\text {th }}$ Parliament, $2^{\text {nd }}$ Session. Available:

http://www.parl.gc.ca/HousePublications/Publication. aspx?Language=E\&Mode= $1 \&$ DocId=3415445.

- - Parliament. House of Commons. Standing Committee on Citizenship and Immigration. (2008). Evidence. Meeting 32, April 15. 39 $9^{\text {th }}$ Parliament, $2^{\text {nd }}$ Session. Available:

http://www.parl.gc.ca/HousePublications/Publication.aspx?Language=E\&Mode= $1 \&$ DocId=3426181.

- _. Parliament. House of Commons. Standing Committee on Citizenship and Immigration. (2008). Evidence. Meeting 34, April 16. $39^{\text {th }}$ Parliament, $2^{\text {nd }}$ Session. Available:

http://www.parl.gc.ca/HousePublications/Publication.aspx?Language=E $\&$ Mode $=$ $1 \&$ DocId=3432030.

-_. Parliament. House of Commons. Standing Committee on Citizenship and Immigration. (2008). Evidence. Meeting 41, May 12. $39^{\text {th }}$ Parliament, $2^{\text {nd }}$ Session. Available:

http://www.parl.gc.ca/HousePublications/Publication.aspx?Language=E\&Mode= $1 \&$ DocId=3488835. 
- - Parliament. House of Commons. Standing Committee on Citizenship and Immigration. (2009). Evidence. Meeting 36, November 26. $40^{\text {th }}$ Parliament, $2^{\text {nd }}$ Session. Available:

http://www.parl.gc.ca/HousePublications/Publication.aspx?Language=E\&Mode= $1 \&$ DocId=4266764.

- _- Parliament. House of Commons. Standing Committee on Citizenship and Immigration. (2011). Evidence. Meeting 4, October 20. $41^{\text {st }}$ Parliament, $1^{\text {st }}$ Session. Available:

http://www.parl.gc.ca/HousePublications/Publication.aspx?Language=E\&Mode= $1 \&$ DocId $=5184184$.

- - Parliament. House of Commons. Standing Committee on Citizenship and Immigration. (2011). Evidence. Meeting 9, November 15. $41^{\text {st }}$ Parliament, ${ }^{\text {st }}$ Session. Available:

http://www.parl.gc.ca/HousePublications/Publication.aspx?Language=E\&Mode= $1 \&$ DocId=5245634.

Parliament. House of Commons. Standing Committee on Citizenship and Immigration. (2011). Evidence. Meeting 11, November 24. $41^{\text {st }}$ Parliament, $1^{\text {st }}$ Session. Available:

http://www.parl.gc.ca/HousePublications/Publication.aspx?Language=E\&Mode= $1 \&$ DocId $=5272116$.

- _. Parliament. House of Commons. Standing Committee on Citizenship and Immigration. (2013). Evidence. Meeting 78, April 25. $41^{\text {st }}$ Parliament, $1^{\text {st }}$ Session. Available:

http://www.parl.gc.ca/HousePublications/Publication.aspx?Language=E\&Mode= $1 \&$ DocId=6104539.

- _. Parliament. House of Commons. Standing Committee on Citizenship and Immigration. (2013). Evidence. Meeting 2, November 7. $41^{\text {st }}$ Parliament, $2^{\text {nd }}$ Session. Available:

http://www.parl.gc.ca/HousePublications/Publication.aspx?Language=E\&Mode= $1 \&$ DocId=6297021.

- _. Parliament. House of Commons. Standing Committee on Citizenship and Immigration. (2014). Evidence. Meeting 32, June 11. $41^{\text {st }}$ Parliament, $2^{\text {nd }}$ Session. Available:

http://www.parl.gc.ca/HousePublications/Publication.aspx?Language=E\&Mode= $1 \&$ DocId $=6667693$.

- - Parliament. House of Commons. Standing Committee on Human Resources, Skills and Social Development and the Status of Persons with Disabilities. (2012). Evidence. Meeting 40, November 7. $41^{\text {st }}$ Parliament, $1^{\text {st }}$ Session. Available: http://www.parl.gc.ca/HousePublications/Publication.aspx?Language=E\&Mode= $1 \&$ DocId $=5611305$. 
- - Parliament. House of Commons. Standing Committee on Human Resources, Skills and Social Development and the Status of Persons with Disabilities. (2013). Evidence. Meeting 82, May 21. $41^{\text {st }}$ Parliament, ${ }^{\text {st }}$ Session. Available: http://www.parl.gc.ca/HousePublications/Publication.aspx?Language=E\&Mode= $1 \&$ DocId $=6163642$.

- Parliament. House of Commons. Standing Committee on Human Resources, Skills and Social Development and the Status of Persons with Disabilities. (2014). Evidence. Meeting 28, June 5. $41^{\text {st }}$ Parliament, $2^{\text {nd }}$ Session. Available:

http://www.parl.gc.ca/HousePublications/Publication.aspx?Language=E\&Mode= $1 \&$ DocId $=6649726$.

. Parliament. House of Commons. Standing Committee on Human Resources, Skills and Social Development and the Status of Persons with Disabilities. (2014). Evidence. Meeting 29, June 10. $41^{\text {st }}$ Parliament, $2^{\text {nd }}$ Session. Available:

http://www.parl.gc.ca/HousePublications/Publication.aspx?Language=E\&Mode= $1 \&$ DocId $=6663684$.

- - Parliament. House of Commons. Standing Committee on Human Resources, Skills and Social Development and the Status of Persons with Disabilities. (2014). Evidence. Meeting 37, November 18. $41^{\text {st }}$ Parliament, $2^{\text {nd }}$ Session. Available: http://www.parl.gc.ca/HousePublications/Publication.aspx?Language=E\&Mode= $1 \&$ DocId $=6777314$.

- - Parliament. Library of Parliament. 2014. Temporary Foreign Workers by Sandra Elgersma. Background Paper (Publication No. 2014-79-E). Ottawa, Canada. Accessed June 30, 2015. http://www.parl.gc.ca/Content/LOP/ResearchPublications/2014-79-e.pdf.

- - Statistics Canada. Analysis Branch. 2013. The Evolution of Canadian Wages Over the Last Three Decades, by René Morissette, Garnet Picot and Yuqian Lu. (11F0019M No. 347). Ottawa, Canada. http://www.statcan.gc.ca/pub/11f0019m/11f0019m2013347-eng.pdf. Accessed June 30, 2015.

The Canadian Press. "Live-in caregivers no longer required to reside with employers." CTV News, October 31, 2014. Accessed May 15, 2015. http://www.ctvnews.ca/canada/live-in-caregivers-no-longer-required-to-residewith-employers-1.2080614.

Canadian Union of Public Employees (CUPE). "CUPE extends solidarity to migrant workers." Last modified October 3, 2013. Accessed May 11, 2015. http://www.esdc.gc.ca/eng/jobs/foreign_workers/reform/past_reform.shtml. 
- _. "Fact Sheet: Temporary Foreign Workers Program." Last modified August 28, 2013. Accessed May 9, 2015. http://cupe.ca/fact-sheet-temporary-foreignworkers-program.

CBC News. "Temporary foreign workers' vulnerability noted in sexual harassment case." CBC News, May 28, 2015. Accessed June 5, 2015. http://www.cbc.ca/m/news/business/temporary-foreign-workers-vulnerabilitynoted-in-sexual-harassment-case-1.3089970.

Citizenship and Immigration Canada. "Become a permanent resident: live-in caregivers." Last modified December 5, 2014. Accessed July 11, 2015. http://www.cic.gc.ca/english/work/caregiver/permanent_resident.asp.

. "Facts and Figures 2008." Last modified August 25, 2009. Accessed May 14, 2015. http://www.cic.gc.ca/english/resources/statistics/facts2008/.

—_. "Facts and Figures 2012." Last modified 2012. Accessed July 2, 2015. publications.gc.ca/collections/collection_2013/cic/Ci1-8-2012-eng.pdf.

—_. "Fact Sheet: Temporary Foreign Worker Program." Last modified February 19, 2015. Accessed May 9, 2015. http://www.cic.gc.ca/english/resources/publications/employers/temp-foreignworker-program.asp.

—_. "How Express Entry Works." Last modified February 2, 2015. Accessed May 15, 2015. http://www.cic.gc.ca/english/express-entry/index.asp.

. "International Mobility Program work permit holders with a valid permit on December $31^{\text {st }}$ by top 50 countries of citizenship, 2004-2013." Last modified December 31, 2014. Accessed July 10, 2015. http://www.cic.gc.ca/english/resources/statistics/facts2013/temporary/1-6.asp.

- - "Temporary Foreign Worker Program work permit holders with a valid permit on December $31^{\text {st }}$ by gender and occupational skill level, 2004 to 2013." Last modified December 31, 2014. Accessed March 20, 2015. http://www.cic.gc.ca/english/resources/statistics/facts2013/temporary/1-7.asp.

—_. "Temporary Foreign Worker Program work permit holders with a valid permit on December $31^{\text {st }}$ by top 50 countries of citizenship, 2004-2013." Last modified December 31, 2014. Accessed June 5, 2015. http://www.cic.gc.ca/english/resources/statistics/facts2013/temporary/1-5.asp.

__ . "Temporary Foreign Worker Program work permit holders who became permanent residents by immigration category and landing year, 2004 to 2013." Last modified March 27, 2015. Accessed June 5, 2015. http://www.cic.gc.ca/english/resources/statistics/facts2013/temporary/9-4.asp. 
—_. "Work Permit Holders for Work Purposes with a valid permit on December $31^{\text {st }}$." Last modified December 31, 2014. Accessed March 20, 2015. http://www.cic.gc.ca/english/resources/statistics/facts2013/temporary/1-1.asp.

Curry, Bill. "Everything you need to know about temporary foreign workers." Globe and Mail, May 2, 2014. Accessed July 2, 2015.

http://www.theglobeandmail.com/news/politics/temporary-foreign-workerseverything-you-need-to-know/article18363279/.

Dauvergne, Catherine and Sarah Marsden. "Beyond Numbers Versus Rights: Shifting the Parameters of Debate on Temporary Labour Migration." International Migration and Integration 15, no. 3 (2014): 525-545.

Deere, Carmen Diana. "The Feminization of Agriculture?: The Impact of Economic Restructuring in Rural Latin American." In The Gendered Impacts of Liberalization: Towards Embedded Liberalism?, edited by Shahra Razavi, 99127. New York: Routledge, 2009

Dunn, L. 1994. "Education of Women Workers in Caribbean Export Processing Zones: Challenges and Opportunities." Labour Economics, no. 96. Bulletin of International Labour Office, Workers' Education Branch.

Encalada Grez, Evelyn and Kerry L. Preibisch. 2010. "The Other Side of el Otro Lado: Mexican Migrant Women and Labor Flexibility in Canadian Agriculture." Signs 35 (2): 289-316.

Flecker Karl. 2011. Canada's Temporary Foreign Worker Program (TFWP): Model or Mistake? Canadian Labour Congress.

Friesen, Joe. "Manitoba's foreign worker strategy called a model for other provinces." CBC News, July 2, 2014. Accessed July 10, 2015. http://www.theglobeandmail.com/news/politics/manitobas-foreign-workerstrategy-called-a-model-for-other-provinces/article19434284/.

Gilbert, Emily. "The Permanence of Temporary Labour Mobility: Migrant Worker Programs Across Australia, Canada, and New Zealand." In Liberating Temporariness: Migration, Work, and Citizenship in an Age of Insecurity edited by Leah F. Vosko, Valerie Preston, and Robert Latham, 152-174. Montreal \& Kingston: McGill University Press, 2014.

Global Commission on International Migration. 2005. Migration in an interconnected world: New Directions for Action. Switzerland: GCIM.

Goldring, Luin. "Resituating Temporariness as the Precarity and Conditionality of NonCitizenship." In Liberating Temporariness: Migration, Work, and Citizenship in an Age of Insecurity edited by Leah F. Vosko, Valerie Preston, and Robert Latham, 218-254. Montreal \& Kingston: McGill University Press, 2014. 
Guard, Julie. 2014. "Work Life: Manitoba's Proactive Enforcement of Temporary Foreign Workers' Rights is a Model for Canada." Canadian Centre for Policy Alternatives. Accessed July 10, 2015.

https://www.policyalternatives.ca/publications/commentary/work-life-manitobasproactive-enforcement-temporary-foreign-workers-rights.

Hughes, Christine. "Costly Benefits and Gendered Costs: Guatemalans' Experiences of Canada's 'Low-Skill Pilot Project.'” In Legislated Inequality: Temporary Labour Migration in Canada, edited by Patti Tamara Lenard and Christine Straehle, 139157. Montreal \& Kingston: McGill-Queen’s University Press, 2012.

Hussan, Syed. "Fear of Migrant Workers is Xenophobia." Huffington Post, April 25, 2014. Accessed April 18, 2015. http://www.huffingtonpost.ca/syedhussan/foreign-workers-canada_b_5200186.html.

International Organization for Migration. N.d. Integration of a Gender Perspective in the Migration and Development Debate: IOM's Contribution.

—_. 2015. "Mission." Accessed April 16, 2015. http://www.iom.int/mission.

—. 2008. World Migration 2008: Managing Labour Mobility in the Evolving Global Economy. IOM World Migration Report Series. Geneva: International Organization for Migration.

- 2010. World Migration Report 2010. The Future of Migration: Building Capacities for Change. IOM World Migration Report Series. Geneva: International Organization for Migration.

Jenson, Jane. "The Talents of Women, the Skills of Men: Flexible Specialization and Women." In The Transformation of Work? Skill, Flexibility and the Labour Process edited by Stephen Wood. Boston: Unwin Hyman, 1989

Justicia for Migrant Workers. 2008. Organizational Profile. Toronto: Justicia for Migrant Workers.

Kofman, Eleonore and Parvati Raghuram. 2006. "Gender and Global Labour Migrations: Incorporating Skilled Workers.” Editorial Board of Antipode, 282-303.

Kofman, Eleonore. "Gendered Labour Migrations in Europe and Emblematic Migratory Figures." Journal of Ethnic and Migration Studies 39 (2013): 579-600.

Landolt, Patricia and Luin Goldring. "The Social Production of Non-Citizenship: The Consequences of Intersecting Trajectories of Precarious Legal Status and Precarious Work." In Producing and Negotiating Non-Citizenship: Precarious 
Legal Status in Canada edited by Luin Goldring and Patricia Landolt, 154-174. Toronto: University of Toronto Press, 2013.

Latham, Robert, Leah F. Vosko, Valerie Preston, and Melisa Bréton. "Liberating Temporariness? Imagining Alternatives to Permanence as a Pathway for Social Inclusion." In Liberating Temporariness: Migration, Work, and Citizenship in an Age of Insecurity edited by Leah F. Vosko, Valerie Preston, and Robert Latham, 3-31. Montreal \& Kingston: McGill University Press, 2014.

Lenard, Patti Tamara and Christine Straehle. "Temporary Labour Migration: Exploitation, Tool of Development, or Both?" Policy and Society 29, no. 4 (2010): 283-294.

Mah, Bonnie. "Changes to Temporary Foreign Worker Program a small piece of the big picture." Maytree Foundation. Last modified May 13, 2013. Accessed May 9 , 2015. http://maytree.com/blog/2013/05/changes-to-temporary-foreign-workerprogram-a-small-piece-of-the-big-picture/.

Mahler, Sarah J. and Patricia R. Pessar. 2001. "Gendered Geographies of Power: Analyzing Gender Across Transnational Spaces." Identities 7:441-459.

Marcelino, Diwa. "LCP's live-in requirement ends." Pilipino Express, November 16, 2014. Accessed July 11, 2015. http://www.pilipino-express.ca/news/2691-lcp-slive-in-requirement-ends.html.

Maytree Foundation. "Alternatives to the 'Low-Skilled' Pilot Program." Adjusting the Balance: Fixing Canada's Economic Immigration Policies Discussion Paper 4.

Nakache, Delphine. 2013. "The Canadian Temporary Foreign Worker Program: Regulations, Practices, and Protection Gaps.” In Producing and Negotiating NonCitizenship: Precarious Legal Status in Canada edited by Luin Goldring and Patricia Landolt. University of Toronto Press: Toronto, 71-95.

Noakes, Susan. "Migrant workers get little protection from workplace abuse." $C B C$ News, July 1, 2015. Accessed July 2, 2015. http://www.cbc.ca/news/business/migrant-workers-get-little-protection-fromworkplace-abuse-1.3132292

No One is Illegal. n.d. "Temporary Foreign Workers." Accessed April 17, 2015. http://toronto.nooneisillegal.org/node/380.

—_. "Vision, Demands, Organizing Pillars." Accessed April 17, 2015. http://toronto.nooneisillegal.org/demands.

Nuttall, Jeremy J. "Why 'Abuse' of Temp Foreign Workers is Hard to Stop.” The Tyeee, January 20, 2014. Accessed July 5, 2015. http://thetyee.ca/News/2014/01/20/Why-Abuse-is-Hard-to-Stop/. 
Ontario Federation of Labour. "Statement: OFL Calls for a Migrant Workers' Bill of Rights to End Exploitation." Last modified December 16, 2014. Accessed April 16, 2015. http://ofl.ca/index.php/migrantsday-2014/.

Ontario Human Rights Commission. "Position Statement: Discrimination on the basis of sex in recruitment for the Seasonal Agricultural Workers Program." Ontario Human Rights Commission, December 10, 2014. Accessed July 11, 2015. http://www.ohrc.on.ca/en/news_centre/position-statement-\%E2\%80\%93discrimination-basis-sex-recruitment-seasonal-agricultural-workers-program.

Pessar, Patricia R., and Sarah J. Mahler. "Transnational Migration: Bringing Gender in.” International Migration Review 37, no. 3, (2003), pp. 812-846.

Rajkumar, Deepa, Laural Berkowitz, Leah F.Vosko, Preston, Valerie and Robert Latham. "At the Temporary-Permanent Divide: How Canada Produces Temporariness and Makes Citizens Through its Security, Work, and Settlement Policies. Citizenship Studies 16 (2012): 483-510.

Shachar, Ayelet. 2006. “The Race for Talent: Highly-Skilled Migrants and Competitive Immigration Regimes.” New York University Law Review (81) 1: 148-206.

Sharma, Nandita. Home Economics: Nationalism and the Making of 'Migrant Workers' in Canada. Toronto: University of Toronto Press, 2006.

- - "Immigrant and Migrant Workers in Canada: Labour Movements, Racism and the Expansion of Globalization." Canadian Woman Studies 2, no. 3 (2002): 18-25.

Steinburg, Ronnie J. 1990. "Social Construction of Skill: Gender, Power, and Comparable Worth." Work and Occupations 17(4): 449-482.

Tungohan, Ethel. 2012. "Debunking Notions of Migrant 'Victimhood': A Critical Assessment of Temporary Labour Migration Programs and Filipina Migrant Activism in Canada." Filipinos in Canada: Disturbing Invisibility, edited by Roland Sintos Coloma, Bonnie McElhinny, Ethel Tungohan, John Paul C. Catungal and Lisa M. Davidson. University of Toronto Press:161-180.

- - "Live-in caregivers fight against proposals to remove their right to permanent residency." October 21, 2014. Accessed July 11, 2015. http://rabble.ca/news/2014/10/live-caregivers-fight-against-proposals-to-removetheir-right-to-permanent-residency.

UN Women. 2013. Managing Labour Migration in ASEAN: Concerns for Women Migrant Workers. Bangkok, Thailand: UN Women. 
Unifor. "Landmark human rights ruling highlights systemic abuse of temporary foreign workers.” CNW Group, May 27, 2015. Accessed May 30, 2015.

http://www.newswire.ca/en/story/1544179/landmark-human-rights-rulinghighlights-systemic-abuse-of-temporary-foreign-workers.

United Food and Commercial Workers Union. "UFCW denounces gender-based discrimination against migrant women under Seasonal Agricultural Workers Program.” Last modified July 31, 2014. Accessed October 20, 2014. http://www.ufcw.ca/index.php?option=com_content\&view $=$ article\&id=30175:ufc w-canada-denounces-gender-based-discrimination-against-migrant-womenunder-seasonal-agricultural-workers-program\&catid=9536:directions-14$59 \&$ Itemid $=6 \&$ lang $=$ en.

Valiani, Salimah. 2013. "The Shifting Landscape of Contemporary Canadian Immigration Policy: The Rise of Temporary Migration and Employer-Driven Immigration." In Producing and Negotiating Non-Citizenship: Precarious Legal Status in Canada edited by Luin Goldring and Patricia Landolt. University of Toronto Press: Toronto, 55-70.

Vosko, Leah F. 2000. Temporary Work: The Gendered Rise of a Precarious Employment Relationship. Toronto: University of Toronto Press.

World Bank. 2006. Global Economic Prospects: Economic Implications of Remittances and Migration. Washington, D.C: World Bank.

—_. 2010. "Defining Civil Society." Accessed September 16, 2015. http://web.worldbank.org/WBSITE/EXTERNAL/TOPICS/CSO/0,,contentMDK:2 0101499 menuPK:244752 pagePK:220503 piPK:220476 theSitePK:228717,00 .html. 